\title{
The excavation of four caves in the Geodha Smoo near Durness, Sutherland
}

\author{
by Tony Pollard*
}

with contributions by D Alldrit, J H Barrett, E Photos-Jones, $\mathrm{R}$ Cerón-Cerrasco, $\mathrm{C}$ Smith and R Squair

* GUARD, Department of Archaeology, University of Glasgow, Glasgow G12 8QQ

Scottish Archaeological Internet Report 18, 2005

www.sair.org.uk 
Published by the Society of Antiquaries of Scotland, www.socantscot.org with Historic Scotland, www.historic-scotland.gov.uk and the Council for British Archaeology, www.britarch.ac.uk

Editor Debra Barrie

Produced by Archetype Information Technology Ltd, www.archetype-it.com

ISBN: 0903903873

ISSN: $1473-3803$

Requests for permission to reproduce material from a $S A I R$ report should be sent to the Director of the Society of Antiquaries of Scotland, as well as to the author, illustrator, photographer or other copyright holder.

Copyright in any of the Scottish Archaeological Internet Reports series rests with the SAIR Consortium and the individual authors.

The maps are reproduced from Ordnance Survey material with the permission of Ordnance Survey on behalf of The Controller of Her Majesty's Stationery Office. CCrown copyright 2001. Any unauthorized reproduction infringes Crown copyright and may lead to prosecution or civil proceedings. Historic Scotland Licence No GD 03032G, 2002.

The consent does not extend to copying for general distribution, advertising or promotional purposes, the creation of new collective works or resale. 


\section{Contents}

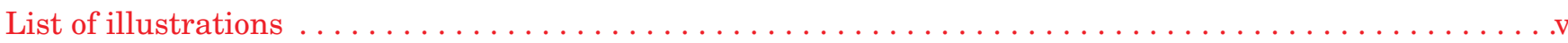

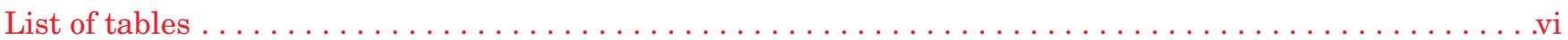

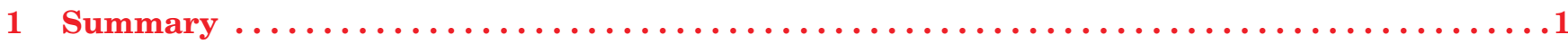

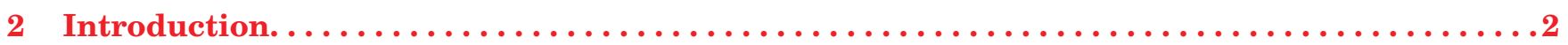

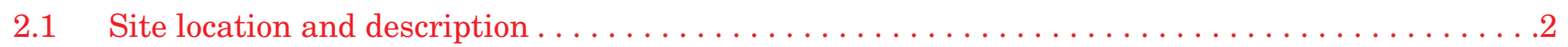

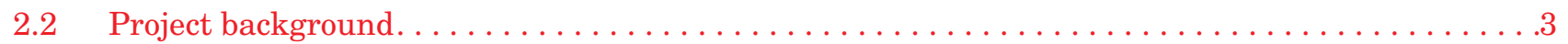

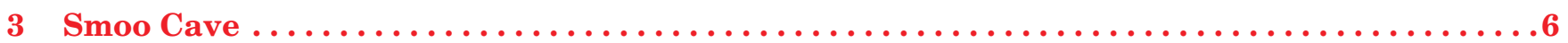

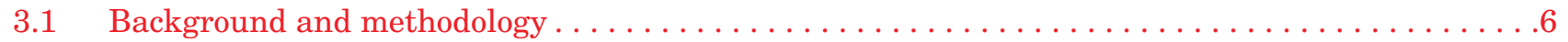

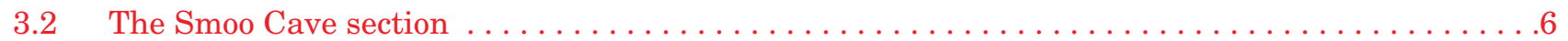

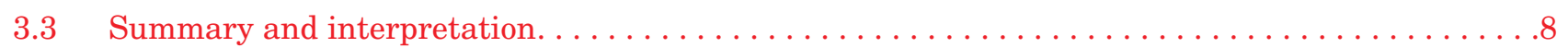

4 Glassknapper's Cave, Antler Cave and Wetweather Cave. . . . . . . . . . . . . . . . . 9

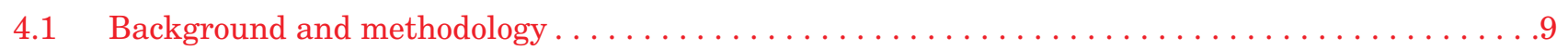

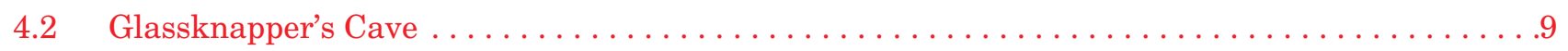

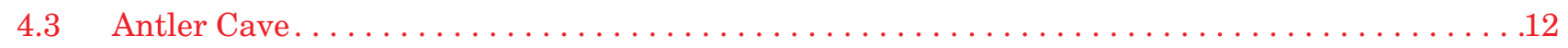

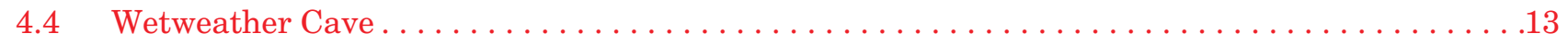

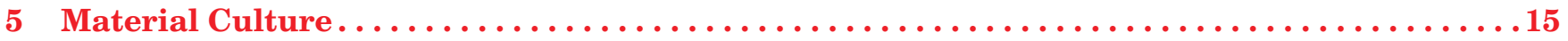

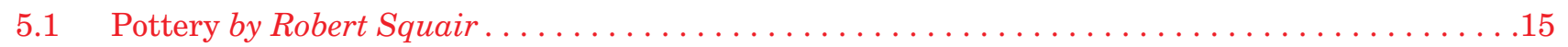

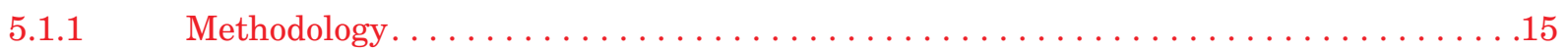

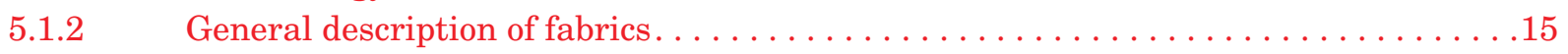

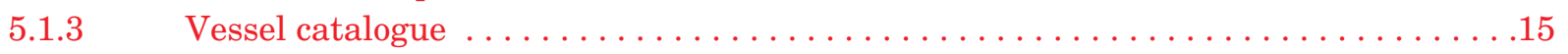

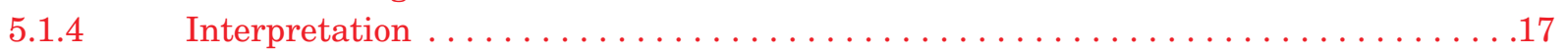

5.1.5 Depositional practices and post-depositional processes $\ldots \ldots \ldots \ldots$

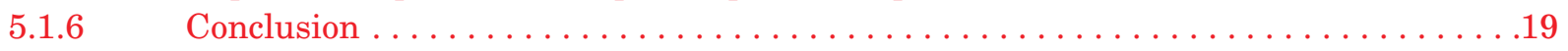

5.2 Bone and antler artefacts by Tony Pollard (with species identifications by Catherine Smith) . . . 19

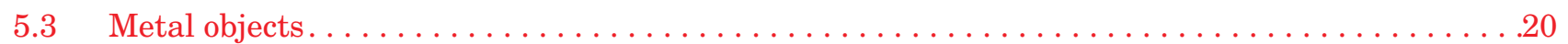

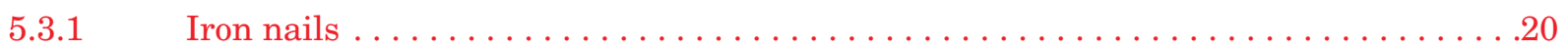

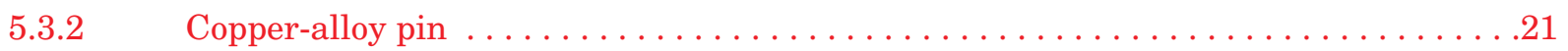

6 Analysis of Slag and Fuel Samples from Smoo Cave by E Photos-Jones . . . . . . . . . . . . . 22

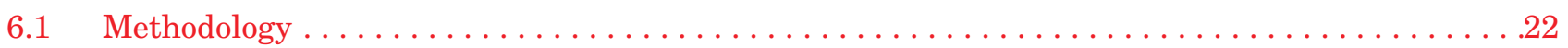

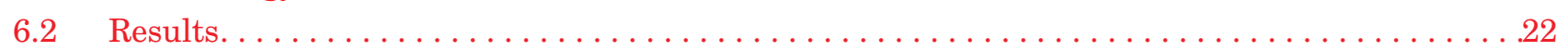

7 Animal and Plant Remains. . . . . . . . . . . . . . . . . . . . . . . . . . 23

7.1 Aminal bones from Smoo Cave by James H Barrett . . . . . . . . . . . . . . . . . . . . . . 23

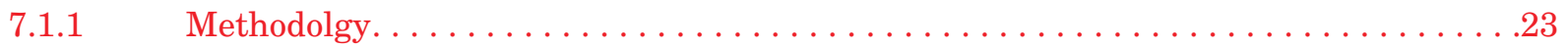

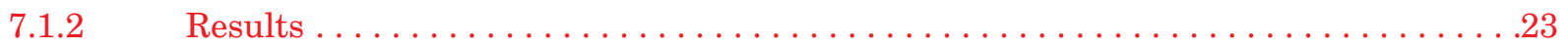

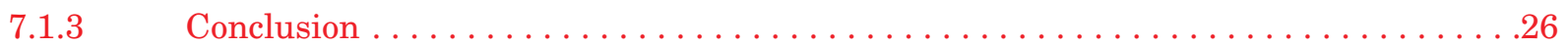

7.2 The fish remains from Glassknapper's Cave, Antler Cave and Wetweather Cave

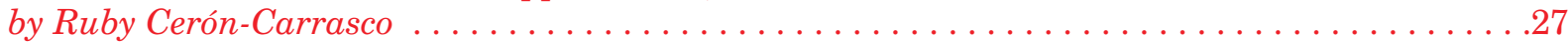

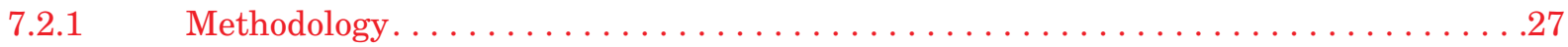


7.3 The mammal and bird bone from Glassknapper's Cave, Antler Cave and Wetweather Cave

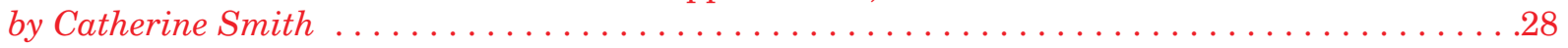

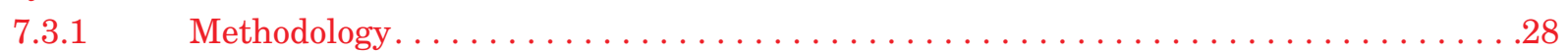

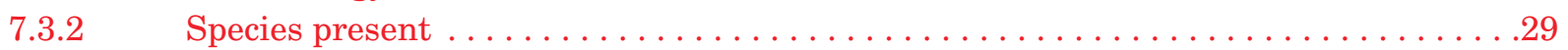

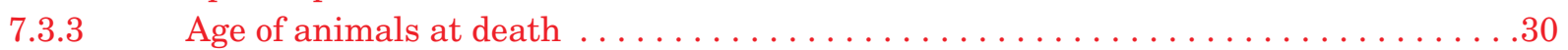

7.3.4 Economy of the site: evidence of butchery and bone working $\ldots \ldots \ldots \ldots \ldots \ldots$

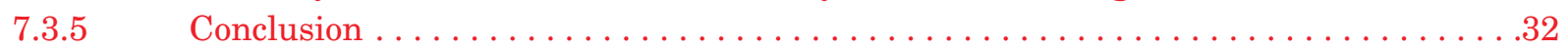

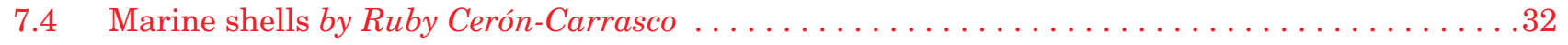

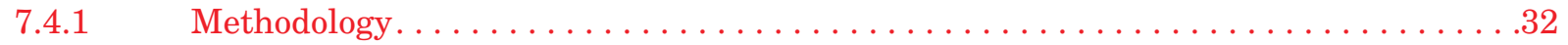

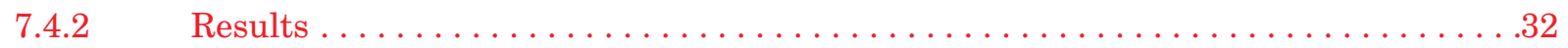

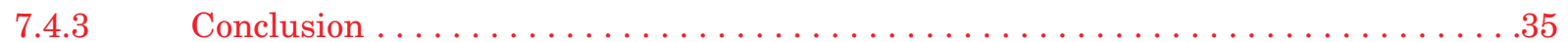

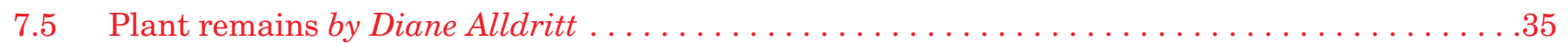

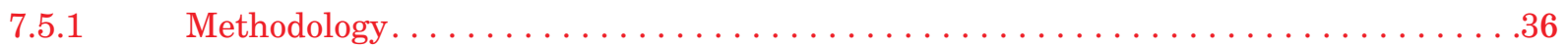

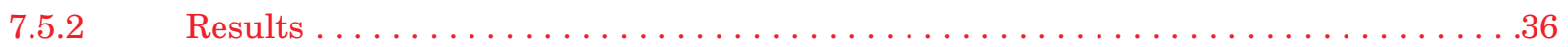

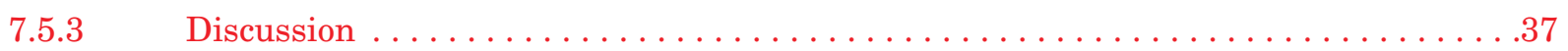

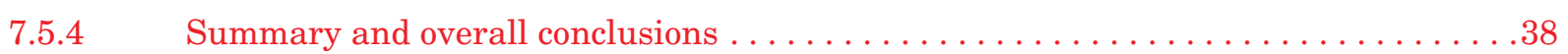

8 Conclusions and Discussion. ................................... 40

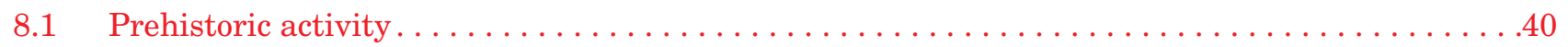

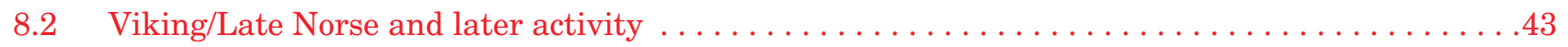

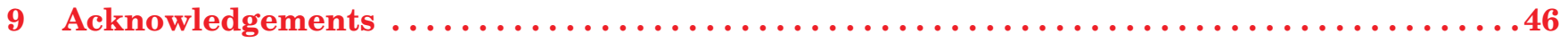

10 References ................................................. 


\section{List of illustrations}

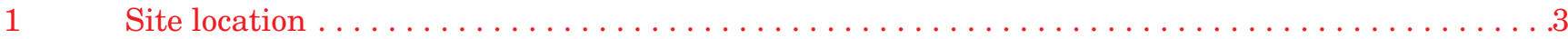

2 Site plan of Glassknapper's Cave and Antler Cave. . . . . . . . . . . . . . . . . . . . . . .4

3 Smoo Cave: section through the midden and occupation deposits . . . . . . . . . . . . . . . 7

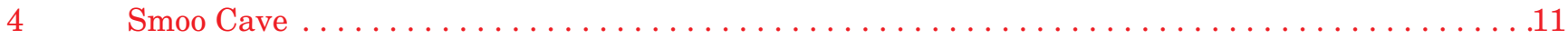

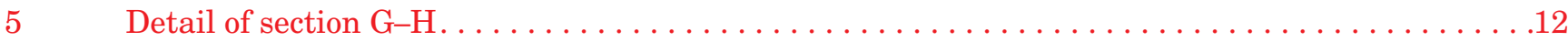

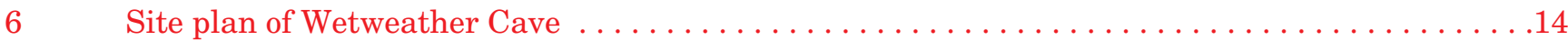

$7 \quad$ Metal and pottery $\operatorname{artefacts.\ldots \ldots \ldots \ldots \ldots \ldots \ldots \ldots \ldots \ldots \ldots \ldots \ldots \ldots \ldots \ldots \ldots \ldots \ldots \ldots \ldots \ldots \ldots \ldots }$

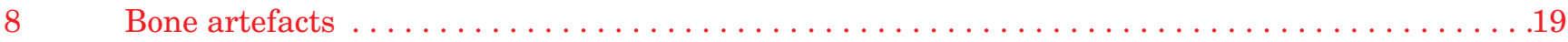

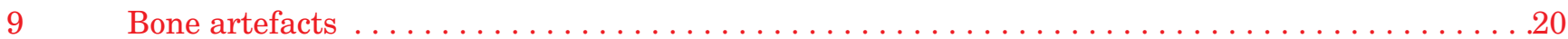

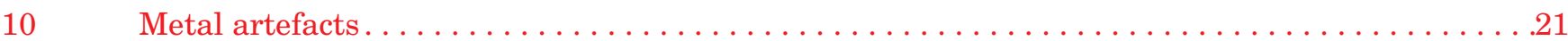




\section{List of tables}

1 Radiocarbon determinations from Smoo Cave and Glassknapper's Cave (GKC).

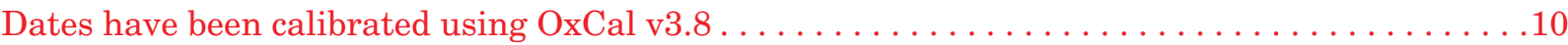

2 Fish specimens from Smoo Cave by fragment count. . . . . . . . . . . . . . . . . . . . . . 224

3 Comparison of nine (Q1) haddock cranial and 'appendicular' elements from

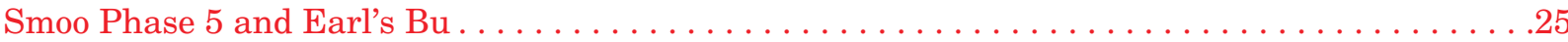

4 Chi-square comparison of haddock cranial and 'appendicular' specimens from

Smoo Phase 5 and Earl's Bu . . . . . . . . . . . . . . . . . . . . . . . . . . . . . . . . 25

5 Total numbers of mammal bones found in Glassknapper's Cave (GKC),

Antler Cave (AC) and Wetweather Cave (WWC) . . . . . . . . . . . . . . . . . . . 30

6 Total numbers of bird bones found in Glassknapper's Cave (GKC) and

Wetweather Cave (WWC) . . . . . . . . . . . . . . . . . . . . . . . . . . . . . . . . . . . . 31

$7 \quad$ The marine shell representation from $\mathrm{Smoo}$ Cave $\ldots \ldots \ldots \ldots \ldots \ldots \ldots \ldots \ldots \ldots \ldots \ldots \ldots \ldots$

$8 \quad$ Marine molluscs from Geodha Smoo: Glassknapper's Cave 100\% sorted samples. . . . . . . . . . . 34

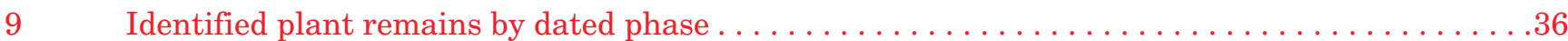

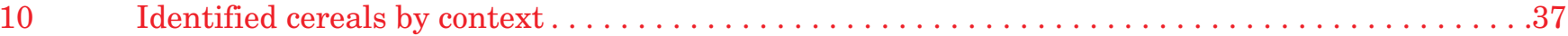

11 Number of weeds recovered from each phase, divided into ecological groupings . . . . . . . . . . 38

12 Comparison of artefactual and ecofactual material from the four caves. . . . . . . . . . . . . . 41 


\section{Summary}

In response to the threat posed by marine and river erosion, a series of deeply stratified midden deposits was excavated in caves leading off a narrow, rock-cut inlet known as the Geodha Smoo, near Durness, Sutherland. These included the famous Smoo Cave (NGR: NC 4136 6714), at the southern end of the inlet; two smaller caves cut into the western wall of the inlet (Glassknapper's Cave and Antler Cave); and a fourth cave (Wetweather Cave) in the eastern wall. The majority of excavated deposits from these caves appear to relate to Viking/Norse or post-Norse activity, with fish bones, marine shells and mammal and bird bones representing the processing and consumption of marine and terrestrial foods. Possible evidence for metalsmithing in the form of iron slag and boat nails could suggest that boats were repaired in the sheltered inlet. Four radiocarbon dates from Smoo Cave and Glassknapper's Cave provide evidence for use of these sites between the eighth and 11th centuries AD. Convincing evidence for pre-Norse activity, although unsupported by radiocarbon dates, was recovered from Glassknapper's Cave in the form of probable Iron Age pottery, while late Neolithic pottery came from floor deposits in the Wetweather Cave. 


\section{Introduction}

This report combines the results of two programmes of archaeological fieldwork. The first took place in 1992 and involved the cleaning back, sampling and recording of a midden section inside Smoo Cave prior to the erection of a protective wall (Illus 1). This remedial work was necessitated by erosion of the midden face by the river, known as the Allt Smoo, which flows down through the cave into the inlet and the sea. The project was sponsored by Caithness and Sutherland Enterprise and facilitated by Highland Council's Archaeology Service. The second, and more extensive, programme of work was funded by Historic Scotland and took place outside Smoo Cave proper in 1995, in a pair of adjoining caves in the western wall of the inlet some $80 \mathrm{~m}$ to the north of Smoo Cave and in a fourth cave in the eastern wall (Illus 1).

\subsection{Site location and description}

Smoo Cave (NGR: NC 4138 6714) is situated at the head of a narrow inlet (Geodha Smoo) that runs inland for about $600 \mathrm{~m}$ from the northern coast of Durness, Sutherland (see Illus 1). The main cave, which is of impressive dimensions (approx 35m wide by $50 \mathrm{~m}$ deep), has been carved into the Cambrian Limestone by successive episodes of high sea level over the past several hundred thousand years. The main cavern is connected to several smaller fresh water chambers, eroded by the Allt Smoo as it cut its way to the sea.

Smoo Cave was carved along the line of a weak fault in the limestone, both by the river which today flows through it and by the sea which at times of very high tide laps the back wall of the cave. The inlet itself was created as the cave roof progressively collapsed with the deepening of the cavern over hundreds of thousands of years (Gleed-Owen 1992).

Still a popular tourist attraction on Sutherland's north coast, Smoo Cave has drawn visitors and comment since at least the 18th century, as illustrated by this early reference, dating from between 1720 and 1745 and cited in Macfarlane's Geographical Collections:

Betwixt the two Sangoes at the shore, there is a cave stretching pretty far under ground with a naturall [sic] vault above; Its called Smoa [sic], at the mouth of it is a harbour for big boats, on the floor of the cave there is room enough for 500 men to exercise their arms, there is a burn comes out of the earth in one side of the said cave and forms a large and deep pool there where trouts are catched and then runs out of the pond to the sea; there is also a spring of excellent water in the other side of the said cave (Mitchell 1906, 192).

The investigation of Smoo Cave reported here, though limited in extent, represented the first systematic archaeological work to be carried out inside it. The deposits are thought to have been 'turned over' in 1904, with bone pins recovered (Johnston 1981). No evidence for this earlier disturbance was noted during the 1992 investigation. Very little was previously known about the age of the deposits, although it has been suggested (Keiller 1972) that recovered bone and stone artefacts resembled Mesolithic tools recovered from the socalled Obanian cave sites on the west coast.

As noted above, several smaller caves lead off the Geodha Smoo. The most obvious of these are two shallow caves situated side by side in the western wall of the inlet, some $80 \mathrm{~m}$ to the north of the main cave: Glassknapper's Cave to the south and Antler Cave to the north. The cave mouths open directly onto a narrow shingle beach, which here occupies a shallow concavity in the inlet wall.

The caves that today exist outside the main cavern may, in the distant past, have been side chambers leading off the main cavern now represented by Smoo Cave. With the southward retreat of the main cavern, these side chambers were left behind as separate caves opening out from the walls of the Geodha. It is likely that further cave systems exist in the vicinity; work on one of the caves discussed in this report (Wetweather Cave) brought to light a partially collapsed passage at its rear (see below).

The formation of cave deposits is a dynamic and complex interaction between anthropogenic and biogenic agencies. The type of sediment inside a cave depends on access to external sediment carriers such as wind, water, people and animals. Endogenous sediment sources such as roof-fall (rock fragments and fine particles), re-precipitated limestones (speleothems, crusts, flowstone, stalagmites, stalactites, tufas/traverine), residual minerals left over after solution of carbonates (silicas, metal compounds and clays) and fluvial deposits. The importance of human activities in the formation of such deposits has been underlined (Butzer 1977, 79-85). External sources of sediment can be represented by aeolian materials, drainage into fissures, slope wash and colluvium, and particles deposited by the high water reaching the cave mouth.

Secondary complexities arise from postdepositional alteration (diagenesis) of deposits such as translocation of solid particles, bioturbation and chemical weathering, in addition to the larger-scale 

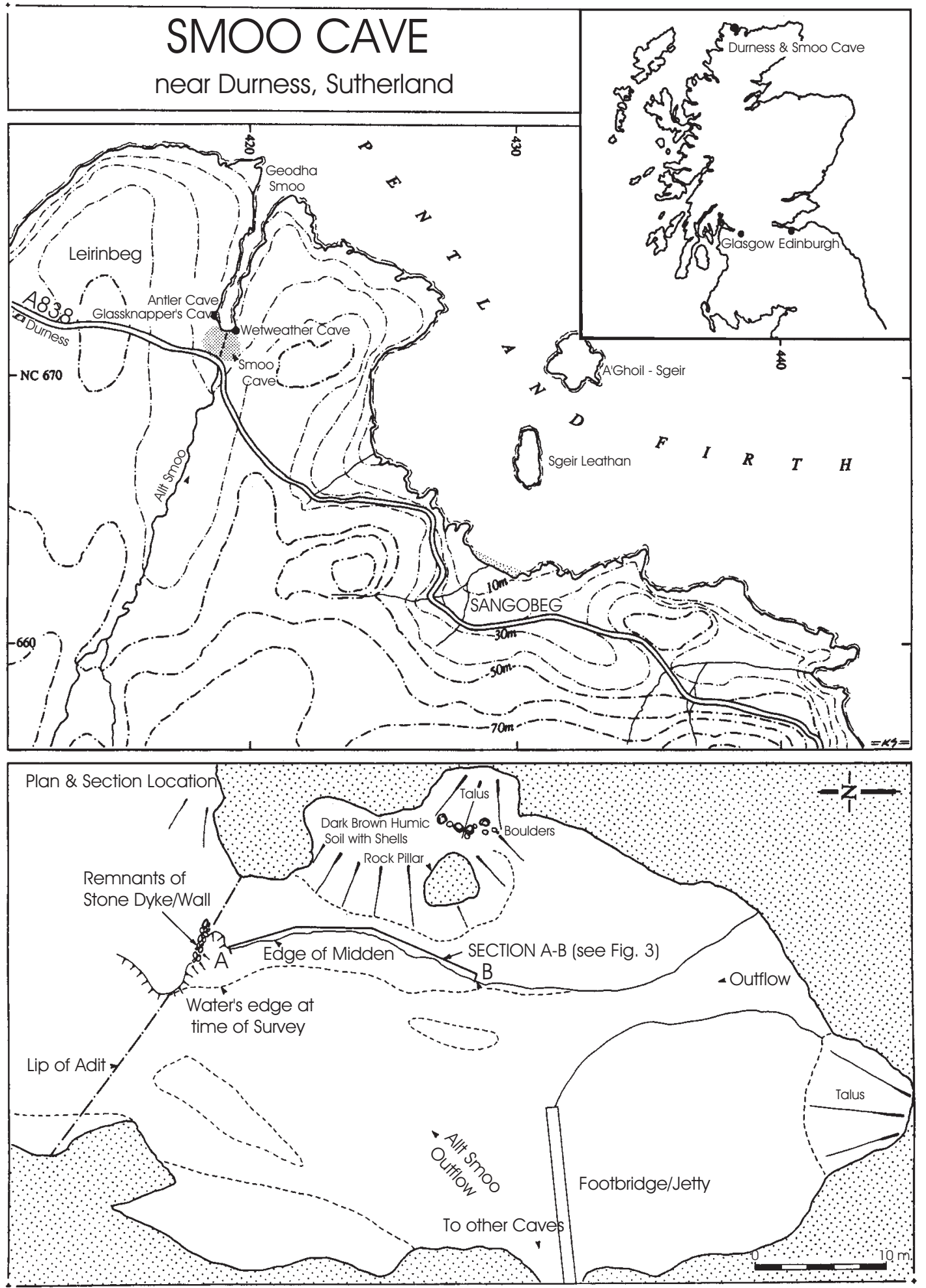

Illus 1 Site location

problems of erosion and collapse of the cave structure (Courty et al 1989). Gleed-Owen identifies the complexities in his attempt to reconstruct the marine history of Smoo Cave including the issues of, for example, small-scale fluctuations of sea level, which even over a relatively short period of time can lead to the repeated reworking of the marine sands present (Gleed-Owen 1992).

\subsection{Project background}

When Smoo Cave was investigated in 1992 at the behest of Highland Council, both Glassknapper's Cave and Antler Cave were observed to contain deeply stratified archaeological deposits. In order to avoid confusion with the better known cavern, long ago named Smoo Cave (from the Old Norse smuga, 


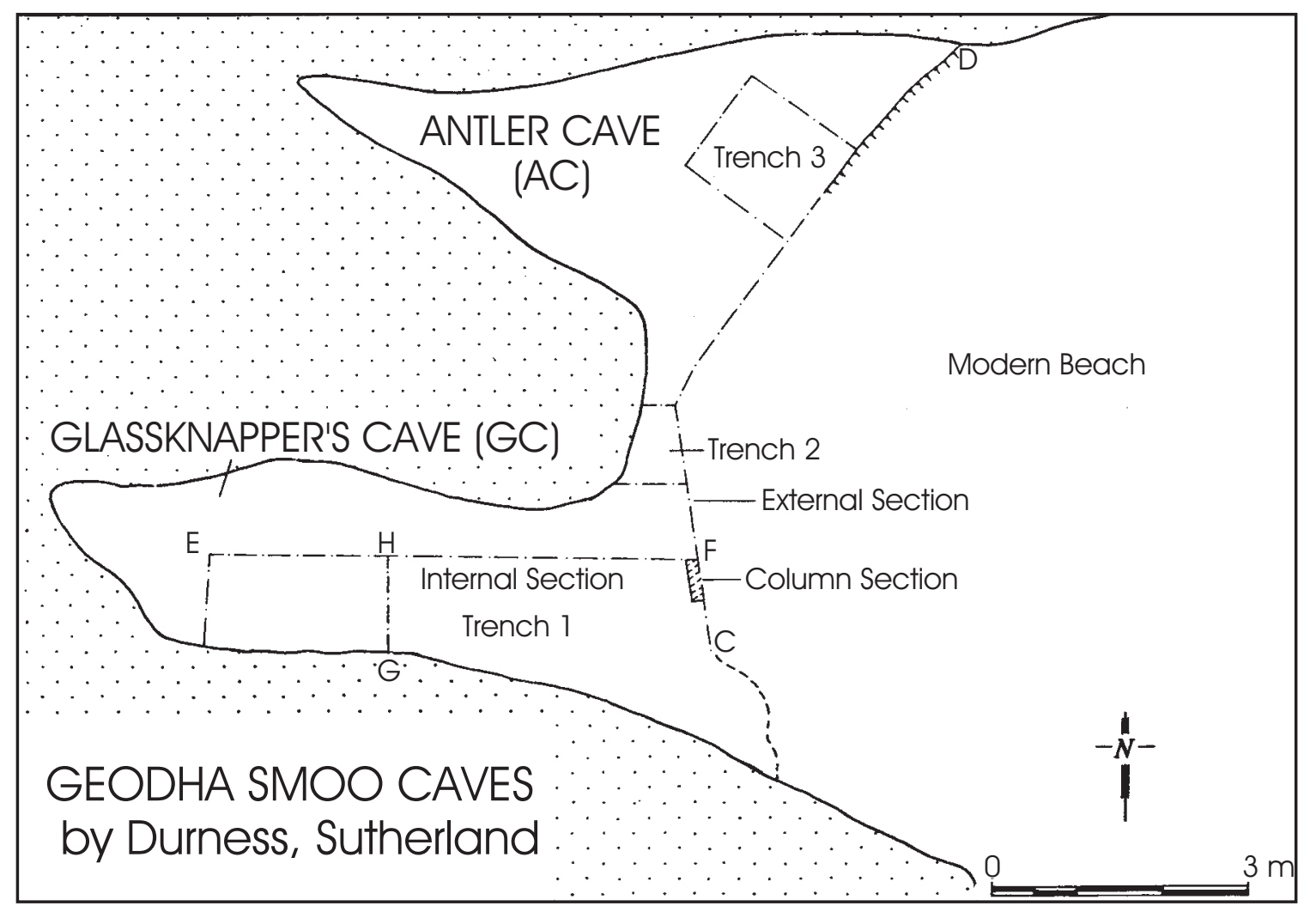

Illus 2 Site plan of Glassknapper's Cave and Antler Cave

meaning 'rift', 'cleft' or 'cave'; Fraser 1995), the two smaller caves were given names of their own during the excavation. The presence of fragments of modern glass, which at first appeared to have been knapped like flint, in the upper deposits of the southern cave provided the inspiration for the name Glassknapper's Cave. The discovery, again early on in the excavation, of antler tines in the deposits in the northern cave earned it the title Antler Cave. Bad weather at the time of the excavation made work in both of these caves dangerous, as the trenches were deep and the sections easily weakened by rain water and melted snow draining into the caves. In order to maximize working time during these periods of wet weather, attention turned to a fourth cave on the opposite side of the inlet, where conditions were less hazardous; hence its name, Wetweather Cave.

The mouths of both Glassknapper's and Antler Caves, which open onto a shingle beach, were partially blocked by midden-rich archaeological deposits, in places over $2 \mathrm{~m}$ deep (Illus 2). These deposits were vulnerable to erosion by breaking waves at times of high tide, with quantities of collapsed material, including animal bones, sitting on the beach at the base of the exposed archaeological deposits. These caves, like the parent cave, appear to have undergone considerable collapse through time, attested by fragments of limestone in the eroding deposits. The presence of collapsed midden material on the beach below the cave mouths attested to more recent erosion. As in Smoo Cave, these deposits were suffering from active erosion, but here caused by wave action at times of especially high tide as opposed to the action of the river.

The fourth of the caves (Wetweather Cave) is in the eastern wall of the inlet, where it curves to the south-west to meet the entrance of Smoo Cave (Illus 1 ). The cave is at the top of a steep, grass-covered slope, which may itself have resulted from cave roof collapse, where it meets the present cliff face around $15 \mathrm{~m}$ above sea level.

Wetweather Cave differs from the other caves not only in its elevated position, but also in its dimensions and appearance. Where the other caves have high ceilings and are longer than they are wide, Wetweather Cave has a relatively low ceiling (c $2.5 \mathrm{~m}$ ) and is much wider than it is deep. It is perhaps better described as an overhang or rockshelter than a cave. However, closer inspection proved that there was much more to the Wetweather Cave than first appeared; at its eastern edge the back wall gives way to a calcified fan of talus, above which is a small, circular chamber. Further to the east, a narrow gap allows access to a long, narrow chamber filled with collapsed rock to the extent that it is not possible to stand up once inside. It is possible that this passage was at some time joined to a complex series of chambers and tunnels like those known to exist elsewhere in north-western Sutherland (Lawson 1988). The successive collapse of the cave roof has concealed any further continuation of the passage. 
Wetweather Cave also differs from its neighbours in that archaeological deposits were not obvious from the outset. The floor of the cave was covered by a carpet of sheep dung and, in the absence of erosion by either river or sea, there was no exposed anthropogenic material. The site was initially investigated because of its proximity to caves known to contain archaeological deposits and also because its higher position and appearance as a sheltered overhang struck the excavation team, correctly as it happened, as a likely place for prehistoric activity.

From the outset it was obvious that the deposits in Smoo Cave and its neighbours had high archaeological potential. Shell midden deposits are well known for promoting good preservation and this factor, along with the apparent complexity of the deposits, suggested that excavation would provide a valuable insight into past lifeways in this part of coastal Scotland. This research potential aside, it was also obvious that the deposits were suffering badly from marine and riverine erosion. It was in recognition of this last factor that a programme of rescue excavation was developed, with the investigation and recording of the archaeological deposits prior to their total destruction being the highest priority.

As no formal archaeological recording or investigation of the Smoo Caves had taken place prior to the work reported here it was essential that a survey of the caves and their deposits took place before excavation commenced. All of the caves were subject to instrument survey and the apparent extent of the archaeological deposits was mapped as part of this exercise.

The first programme of work, in 1992, involved the cutting back and recording of the deposits in Smoo Cave, in advance of the revetting work which would, it was hoped, protect the deposits from further erosion. This work was carried out to a brief provided by the Highland Archaeology Service and involved minimal intervention rewarded with informative results. The protection of the Smoo deposits is also a cause of public interest, as the site is visited by thousands of people every year and is an important tourist attraction in north-western Scotland. The impact of visitors walking over the deposits as they enter the cave is a further cause of erosion, with walkers exposing deposits on the footpath surface and the pressure exerted through their body weight pushing the deposits outward through the exposed erosion face and thus speeding up the process of section collapse. It was hoped that this additional problem would be at least temporarily circumvented through the construction of the revetment and the laying of gravel over the portion of midden surface used as a footpath.

In the case of Glassknapper's Cave and Antler Cave, it was recognized that protective measures such as those adopted in Smoo Cave were inappropriate. Here the main priority was to investigate and record the deposits prior to their total and imminent destruction through marine erosion. The main aims and objectives were set out in a brief provided by Historic Scotland. It was hoped that intensive excavation of these caves would provide a more detailed insight into the history of human use of the caves than that afforded by the limited programme of recording carried out in Smoo Cave, though this exercise did result in the recovery of an important set of data. Excavation was geared to the recovery of information on the economic function of the caves and the period over which activities took place. The excavation of deposits in the cave interiors, away from the exterior exposed face, would also allow an understanding of depositional process and patterning not possible in the more limited cutting back of the Smoo Cave section.

The investigation of the Wetweather Cave was not part of the Historic Scotland brief and is best understood as an assessment of archaeological potential of a site discovered during the survey of the other caves and their environs and carried out at times when work in these other sites was prevented by dangerous weather conditions.

More specific objectives and the methodologies adopted in order to achieve them are discussed in the relevant sections of the report.

Terminology for the chronological periods represented by the excavated remains follows that set out previously (Batey \& Graham-Campbell 1998, 2): Viking and/or Norse are used interchangeably to refer to the period from the late eighth to 11th centuries, while Late Norse is understood to have begun around AD 1050 . 


\section{Smoo Cave}

The archaeological investigation in Smoo Cave involved the cutting back, sampling and recording of an eroding section around $17.5 \mathrm{~m}$ long prior to the construction of a protective wall along it, and was carried out over four days in March 1992. The construction of a causeway (Illus 1 ) to allow visitors to walk from the main cave to the smaller, adjoining chamber had inadvertently diverted the course of the Allt Smoo. At times of heavy rain or snow melt, the obstruction created by the causeway caused the river to flow directly alongside archaeological deposits lying near the cave's mouth at its eastern side. The erosive action of the river exposed these deposits and, over several years, washed away a considerable quantity of material. In an attempt to curtail the erosion, a revetting wall was to be constructed against the face of the archaeological deposits. In order to ensure that the wall sat flush against the deposits, they were to be cut back along several planes, a process which provided the opportunity to examine their nature and remove samples for further analysis.

\subsection{Background and methodology}

The first aim of the work was to carry out a theodolite survey of the main cave, recording the location and visible extent of the archaeological deposits on the plan produced (Illus 1). In order to understand the nature and extent of the deposits, the eroding face was first cleaned and drawn. This initial section drawing is not reproduced here, as in many respects it closely resembles the final drawing. However, several ephemeral features present in the initial section did not survive a further trowelling. These included a cut pit (015), which may have been a post-hole, and the remnants of a possible hearth (012).

After recording the eroding section, the process of cutting back the face began. In order to accommodate the revetting wall, while at the same time removing as little material as possible, the section face was cut back on three planes, shown on Illus 1.

The Highland Region Sites and Monuments Record gave the dimensions of the midden as $3 \mathrm{~m}$ in diameter by $0.2 \mathrm{~m}$ high. Cursory examination of the site soon established that this was a considerable underestimate of the scale of the deposits. The exposed midden face was found to extend southwards into the cave for some $17 \mathrm{~m}$, with deposits possibly several metres in depth stretching back for at least $8 \mathrm{~m}$ towards the eastern wall of the cave.

The area around a natural pillar in the northeastern part of the cave and a small recess in the northern curve of the cave wall (Illus 1) were occupied by a flat-topped mound which rose for well over a metre above the top of the eroding section. Marine shells were observed eroding from the humic soil which covered this mound, and a sondage rapidly excavated on its top and western slope established that archaeological deposits, consisting of shells and concentrations of charcoal, lay about $0.30 \mathrm{~m}$ below the surface. It also became apparent, after initial cleaning back of the section, that the shell midden was not the only evidence for archaeological activity inside the cave; deposits below the shell midden provided convincing evidence for several occupation horizons.

Time constraints did not permit an assessment of the deposits' full extent as this would have involved extensive trial trenching. The presence of marine shells eroding onto the cave floor seemed at first to suggest that the deposits roughly corresponded with the extent of the mound. However, limited excavation later revealed that earlier archaeological deposits are stratified beneath the present floor of the cave, and these may extend beyond the edges of the mound.

It was immediately apparent that the threatened section was in a seriously denuded state. Recently collapsed portions of the exposed face covered the narrow pebble beach, which at the time separated the midden from the river. However, during the course of the work, with several days of only moderate rain, the water level rose dramatically. At its highest point the river was observed flowing along the base of the section, totally submerging the pebble beach.

\subsection{The Smoo Cave section}

The following discussion of the section investigated in Smoo Cave moves from the latest deposits to the earliest; Illus 3 illustrates the section.

The upper layers in the section (contexts 006a and 006b) consisted of large numbers of shells in a matrix of dark, organic-rich sandy soil. The uppermost layer (006a) comprised shells (mostly limpets and winkles) in a dark brown sandy matrix and was $c 0.2-0.3 \mathrm{~m}$ deep for most of its length. However, towards the northern end of the section (Illus 3, point A), this deposit was considerably deeper, and in the initial section there was some suggestion of a cut pit which had been filled with shells. Again, this feature did not survive more than the initial clean, but after the section had been cut back the northern side of this cut was still evident and can be seen in Illus 3 , where the upper deposit (006a) rises to the surface. 

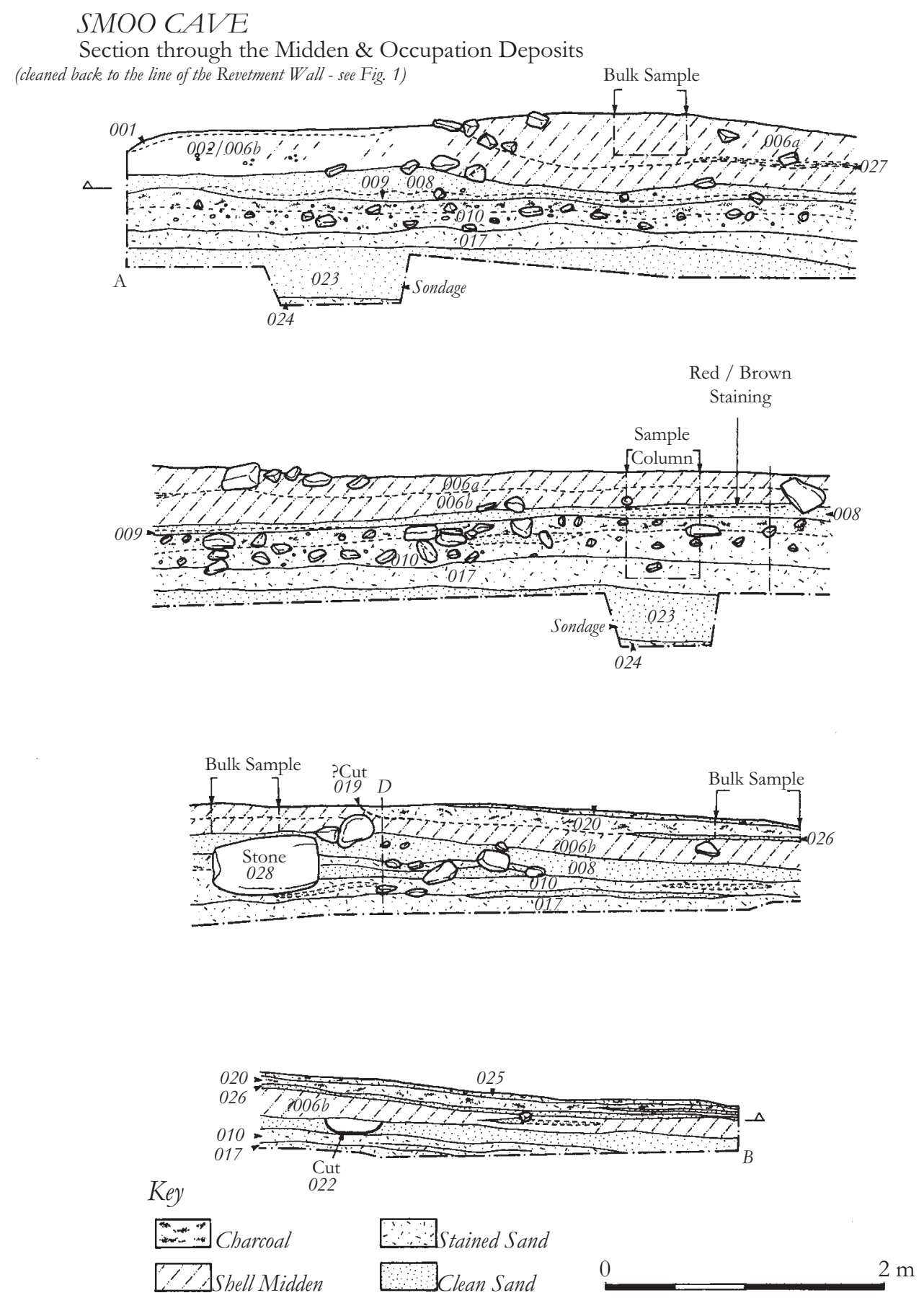

Illus 3 Smoo Cave: section through the midden and occupation deposits

Underlying the deposit (006a) was another shell midden layer (006b), which on initial cleaning appeared to be the same as context 006 a but proved to contain more charcoal and represented an earlier phase of deposition. A thin, charcoal-rich layer (027), devoid of shells, lay between the two midden deposits.

The upper shell midden layer (006a) terminated towards the southern end of the section, giving way to a deposit of dark greasy soil (020), containing butchered animal bone, which lay in a shallow cut (019). This was overlain by a thin spread of a similar soil with a higher charcoal content (025).
Beneath the lower shell midden layer (006b) was a deposit of reasonably clean yellow sand (008) which may have been deposited by wave action during marine inundation of the cave some time in the past. Such inundations are still a regular occurrence, with northerly winds and spring tides carrying waves into the back of the cave. It is difficult to establish when this inundation took place or how long it lasted. Immediately below the marine sand (008), though not visible throughout the entire section, was a thin band of grey sand (009), which may have been stained as a result of human activity. 
A hearth or firepit (021), extremely rich in charcoal, lay towards the southern end of the section. Birch and hazel charcoal from this feature provided a radiocarbon date which falls within the range cal AD 780-1020 (GU-4545) at the 2-sigma level of confidence. The charcoal sat in a cut (022) in the marine sand (008). It thus appears to represent activity on the waterborne sandy surface (008) just before the shell midden (006b) began to accumulate. The thin bands of washed sand - including context 026, sandwiched between the lower shell midden layer (006b) and the charcoal-rich layer (020) - are perhaps more likely to represent riverine deposition (by the Allt Smoo) than marine inundation.

Lying beneath the marine sand (008) and the grey sand (009) was a deposit of water-rolled and fractured stones with some gravel and pebbles (context 010). Most of these stones probably represent a natural beach surface, with the stones smoothed and rounded by the action of the waves. However, this beach surface had seen intensive human activity, as evidenced by bands of dark humic sandy soil and frequent charcoal. Discolouration caused by human occupation was most obvious in the upper part of the beach deposit (010), but there were also clear archaeological horizons in its lower levels. Artefactual material, including butchered bone and possibly struck stones, was found throughout it. Marine shells were also present, but in nowhere near the numbers present in the shell midden (006).

Some of the larger stones in the beach deposit (010), including Boulder 028, may represent structural features, but it was not possible to substantiate this from the section alone. However, it is interesting to note that the possible post-hole (context 016), which was visible only in the initial section and is not illustrated, actually sat next to Boulder 028, which only became visible once the section was cut back. Their proximity strengthens the argument that the boulder represented a structural element, perhaps part of a wall, and helped to brace the post that stood in Post-hole 016.

The lower levels of beach deposit (010) merged with a substantial deposit of laminated sands (017), again representing successive episodes of marine inundation. The upper levels of these sands were heavily stained and contained both charcoal and butchered animal bone, once more providing evidence for human activity.

In order to establish the full depth of deposits, two small sondages were dug along the base of the section (see Illus 3 ). These revealed a layer of clean, washed sand (context 023) 0.65-0.8m deep, lying below stained sand (context 017) and representing a period when this part of the cave saw no human activity. Excavation of these sondages stopped where a surface was encountered that provided evidence for an earlier phase of human activity on the site; time did not permit excavation below this level. On the surface of a layer of heavily stained sand (024) lay pieces of quartz, possibly chipped by human action, butchered animal bones and flecks of charcoal.

\subsection{Summary and interpretation}

The cleaning back and recording of the eroding section revealed considerable evidence for sequential phases of human activity.

The charcoal-stained, artefact-littered surface (024) encountered in the sondages provides evidence for the earliest known human activity in the cave (Phase 1), at a time when the cave floor was substantially lower than today. Unless the sea level was considerably lower than at present, marine inundation would then have been a more common occurrence than it is today. The thick layer of washed sand (023) sealing the surface was deposited over an unknown period of time by these incursions of the sea. Without dates or diagnostic artefactual material it is not possible to say when or over how long a period this sand accumulated. The absence of lamination within this deposit and the lack of identifiable soil horizons may suggest a single event such as the 'tsunami' type episode thought to be responsible for sand deposits investigated at Wick (Dawson \& Smith 1997).

Following the inundation that deposited the sand, the cave saw another phase of human activity (Phase 2 ), evidenced by the charcoal and animal bone in a heavily stained sandy matrix (017). Subsequently, a stony beach deposit (010) formed during further human activity (Phase 3), which left behind abundant charcoal, animal bone and possible stone structural elements. After a further phase of inundation (context 008), a hearth was constructed (Phase 4). This was sealed by the charcoal-rich shell midden (006b) which was then overlain by another shell midden (006a). For the purposes of this report both phases of shell midden have been grouped together as Phase 5. The radiocarbon date from the hearth immediately below the lower shell midden deposit provides a terminus post quem of cal $\mathrm{AD} 780-1020$ for its formation. Activity related to the shell midden may have continued into the medieval period. The final phase of activity was marked by the upper horizon (025), which consisted of dark greasy soil with a high charcoal content.

The presence of six main archaeological horizons is certainly a simplified breakdown of the stratigraphy. As became obvious with the later phase of work in the other caves, the real picture is likely to be a great deal more complicated, with various layers separated by thin lenses of both clean and stained sands, the discolouration of the latter probably the result of human activity. With only the section recorded, it is very difficult to offer a more complex interpretation of these deposits. 


\section{Glassknapper's Cave, Antler Cave and Wetweather Cave}

\subsection{Background and methodology}

During the examination of midden deposits in Smoo Cave reported above, archaeological deposits, including midden material, were also noted in the two marine caves in the western wall of the inlet and observed to be vulnerable to serious erosion caused by high tides and storm-driven waves. Consequently, a grant was provided by Historic Scotland to enable the rescue excavation and recording of these deposits before they were entirely lost to the sea. This work was carried out over four weeks in February and March 1995.

By the time of the excavation the deposits had already suffered heavily from marine erosion, with between 1 and $2 \mathrm{~m}$ of deposit taken away between the Smoo Cave investigation in 1992 and the commencement of excavation in 1995. Given the rescue motivation of the work and the limitations on budget and time available, a pragmatic approach was adopted and the main objectives were set out by Historic Scotland. It was proposed that a sample assessment of between 30 and $50 \%$ of the deposits would establish the depth of midden, extent of midden, nature and date of stratigraphy forming the midden and the nature of any internal structure within the midden (R Hingley, pers comm).

Prior to excavation, the exposed section (Illus 2, CD) was only partly visible behind a loose slope of earth and stones which had collapsed from the section face. Much of this material had accumulated since the site was first identified in 1992, clearly indicating the rapid rate of erosion. In order to obtain an impression of the nature and depth of the deposits it was necessary to remove this material. However, in case it contained residual in-situ deposits, two slots were first excavated through it. This controlled removal and examination of the sections confirmed that it entirely comprised loose material that had fallen from the section face.

The section face was cleaned by trowel and recorded by measured drawing. It was immediately obvious that there were differences between the deposits in the southern cave and those in the northern cave (Illus 2, C-D). The southern cave (Glassknapper's Cave) appeared to contain a far more complex series of deposits, which included several strata rich in marine shells and animal bones. The deposits in the northern cave (Antler Cave) were less well-defined and varied, with marine shells at this stage visible only at one level. The collapsed material in front of Antler Cave proved to contain fragments of red deer antler, which were also observed in this part of the cleaned-back section.

The presence of substantial fragments of limestone in various parts of the section indicated that the roofs of both caves had suffered collapse at some point in the past. The caves may therefore have been somewhat larger than they are now, which would have made them more fitting for human use than they appear today. Nevertheless, the presence of tractor batteries, boating equipment and even a length of Scalextric track in the southern cave clearly indicated its use an equipment store and dumping ground in recent times.

After surveying the cave interiors (Illus 2), it became apparent that the most efficient means of fulfilling the excavation objectives would be to cut a single trench from the exposed section to the back of Glassknapper's Cave. The same would also be attempted for the Antler Cave, but priority was given to the southern cave, as it appeared to contain more complex archaeological deposits. The cave floor was divided in two roughly along its central axis (Illus 2). By the end of the excavation, most of the material had been removed from the southern half, while the northern portion remained intact, proviHding a full section through the deposits. A lateral section was cut through the southern half of the cave (Illus 2, G-H), at right angles to the axial section, thus providing insight into the nature of the stratigraphy in a north/ south plane (across the cave interior) as well as in an east/west plane from cave mouth to cave interior (Illus 2, E-F). The deposits were excavated in spits down onto the former beach surface, at which point the concreted nature of the gravels and safety considerations prevented further investigation.

An important aim of the project was to recover bulk samples from the excavated deposits, as coastal deposits rich in marine shells represent a rare opportunity to recover well-preserved faunal, palaeobotanical and organic artefactual evidence. Where possible, samples were removed from individual deposits. However, the stratigraphy in Glassknapper's Cave was of such complexity that sampling individual contexts was not always possible. In order to overcome this problem, a column sample was taken through the deposits, with samples removed in spits. Wet-sieving of samples was carried out on site.

\subsection{Glassknapper's Cave}

Glassknapper's Cave displayed the most extensive and complex series of archaeological deposits. The 
Table 1 Radiocarbon determinations from Smoo Cave and Glassknapper's Cave (GKC). Dates have been calibrated using OxCal v3.8

\begin{tabular}{|c|c|c|c|c|c|}
\hline \multirow[t]{2}{*}{ Lab code } & \multirow[t]{2}{*}{ Sample material } & \multirow[t]{2}{*}{ Lab age } & \multirow[t]{2}{*}{$\partial \mathbf{1 3 C} \%$} & \multicolumn{2}{|l|}{ Calibrated dates } \\
\hline & & & & 1-sigma & 2-sigma \\
\hline GU-4545 & $\begin{array}{l}\text { Birch and hazel from Hearth } \\
021 \text { (Smoo Cave) }\end{array}$ & $1120 \pm 50$ & -27.1 & $\mathrm{AD} 880-1000(68.2 \%)$ & $\mathrm{AD} 780-1020(95.4 \%)$ \\
\hline OxA-8210 & $\begin{array}{l}\text { Birch and willow from Spit } 2 \\
\text { (near top of column sample, } \\
\text { GKC - see section drawing) } \\
\text { Context } 008\end{array}$ & $1030 \pm 40$ & -25.7 & $\begin{array}{l}\mathrm{AD} 900-920(2.6 \%) \\
\mathrm{AD} 970-1040(65.6 \%)\end{array}$ & $\begin{array}{l}\mathrm{AD} 890-930(8.4 \%) \\
\mathrm{AD} 940-1050(78.3 \%) \\
\mathrm{AD} 1090-1160(8.7 \%)\end{array}$ \\
\hline OxA-8211 & $\begin{array}{l}\text { Birch from Spit } 15 \text { (middle of } \\
\text { GKC column - see section } \\
\text { drawing) }\end{array}$ & $1160 \pm 35$ & -27.1 & $\begin{array}{l}\mathrm{AD} 780-800(5.5 \%) \\
\mathrm{AD} 810-900(38.5 \%) \\
\text { AD } 910-960(24.1 \%)\end{array}$ & $\mathrm{AD} 770-980(95.4 \%)$ \\
\hline OxA-8212 & $\begin{array}{l}\text { Hazel from Spit } 33 \text { (bottom } \\
\text { of GKC column) }\end{array}$ & $1120 \pm 30$ & -25.7 & $\mathrm{AD} 890-980(68.2 \%)$ & $\begin{array}{l}\mathrm{AD} 820-840(1.1 \%) \\
\mathrm{AD} 860-1000(94.3 \%)\end{array}$ \\
\hline
\end{tabular}

external section (Illus 2) contained a considerable amount of overburden in its upper portion, with a gritty deposit (001) overlying a black humic layer that contained many small fragments of quartz and other stone (003). The upper deposit (001) contained sherds of bottle glass, some of which, on first examination, gave the appearance of having been modified (they had not been), hence the name Glassknapper's Cave. The humic deposit (003) represented organic soils washed down from the cliff face above and did not extend far back into the cave.

An earlier episode of largely natural build up (context 004) was evident directly beneath the humic deposit (003). The presence of angular fragments of limestone in it suggested that this deposit (context 004) was at least partially composed of cave roof collapse. As in the case of the humic layer, the roof collapse appeared to be limited to the area of the cave mouth. However, it also contained rounded stones of various types, which may have been driven there by high tides and storm waves. Excavation of the trench through the cave (Illus $2, \mathrm{E}-\mathrm{F}$ ) revealed relatively little difference between these upper deposits. Although they were largely sterile, the presence of the bottle glass and a number of brown-glazed pottery sherds suggests they accumulated during the 19th and early 20th centuries, although a piece of White Gritty Ware was also recovered from context 004.

These upper layers sealed a series of deposits rich in archaeological material, possibly accumulated over a long period of time. Evidence for this human activity was clearly visible within the eroding section (Illus 2, C-D), where deposits of marine shells and animal bone were visible throughout the lower half. The presence of midden-rich layers stratified between washed sand layers suggested the periodic use of the site interspersed by times when high water levels, perhaps promoted by spring tides or winter storms, washed marine sands into the cave. However, some of these thin, clean sand deposits may have been laid by those using the cave, perhaps to minimize dampness or to cover unpleasant organic deposits. The most substantial sand deposits lay toward the rear of the cave, where they were deposited by marine action before the high concentrations of archaeological material accumulated.

Excavation and recording of both the main internal cave section (Illus 2, E-F) and the internal lateral section (Illus 4; Illus 5, H-G) revealed a complex sequence of deposits, which bore only limited resemblance to those observed in the external, eroding section. The internal deposits (contexts 008, $012 \&$ 013) on the whole consisted of numerous thin layers and lenses of organic material, clays and silts, ash, charcoal, crushed shell, animal bones and washed deposits. It was impossible to excavate each of these deposits individually, with many hundreds of individual contexts being stratified within the deposits. In order to overcome this problem, a column sample was removed from the deepest portion of the deposits (see Illus 2 and Illus 4 for location), with samples bagged in approximately $0.02 \mathrm{~m}$ spits. Environmental analysis of these samples has revealed a wide variety of plant remains (see Section 7.5 - Plant remains) with recovered charcoal providing three radiocarbon dates (Table 1). The latest of these was from Spit 2 (toward the top of the column and consisting of birch and willow), with the date range being cal $\mathrm{AD}$ 890-1160 (OxA-8210); the second was from Spit 15 (middle of column, birch) and gave a range of cal AD 770-980 (OxA-8211); the third came from Spit 33 (bottom of column, hazel) and gave a range of cal AD 820-1000 (OxA-8212); all dates are expressed at the 2-sigma level of confidence (or 95.4\%). These relatively closely spaced dates clearly indicate quite rapid accumulation of considerable quantities of material, with the $0.95 \mathrm{~m}$ depth of the column sample forming in perhaps 100-150 years.

Excavation continued down through the tightly stratified deposits within the cave, onto what appeared to be the cave's primary floor, characterized by hard-packed, water-rolled stones. While these appeared to represent a beach surface, it is not possible to state for certain that earlier archaeological deposits were not sealed beneath; marine shells 


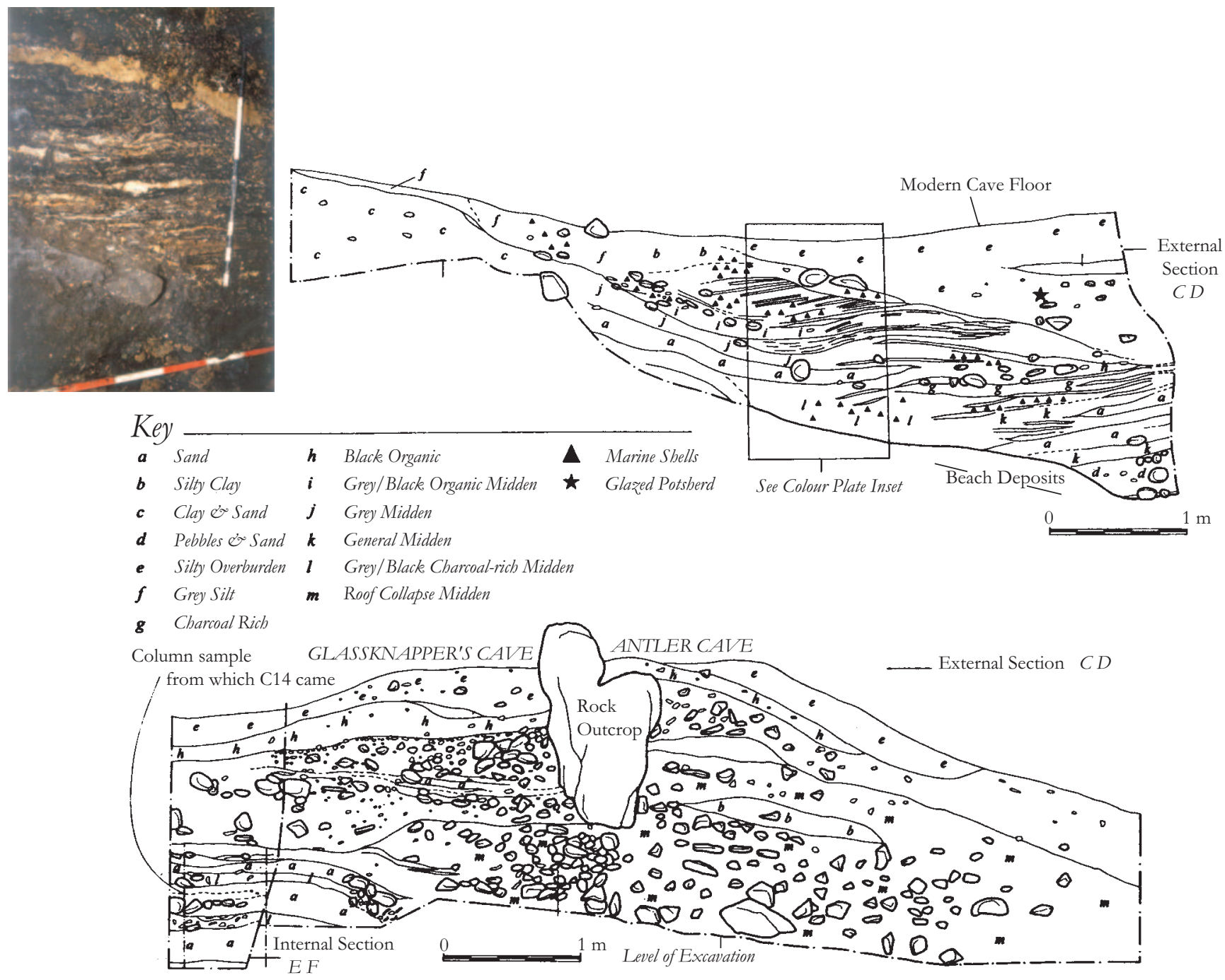

Illus 4 Smoo Cave

and animal bones were found intermixed with the loose beach gravels at the base of the external section. Unfortunately, the hard-packed nature of the basal deposit in Glassknapper's Cave and the obvious safety risks involved in digging the trench any deeper made it impossible to establish the presence or absence of earlier deposits.

There was no convincing evidence for substantial structural elements in Glassknapper's Cave, although two concentrations of stones appeared to represent artificial arrangements (not illustrated). The first of these (context 038) lay toward the rear of the cave and comprised a tightly packed layer of limestone chunks and water-rolled stones, the latter probably collected from the beach. The rear portion sat just beneath the modern surface but dipped down towards the mouth of the cave, following the contour of the sand deposit beneath it. The purpose of the stone concentration was unclear, but it did contain a beach pebble hammerstone and several sherds of wheel-thrown, medieval pottery. The absence of any trace of this feature in the section drawing (Illus 4) suggests it was confined to the southern half of the cave.
The only other possible structural element consisted of several large, angular chunks of limestone (018) stratified well within (approx 1.1m from the surface) the complex cultural deposits (008) observed just inside the cave mouth. These appeared to have been set into the underlying deposits and may represent an attempt to cordon off the mouth of the cave. However, as in the case of the stones (038) toward the rear of the cave, the concentration exhibited little regularity and may simply have been the result of roof collapse.

In the external section, a brown silty layer containing limestone fragments (012) appeared at first to comprise only roof collapse; investigation of the layer farther into the cave, however, found concentrations of winkles, mussels and limpets as well as a scallop shell. The midden deposits (013) directly beneath were very loose, and in places simply consisted of bones and shells lodged in the gaps between fragments of limestone and other rocks. In the interior, however, deposits were on the whole highly compacted and stone-free, apparently representing areas of trample, burning and other 


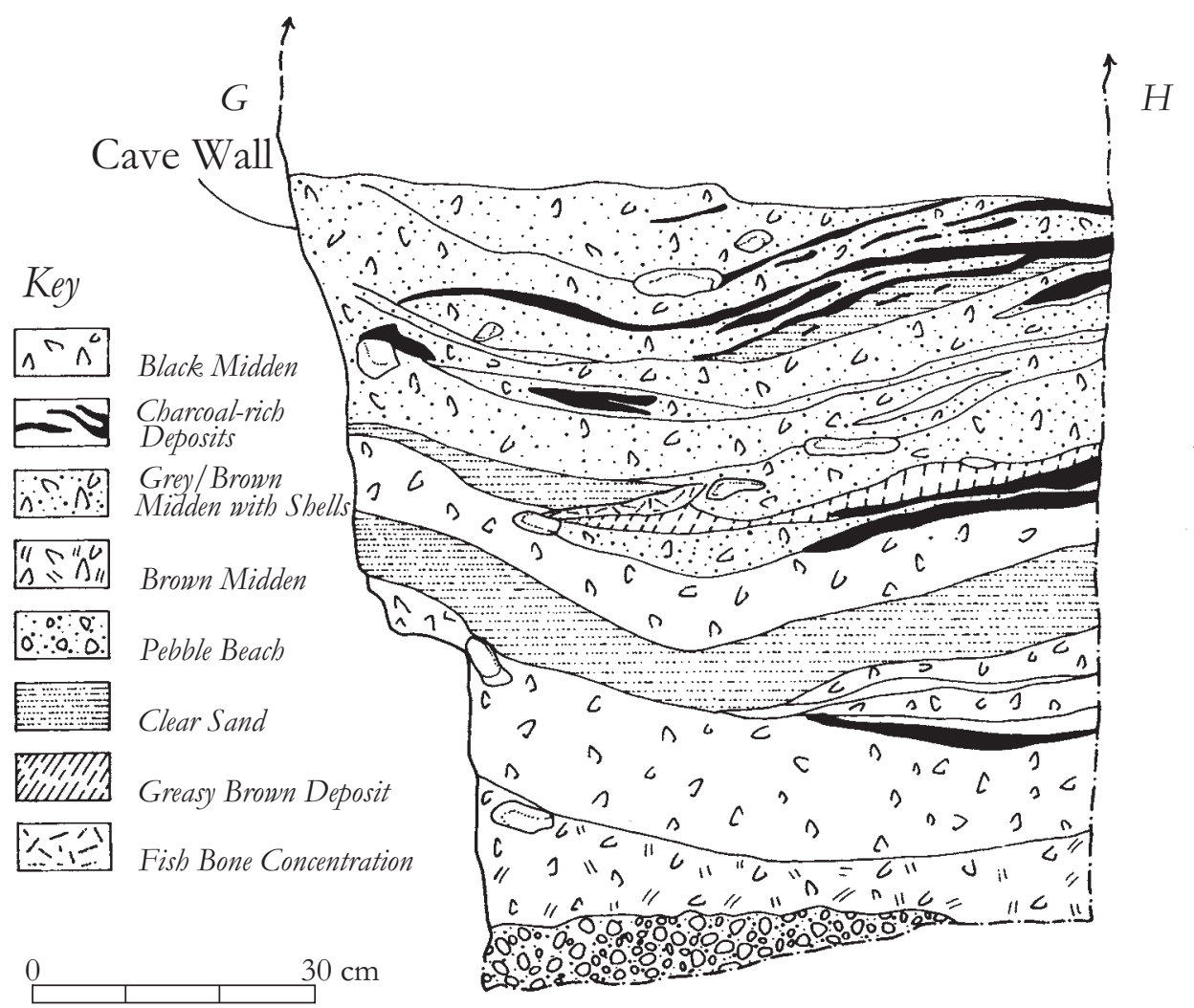

Illus 5 Detail of section $G-H$

activities. In order to clarify the nature of the deposits in the northern portion of the external section, a slot trench was cut back into the section (Illus 2, Trench 2), just east of the rock outcrop between Glassknapper's Cave and Antler Cave. The slot trench was cut back to the rock face that separates the entrances to the caves.

Archaeological material was present throughout the lower deposits (013) in this slot trench, those above representing the same process of silting and collapse observed elsewhere. However, the shells and bones were not present in distinct and compact layers, as in the interior, but on the whole were mixed with the rubble and stone, though in places higher concentrations of midden material existed independent of stone accumulation. A sheep's skull was recovered from the niche created by the outcrop and its juncture with the rock face, in which various other bones and shells had also lodged.

The appearance of water-rolled stones and limestone fragments (015) in this deposit suggests that both roof collapse and marine action had contributed to its formation. Limestone fragments, indicating roof collapse around the cave's mouth, were generally confined to the front part of the cave.

The presence of both water-rolled stones and washed sands within the midden deposits provides evidence for the complex nature of the processes of marine inundation and beach formation. Today the upper beach in front of the caves is composed of water-rolled stones, with sand only visible further down the beach at low tide. The dynamics of wave action and beach morphology must be studied in greater detail before the implications of the appearance inside the cave of both types of beach deposit, usually mutually exclusive, can be fully understood.

The loose midden material (013) identified in Trench 2 probably represents refuse removed from the cave interior and dumped into a semi-confined space otherwise occupied only by tumbled and wave-deposited stones. As this area was not subject to trampling, the deposits did not take on the compacted, greasy consistency of those inside the cave, each of which at some time in their history appear to have formed its floor.

\subsection{Antler Cave}

Archaeologically speaking, Antler Cave did not prove as productive as Glassknapper's Cave. The relative paucity of archaeological deposits may in part be due to the possibility that, as far as human activity is concerned, this cave has always been the damper cousin of its deeper and drier neighbour. However, this is not to say that archaeological deposits were totally lacking, and it is important to note that the consistently wet conditions regularly caused the sections to collapse and thus made it impossible to excavate as extensively as in Glass- 
knapper's Cave. It cannot therefore be stated for certain that more complex deposits, similar to those in Glassknapper's Cave, do not exist within the largely unexplored body of the cave deposits. Excavation of the Antler Cave deposits was limited to a small slot trench cut back from the main section for a little over a metre (Illus 2, Trench 3 ; sections not illustrated).

The upper deposits were similar to those observed in the front section of the Glassknapper's Cave, with the same sequence of silting and collapse forming the upper horizons (contexts 022, $023 \& 024$ equating with contexts $001,003 \&$ \& 004, respectively). A number of distinct archaeological horizons were detected further down in the section. These were sealed beneath a considerable deposit (contexts 024/ 026), around $0.40 \mathrm{~m}$ thick, of limestone fragments and chips, apparently from cave collapse. The first of these archaeological horizons lay directly beneath collapse (contexts 024/026) and consisted of a thin layer of winkles and animal bone in an orange/brown matrix (036). This overlay a less clearly defined deposit (027), some $0.20 \mathrm{~m}$ thick; it consisted of large angular stones in a silty brown matrix, which had shells, animal and fish bones scattered through it. This in turn sealed a midden deposit (029) of shells and fragments of charcoal in a silty grey matrix, which again also contained angular stones. This deposit did not appear to extend far back into the cave, but of course it is impossible to say how much of the deposit outside the cave's present mouth has been lost to erosion. This overlay a sterile layer of orange silty clay with some stones (039), which itself sealed a deposit of large angular stones, grit and gravel (040). The lower limit of excavation was marked by a deposit of very large angular chunks of limestone with virtually no matrix (041), which continued beneath the level of the present beach.

Limited excavation of the Antler Cave succeeded in identifying a series of deposits related to past human activity. Unlike the majority of archaeological deposits in the Glassknapper's Cave, these generally lay within rubble horizons rather than in highly compacted lenses and layers. The deposits on the whole were looser and less dense than most of those in Glassknapper's Cave. The cave appears to have been used on a much more casual basis, with features such as firespots and artefacts largely absent.

\subsection{Wetweather Cave}

An investigation of Wetweather Cave was not included within the original brief to carry out work in the Smoo inlet caves that later became known as Glassknapper's Cave and Antler Cave. In fact, prior to the project the presence of this cave was unknown. The cave was identified during the general survey of the inlet which accompanied the instrument survey of the other caves. Although situated on much higher ground and lacking the eroding sections that made the presence of archaeological deposits obvious, the cave seemed a likely candidate for past human activity.

The original intention was to do nothing more with the cave than include it on the survey. However, as the project progressed, work began seriously to suffer from deteriorating weather conditions. Melting snow made conditions in both Glassknapper's Cave and Antler Cave extremely hazardous as the deep strata became unstable. At times conditions were too dangerous for work in the caves to continue. The third cave did not suffer from water inundation to the same extent, remaining dry and sheltered from the worst of the weather. In order to make the best of the time available it was decided to carry out a limited evaluation of the cave, which became known as Wetweather Cave, during periods when work in the other caves was inadvisable.

Wetweather Cave consists of three elements. The first of these is the outer chamber, which takes the form of a deep overhang that opens out to the north-west. The rear part of the chamber, closest to the entrance to Smoo Cave, is occupied by a deposit of talus and limestone concretion, behind which is a small chamber into which it is possible to gain access with relative ease. To the left of the entrance to this small inner chamber is a third, much larger chamber. However, gaining entry to this chamber is possible only by crawling through a narrow gap, which had been partially blocked by cave roof collapse, with rubble extending into the chamber as far as the eye could see.

Excavation of the Wetweather Cave was confined to the outer chamber, where removal of several centimetres of sheep dung revealed archaeological deposits (Illus 6). The first feature to be identified was a concentration of marine shells, dominated by limpets (context 1/006), which also contained butchered animal bones and a copper-alloy pin (SF 050). A number of cut features were identified with further cleaning. These included several stakeholes and possible post-holes (contexts 1/012 \& 1/009), which had been cut into the chalk-like soil (contexts $1 / 002 \& 1 / 008)$ that covered the cave floor. This highly mineralized deposit, which appears for the most part to be formed from dissolved limestone, was at first thought to be archaeologically sterile, although it did have features cut into it. However, cleaning back in spits revealed animal bones and, in several locations, sherds of late Neolithic impressed ware. A further shell midden deposit (1/015), consisting largely of limpet shells, was identified in the north-eastern part of the trench, lying in a shallow scoop (1/023), again cut into the deposit of degraded limestone (1/008) that covers the floor of the cave.

As the time devoted to this cave was dictated by the inability to work in the other caves, it was not possible to achieve anything more than an assessment of the deposits. However, it does appear that the cave was occupied as a far back as the late Neolithic, with features of considerable complexity 


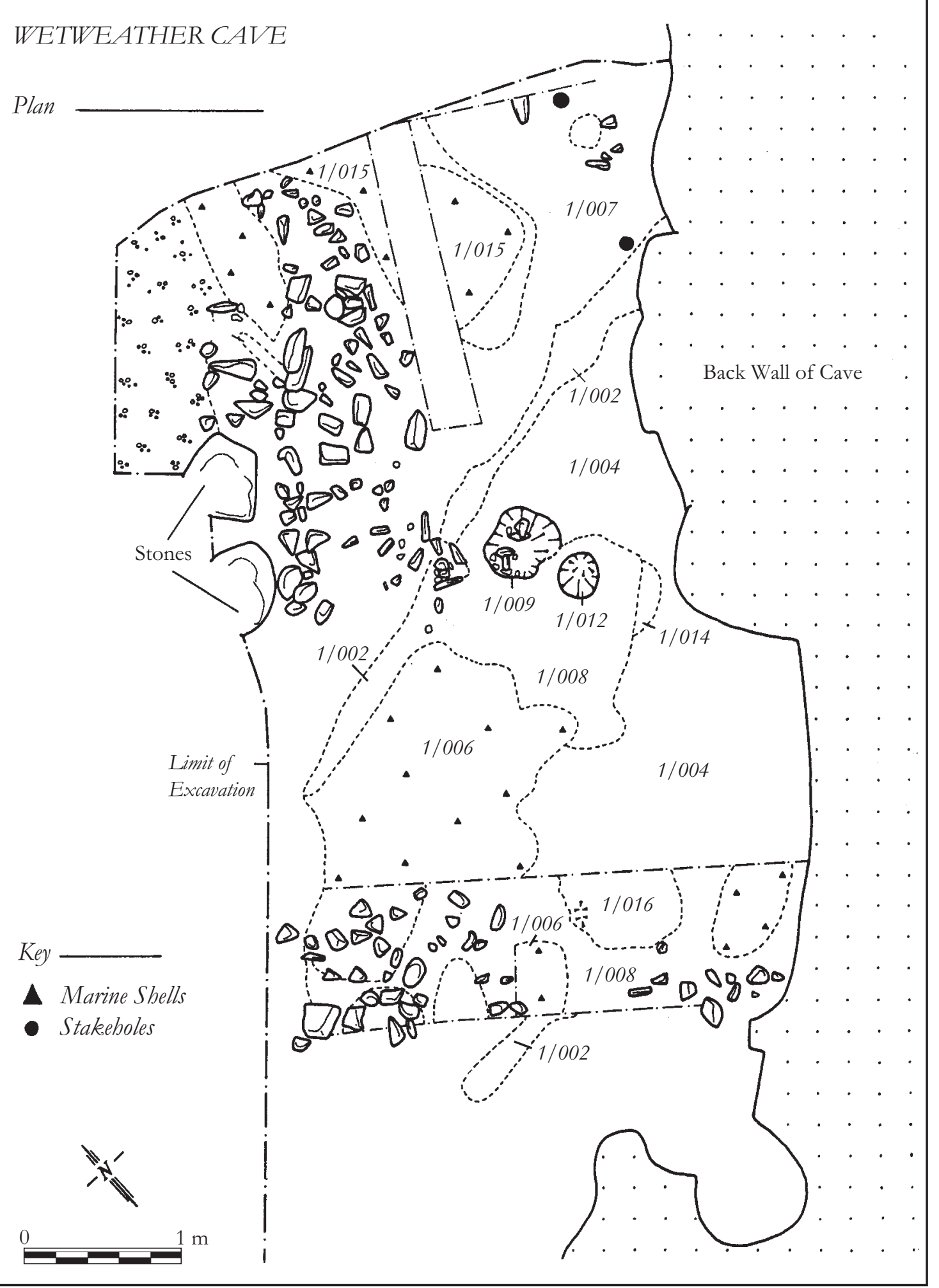

Illus 6 Site plan of Wetweather Cave

cut into the floor of the cave. The copper-alloy pin also indicates it was used in a more recent period. At the end of the fieldwork, plastic was laid down and the sheep dung deposit carefully reinstated, along with the excavated spoil, in order to preserve this potentially important archaeological site. 


\section{Material Culture}

\subsection{Pottery by Robert Squair}

\subsubsection{Methodology}

The excavation of midden and other archaeological deposits in Glassknapper's Cave, Antler Cave and Wetweather Cave recovered a small ceramic assemblage of approximately 350 sherds.

To facilitate effective analysis, much of the assemblage was washed to reveal more clearly the original vessel surfaces and fracture profiles. Various aspects of manufacture, morphology and decoration were recorded for each vessel identified. The physical condition of the sherds was also recorded to ensure a fuller understanding of depositional practices and post-depositional processes. Sherds from the assemblage, with the exception of minute fragments, were individually bagged to reduce further deterioration through abrasion in storage.

\subsubsection{General description of fabrics}

The assemblage comprises approximately 350 sherds and fragments, weighing over 500g. The largest sherd (Illus 7), from P6, is $107 \mathrm{~mm}$ across its maximum dimension. All vessels recognizable in the assemblage, with the exception of P12, which has disintegrated, are represented by a meagre number of sherds, only some of which are conjoinable. The eclectic ceramic styles represented in the assemblage attest to the extensive chronological range and diverse cultural origins of the surviving vessels.

A total of 11 fabrics were distinguished, largely by superficial appearance, frequency, size, degree of sorting and degree of rounding of the constituent mineral and rock inclusions, using a hand lens with 10x magnification and a bright overhead light source. No interpretative significance is necessarily attached to the occurrence of different sherds, evidently from separate vessels, in the same fabric. Unfortunately, due to the small size of the predominantly rock inclusions and the post-depositional concretions on many sherds, it was impossible to identify conclusively the different types of rock in the recognizable fabrics. The overwhelming presence of mineral and rock inclusions, supplemented on occasion by graminaceous inclusions in Fabrics 2 and 5, suggests an original prejudice of raw material selection during production.

It is unclear whether the vessels represented in the assemblage were manufactured locally or imported into the region from elsewhere. It is tempting to envisage a local production source for P2 and P5, manifest in Fabrics 2 and 5, respectively, each containing graminaceous inclusion voids, but it is preferable to interpret P9, manifest in Fabric 8, as imported. The fabrics of $\mathrm{P} 6$, the possible Norse style, and P12, the late Neolithic impressed ware, differ substantially in terms of superficial appearance, if not formal description, from the remaining ceramics.

\subsubsection{Vessel catalogue}

The following vessel catalogue provides a formal description of each vessel represented in the assemblage.

\section{P1}

Manufacture: The vessel is manifest in Fabric 1. Diagonal striations on the interior surface, typical of lifting, indicate that the vessel was probably wheelthrown. The interior and exterior surfaces were both smoothed and slipped.

Morphology: The vessel, probably a moderately sized jar, is represented by a substantial body sherd (015/1) and a possible shoulder sherd (016/1). The vessel evidently incorporated a subtle shoulder into a neutral profile.

Function: Heavy sooting or macroscopic food residues are discernible on the vessel exterior.

\section{P2}

Manufacture: The vessel is manifest in Fabric 2. The manufacturing method, surface treatments and firing profile remain indeterminate.

Morphology: The vessel is represented by a solitary diminutive sherd. The size and shape of the vessel remain indeterminate.

Function: No use-related traces are identifiable on the surviving sherd.

\section{P3}

Manufacture: The vessel is manifest in Fabric 3. The manufacturing method is indeterminate. The exterior surface was smoothed and probably slipped. Morphology: The vessel is represented by three base sherds (014/1,017/1,022/1), none of which are conjoinable, despite the presence of fresh fracture profiles on two of these sherds (014/1, 017/1).

Function: A glossy soot is discernible on the exterior basal surface of the vessel. Abrasion on the interior basal surface of the vessel is readily interpreted as a consequence of attrition incurred during use.

P4

Manufacture: The vessel is manifest in Fabric 4. The manufacturing method remains indeterminate. 

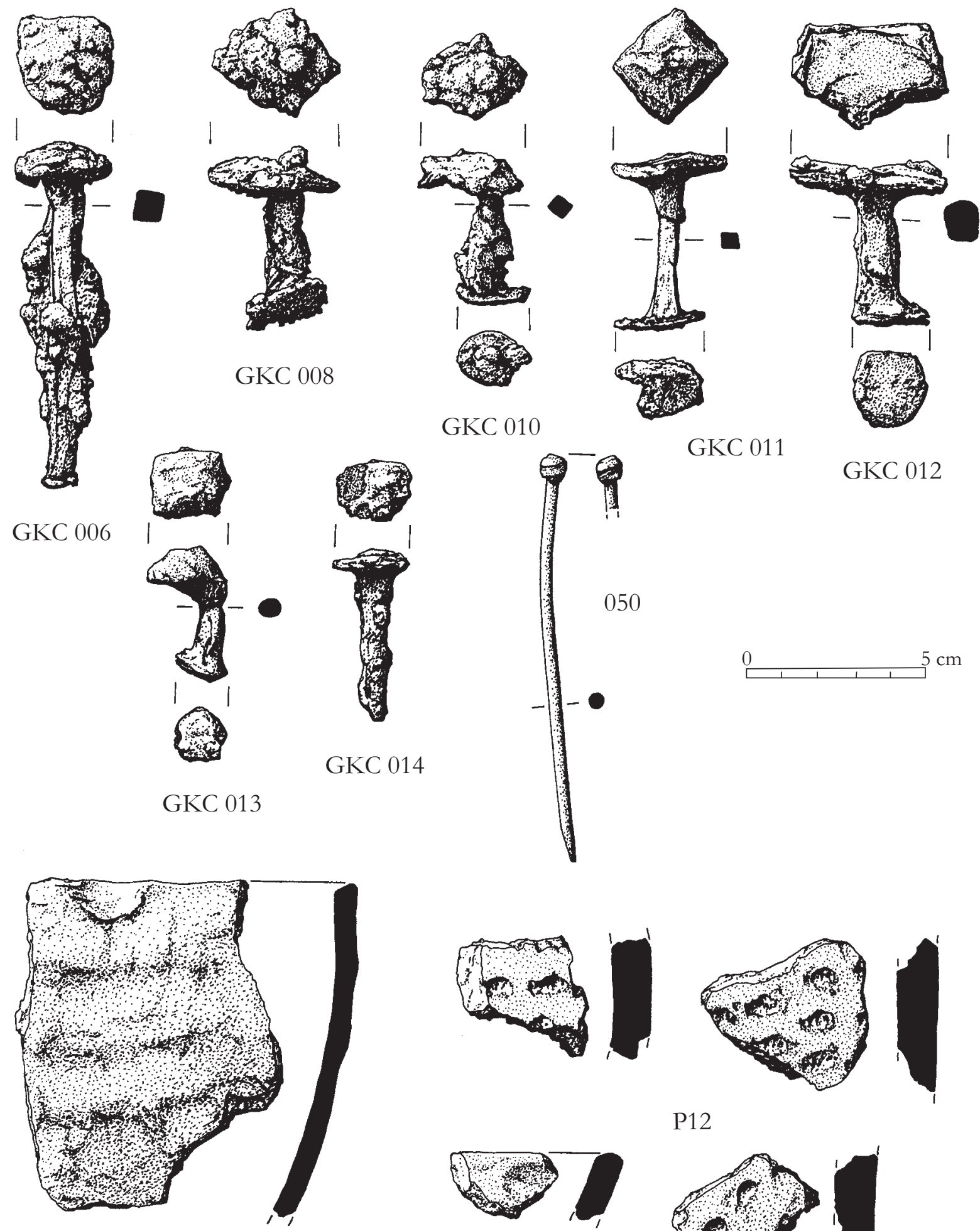

P6

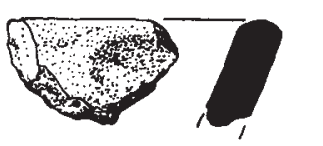

P12

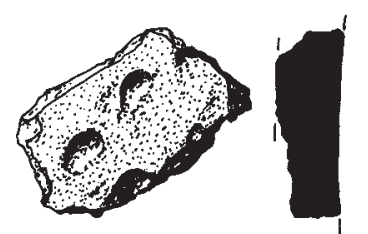

Illus 7 Metal and pottery artefacts

The interior and exterior surfaces were both smoothed and probably slipped.

Morphology: The vessel, a relatively fine ware, is represented by two body sherds $(023 / 1,025 / 1)$. The size and shape of the vessel remain indeterminate. Function: Possible sooting characterizes the exterior surface of the surviving sherds.
P5

Manufacture: The vessel is manifest in Fabric 5. The vessel was probably manufactured by coiling. The interior and exterior surfaces were both smoothed and slipped.

Morphology: The vessel, a heavy-necked bipartite bowl, is represented by a large carinated sherd (013/ 
1), a body sherd (018/1), recently broken into three fragments, and a diminutive fragment (021/1). The vessel incorporated a neck into a bipartite profile.

Function: Striations on the vessel exterior, concentrated above the carination, are preferably interpreted as the vestiges of a use-related attrition pattern.

\section{P6}

Manufacture: The vessel is manifest in Fabric 6. Coil corrugations, tangible on both the interior and exterior surfaces, indicate that the vessel was manufactured by coiling. The interior and exterior surfaces were both wiped and slipped. A large finger mark, incurred at the clayware stage of manufacture, occurs on the vessel exterior immediately below the rim. The firing profile is uniformly dark.

Morphology: The vessel is represented by a substantial rim sherd (1001/1) and a body sherd (1000/1). The vessel, slightly inturned at the rim, had a simple, flattened rim moulding, and a barrelshaped profile. The base, none of which survives, was probably flat, although evidently narrower than the width of the vessel body.

Function: Heavy sooting or macroscopic food resides are discernible on the vessel exterior.

\section{P7}

Manufacture: The vessel is manifest in Fabric 7. The manufacturing method remains indeterminate, although the rim moulding was probably formed by lateral joining. The interior and exterior surfaces were smoothed.

Morphology: The vessel, a relatively fine ware, is represented by a rim sherd (1002/1) and a diminutive fragment (1007/1), broken subsequently into two fragments. The rim form combines an external expansion with an internal bevel. The vessel probably had a neutral profile.

Function: Abrasion, concentrated on the vessel interior and not extending onto the internal bevel, is readily interpreted as use-related attrition.

\section{P8}

Manufacture: The vessel, a relatively fine ware, is manifest in Fabric 4. The vessel was probably wheel-thrown. The interior and exterior surfaces were smoothed and possibly slipped.

Morphology: The vessel is represented by two body sherds $(1003 / 1,1008 / 1)$. The size and shape of the vessel remain indeterminate.

Function: Possible sooting characterizes the vessel exterior.

\section{P9}

Manufacture: The vessel is manifest in Fabric 8. The manufacturing method remains indeterminate. The interior and exterior surfaces were smoothed and glazed, respectively.

Morphology: The vessel is represented by two non-conjoinable fragments of a strap-handle (1004/ 1, 1004/2). Presumably, the strap-handle was luted on to the vessel exterior. The size and shape of the vessel remain unknown.
Function: No use-related traces are identifiable on the surviving sherds representing this vessel.

\section{P10}

Manufacture: The vessel is manifest in Fabric 9. The vessel was wheel-thrown. The interior and exterior surfaces were smoothed and slipped.

Morphology: The vessel, a fine closed bowl, is represented by three shoulder or neck sherds (003/1, 004/1, 1005/1), none of which are conjoinable. The vessel had a closed, globular profile.

Function: Possible sooting occurs on the vessel exterior.

\section{P11}

Manufacture: The vessel, manifest in Fabric 10, was probably wheel-thrown. The interior and exterior surfaces, wiped and smoothed respectively, were both slipped. The slip affords the vessel exterior a lustrous appearance.

Morphology: The vessel, a relatively fine ware, is represented by a solitary body sherd (1006/1). The size and shape of the vessel remain indeterminate. Function: No use-related evidence is discernible on the surviving sherd representing the vessel.

\section{P12}

Manufacture: The vessel is manifest in Fabric 11. An exposed internal building coil and lateral fracture along sloping coil joins indicates that the vessel was manufactured by coiling. The interior and exterior surfaces were smoothed and burnished, respectively. The firing profile, incorporating a dark core, is typical of open firings.

Morphology: The vessel is represented by a rim sherd, a neck sherd, several body sherds, fragments from a detached cordon and innumerable diminutive fragments $(1010 / 1,1011 / 1,1012 / 1,1013 / 1,1014 / 1$, $1014 / 2,1015 /, 1015 / 2,1015 / 3)$. The rim is rolled, with a convex rim surface. The cordon, presumably attached in a horizontal alignment, was evidently luted on to the body of the vessel. The vessel exterior is decorated with whipped cord maggot impressions. The individual maggot motifs, each aligned vertically, are arranged together into horizontal bands around the vessel exterior. Interestingly, each successive row of maggot motifs is offset in relation to the row above, affording the resultant decorative structure an overall uniformity and consistency of design. The vessel, evidently necked, probably had an otherwise neutral profile.

Function: Unsurprisingly, given the prevalence of limestone concretions, no use-related traces are identifiable on the surviving sherds representing the vessel.

\subsubsection{Interpretation}

Ceramic styles represented in the assemblage The assemblage contains a diverse array of ceramic styles. Unfortunately, almost nothing is known 
about local ceramic styles, from the Iron Age onward, in northern Scotland. The settlement archaeology, extending from prehistory into the relatively recent past, fails to inform upon contemporary ceramic production and use (see Reid et al 1967). Norse and medieval pottery in northern Scotland derive primarily from excavations in Caithness and the Northern Isles (see McCarthy \& Brooks 1988, 208 10). Unfortunately, the nature of the relevant assemblages usually precludes the development of coherent ceramic sequences (eg MacAskill 1982, 405; Batey \& Freeman 1986, 338). The meagre assemblage from Geodha Smoo is no exception.

At any rate, despite this unsatisfactory if unavoidable circumstance, P12 is interpreted as a late Neolithic impressed ware; P6 is tentatively identified as a Norse style and came from Glassknapper's Cave; P4, P7, P8, P9, P10 and P11 are immediately recognizable as medieval wares; P1, P3 and P5 are tentatively suggested as post-medieval wares. No stylistic comparisons are offered for P2, a vessel with a distinctive fabric, but represented only by a small, entirely uninformative fragment. Given this dearth of evidence, the following commentary is largely provisional.

The prehistoric pottery $\mathrm{P} 12$, a necked vessel with a neutral profile, a rolled rim and presumably a horizontal cordon, is an impressed ware datable to the late Neolithic and comes from Wetweather Cave (see Illus 7). The rolled rim, not unknown on such pottery, is less usual than the thickened, internally bevelled rims more typical of impressed wares from elsewhere in Scotland (see McInnes 1964; Longworth 1967; Cowie, forthcoming). The individual whipped cord 'maggot' motifs combine into a coherent decorative structure. The decoration on impressed wares from elsewhere in Scotland, particularly the south-west, is usually more haphazard (see McInnes 1964, 50). There is a paucity of comparable vessels in northern Scotland. However, the decoration on an impressed ware vessel from Allt Chrisal on Barra in the Western Isles, comprising successive maggot motifs diagonally aligned, has a comparable coherent structure (see Gibson 1995, 110, illus 4.36, no 170:111). The inadequacy of the concept of impressed ware, conveying a misleading impression of categorical homogeneity based on a decorative technique ubiquitous during the late Neolithic and early Bronze Age, requires mention (cf McInnes 1964, 49).

P1, P3 and P5, from Glassknapper's Cave, are tentatively ascribed an Iron Age date. P5, a heavynecked bipartite bowl probably manufactured by coiling, deserves special mention. These sherds bear some similarity in form and fabric to various Iron Age assemblages from the Northern Isles, including the multi-period site at Howe on Orkney (B BallinSmith, pers comm).

The Norse pottery The Norse ceramics from, for example, Freswick Castle and Freswick Links in Caithness bear some affinity, both technological and stylistic, with some of the vessels from Geodha Smoo (see Batey et al 1984, 105-7, 115-16; Pollard 1996b, 20-1). Indeed, the appearance and form, if not the fabric, of P6 (see Illus 7) explicitly recalls that of Norse pottery from elsewhere in northern Scotland, for example at Jarlshof, Shetland (see Hamilton 1956; cf McCarthy \& Brooks 1988, 208). Interestingly, the fabric of P2, probably grass-tempered, recalls vaguely that of Norse or medieval pottery from Freswick Castle and Freswick Links (Batey et al 1984); Kirkwall, Orkney (MacAskill 1982, 405, 412); and Jarlshof (Hamilton 1956; McCarthy \& Brooks 1988, 208). Admittedly, grass-tempering is an unreliable cultural or chronological indicator in northern Scotland (eg MacAskill 1982, 405, 412).

The medieval pottery $\mathrm{P} 4$ and $\mathrm{P} 8$, each represented only by uninformative body sherds, are broadly recognizable as medieval. P7, with an externally expanded, internally bevelled rim, is comparable, in stylistic rather than technological terms, with medieval vessels from Kirkwall, Orkney (see MacAskill 1982; McCarthy \& Brooks 1988, 208, nos 5234, figure 114:210). Similarly, P9, represented by two non-conjoinable fragments of a strap-handle, is presumably a Scottish White Gritty Ware jug and, as such, is broadly paralleled at Kirkwall (MacAskill 1982, 407).

\subsubsection{Depositional practices and post-depositional processes}

The nature of the assemblage from Geodha Smoo, comprising only a few vessels sparsely represented by diminutive and abraded sherds, suggests that the pottery was casually discarded and subsequently disturbed, prior to eventual incorporation into archaeological deposits. The diversity of styles and breadth of chronology exhibited by the assemblage lend support to this interpretation.

The degree of sherd dispersal across contexts suggest some degree of disturbance of the various pottery-bearing deposits in Glassknapper's Cave, a factor which also appears to have played a part at An Corran, Skye (A Saville, pers comm). Sherds representing P1, P3, P4 and P5 derive exclusively from the lower midden deposit (context 019) in Glassknapper's Cave. P2 and P11, each orphan sherds, derive from a stony deposit within the midden (021) and the lower layer of collapse (006), respectively, again in Glassknapper's Cave. P9 derives exclusively from tumble within Glassknapper's Cave. P12, represented by several sherds and many fragments, derives exclusively from the degraded limestone (1/008) in Wetweather Cave.

Interestingly, the two sherds representing P6 derive from both the upper and lower midden deposits (008 and 019, respectively) in Glassknapper's Cave. The two sherds representing P8 derive from the upper layer of loose collapse and the upper midden deposit (005 and 008, respectively) in 

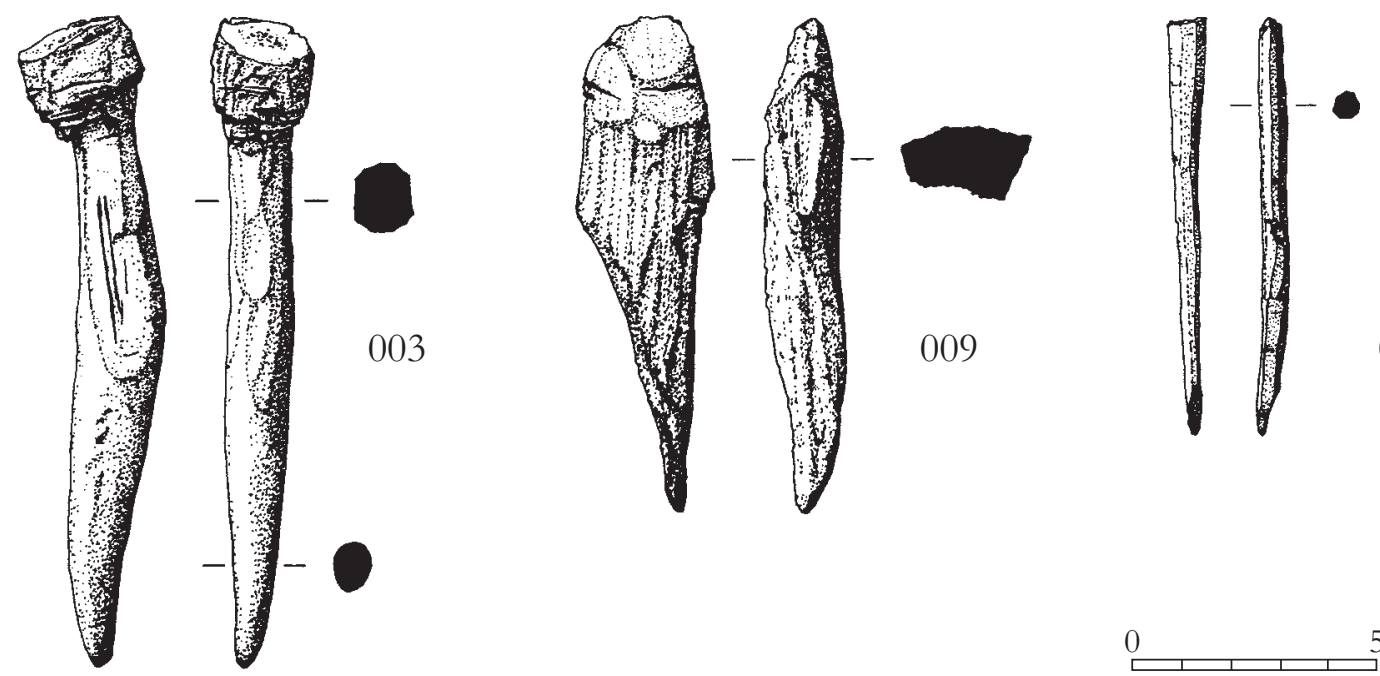

033

0 $5 \mathrm{~cm}$

Illus 8 Bone artefacts

Glassknapper's Cave. The three sherds representing P10 derive separately from a black humic layer, a silt matrix with limestone fragments and a stone deposit (contexts 003, 004 and 038, respectively, in Glassknapper's Cave). Medieval sherd P7 came from collapse (context 004).

\subsubsection{Conclusion}

The variety of ceramic styles represented in the assemblage, encompassing vessels of late Neolithic to medieval date, indicate that the caves in the Geodha Smoo were a focus for sporadic activity, if not continuous occupation, over several successive periods in the past.

\subsection{Bone and antler artefacts by Tony Pollard (with species identifications by Catherine Smith)}

One of the most striking results of the Smoo excavations, and the investigation of Glassknapper's Cave in particular, has been the recovery of worked bone and antler. The recovery of organic artefacts in immaculate condition is largely due to a fortuitous combination of damp and alkaline conditions, the latter promoted by both the limestone geology and the presence of concentrated marine shells.

These finds included a carved peg of red deer antler (SF 003, Illus 8), with cut marks clearly visible on its surface. This artefact was made on an antler tang, with a carved cylindrical head topping a curved and pointed shaft. Its function is uncertain but, in keeping with other elements of the material culture recovered from the site, may represent a piece of ship's furniture, perhaps an alternative form of timber fastening to the iron nails discussed below and sometimes referred to as tree nails. Alterna- tively, the piece may be a shroud-pin, having the same general form as wooden examples recovered from Hedeby Harbour in Denmark (Crumlin-Pedersen 1997, 134). These are devices used for tightening rigging, stays and shrouds, in order to fasten or quickly release them to the side of the ship's hull. However, the Danish examples are considerably larger than the piece from Smoo, and it seems unlikely that the shaft would be anywhere near long enough to perform this function adequately.

Other pieces of worked antler and bone took the form of spatulate or pointed blades (SF 004, SF 005, Illus 9; SF 009, Illus 8). The first of these (SF 004) is a heavily worked piece of bone which has been cut and shaped along its length to create several facets and a multi-sided profile (six-sided at the narrow end and seven-sided at the broad end). The function of this piece is uncertain, although a bevel-ended piece of antler (SF 005) bears some similarity to the bevelended pieces common to western Scottish coastal sites and may have been used for rubbing hides (Pollard 1994).

Another spatulate piece of bone was perforated (SF 002, Illus 9) toward one end, which has been curved through a series of small knife cuts. This may represent either the handle of a knife or a netting needle, but as the piece is snapped it is not possible to say which is the most likely. The object bears some similarity to a piece, though in antler rather than bone, recovered from the Birsay Bay excavations (Morris 1989, 196), although the long sides taper rather than being parallel as they are on the shorter piece from Glassknapper's Cave.

Also recovered, from context 013, was a small, finely worked bone pin (SF 003, Illus 8) with a round, perforated head; this may be made of a pig bone.

The function of the majority of the antler and bone artefacts is uncertain with direct parallels being scarce. It has been noted elsewhere (Batey 1996) that small organic assemblages do not necessarily 

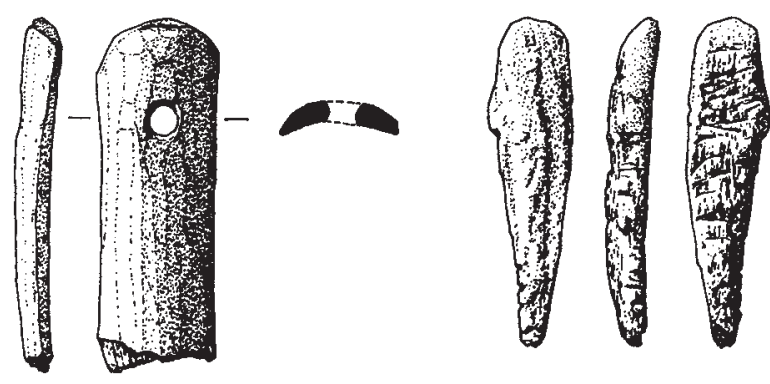

002

005

$$
0
$$
$5 \mathrm{~cm}$

\section{Illus 9 Bone artefacts}

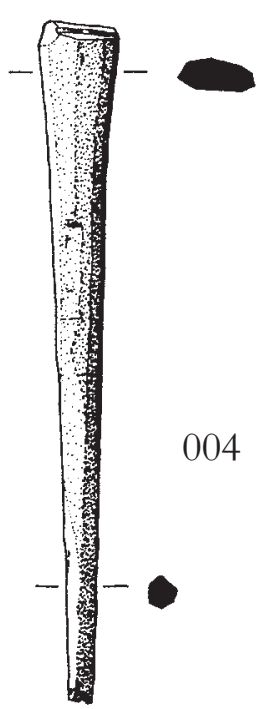

display culturally specific traits. In general, however, the assemblage is not out of place with other collections of bone and antler artefacts from coastal sites in northern Scotland, many of which contain Norse elements.

It is apparent that many early (19th-century) descriptions of bones recovered from coastal midden deposits as split or cut to remove the marrow may in reality have referred to artefacts, or the waste produced by their manufacture, rather than food waste.

No antler or bone artefacts were identified during the excavation of Antler Cave. A number of intact antler tines were recovered from the lower deposits, but their relationship to the finished antler artefacts recovered from the neighbouring cave is unclear, although it is tempting to suggest that the cave was used for the storage of this raw material.

\subsection{Metal objects}

\subsubsection{Iron nails}

Iron nails were recovered from Smoo Cave and Glassknapper's Cave.

Smoo Cave Four nails (SC SF 009, 012, 014, 022) were recovered from the shell midden deposit (006b) in Smoo Cave, one (SC SF 030) came from context 020 and a further three (SC SF 002, SF 008, SF 021) came from the tumble at the base of the section (see Illus 10). One of these pieces, SC SF 009, had a flattened, square head, but was snapped just below the head. The majority had round or semi-rectangular heads and appeared to be standard handmade nails. However, one piece (SC SF 002) had opposing sub-circular heads on either end of the squaresectioned shank. Closer inspection revealed that the larger of the two heads was a separate plate, known as a clench plate. With this in mind, closer inspection of nail SC SF 009 suggests that this is the clench plate end of a clench nail, as the beaten-down nail tip is visible as a raised area on the surface of the plate. Clench nails have a long tradition. They are a relatively common feature on Norse and later coastal sites in Scotland and are usually associated with ships and boats.

The clench nail is really a precursor of the rivet, and was used to hold a boat's timbers together. The rivet is a single-piece fastener with a head and shank; when in position the tip of the shank is flattened out to create what is in effect a second head, thus holding timbers in place. The clench nail, however, was driven through the timbers and then a pre-holed clench plate placed over the end of the nail and the protruding head beaten flat with a hammer, thus holding the clench plate in place. In this way two timbers were effectively bound together, clenched firmly between the nail head and the plate.

The presence of a nail with the clench plate attached suggests that the piece was removed from a rotten or burned timber, as the clench plate would only be added when the nail was actually used, and removal intact would require destruction of the timber. This may indicate that boat repair was taking place on the site, as old timbers were removed from vessels and then replaced, or alternatively that old ship's timbers provided fuel for fires.

Glassknapper's Cave Seven further pieces were recovered from Glassknapper's Cave and in general were larger and sturdier than the examples from Smoo Cave. These came from a variety of contexts: GKC SF 006, SF 010 and SF 012 came from context 008; GKC SF 008 came from context 021; GKC SF 011 and SF 013 came from context 012; and GKC SF 014 came from context 013 . All apart from GKC SF 014 had clench plates, or fragment(s) thereof, attached. On a couple of examples, preservation was 

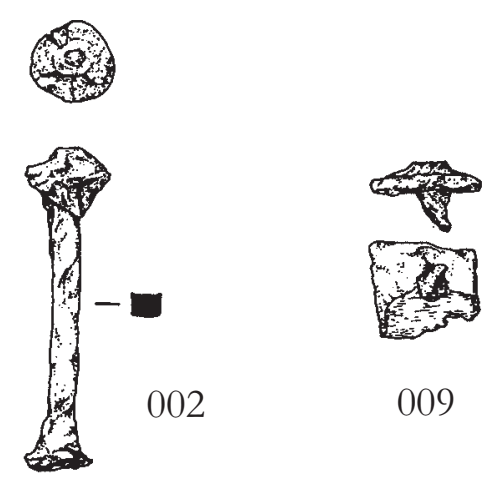

009
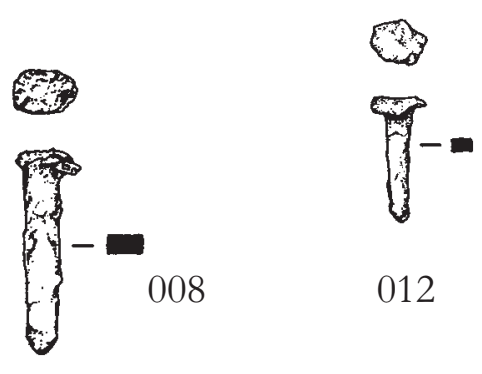

012

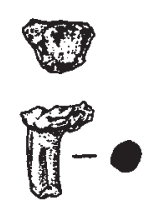

022

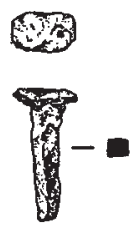

014
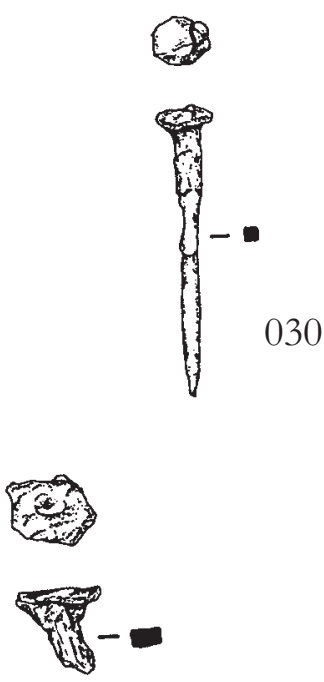

021

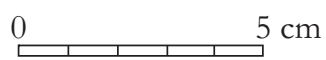

Illus 10 Metal artefacts

good enough to show clearly that the clench plate had at one time been separate and the nail head had been beaten out across its outer face. The nail heads in general appear to have been circular or sub-circular, while the clench plates were square in plan. However, in the majority of cases, it was difficult to distinguish between the nail head and the clench plate.

The association between clench nails and boat construction is a strong one, but not one limited to a specific period. A nail with clench plate attached was recovered along with less well-preserved examples from the excavation of Norse and other deposits in Birsay Bay, Orkney, where the excavator notes that it is difficult to tie this artefact type down to any one period (Morris 1996, 92). Similar nails were also found during excavations at Freswick Links, Caithness, where what are described as rivets are presumably clench nails (Morris et al 1995). Both Birsay and Freswick Links have strong Norse components and some of the nails recovered may relate to the Norse periods of the sites' use.

\subsubsection{Copper-alloy pin}

A single copper-alloy pin (Illus 7) was recovered from a shell midden deposit in the Wetweather Cave.
The pin has a slightly bent shaft, $26 \mathrm{~mm}$ long, which was probably straight when new. The shaft is tipped by a spherical head, some $2 \mathrm{~mm}$ in diameter. The head is decorated by a single incised line that spirals around it.

Numerous examples of copper-alloy pins have been recovered from Norse and later contexts in Scotland, varying in style from the plain to the highly decorated. The pin from Wetweather Cave bears close similarity to two pins recovered during Curle's excavations at Freswick Links in Caithness. The description of these pins (4.8.85-6 in Batey $1987,117)$ states that they have heads of twisted metal. Although numerous pins with twisted metal heads were recovered from Freswick (eg 4.8.3 and 4.8.4 in Batey 1987, 466), the writer believes that the photograph of pins 4.8.85-6 (Batey 1987, 467) shows them to have solid cast heads with incised decoration rather than heads of twisted metal. Unfortunately, these objects, once held in a private collection in Thurso, appear to have been lost (Batey 1987, 117) and so are not available for examination.

Although the pin may be Norse, it is equally possible that the object, which was probably used to fasten garments or headdress, dates from a more recent period, with twisted metal-headed pins ranging in date anywhere between the 14 th and 18 th centuries (Batey 1987, 144). 


\section{Analysis of Slag and Fuel Samples from Smoo Cave by E Photos-Jones}

Three slag and fuel samples from Smoo Cave (all from shell midden, contexts $006 \mathrm{a} / \mathrm{b}$ ) were subjected to scientific investigation in order to establish their nature and composition. The full report is included in the archive report, and a summary of the results is given here.

\subsection{Methodology}

Scientific examination was carried out with a scanning electron microscope to which was attached an energy dispersive analyser (SEM-EDAX). One sample (SM2) was cut, mounted on metallographic resin, ground with silicon carbide papers (Struers $260,600,800$ and 1200) and polished with six-micron diamond paste. A freshly fractured surface was cut from the other two and mounted on a stub. All three were carbon-coated in preparation for analysis (at $20 \mathrm{kV}$ and WD 39).

\subsection{Results}

SM2 This fragment of slag is brownish black, porous and light. It is very inhomogeneous, comprising areas that are mineralogically distinct and others that are amorphous. Fuel (charcoal) inclusions are also evident, as well as areas of extensive weathering due to burial in a damp environment. Overall, the sample is very rich in iron, which occurs in two phases, either as wustite (iron oxide, $\mathrm{FeO}$ ) or as iron silicate (fayalite, $2 \mathrm{FeO} . \mathrm{SiO} 2$ ). The abundance of iron in these two particular phases suggests iron-smithing slag. However, work on traditional bloomerymaking in the Highlands has revealed a relatively high percentage of iron $(60-70 \% \mathrm{FeO})$ in what is certainly tap slag from a smelting cycle (Photos-Jones et al forthcoming).

SM3 This fragment of wood charcoal proved to be rich in calcium. Sulphur and phosphorus are also present in significant amounts and these can either be associated with the fuel or may be derived from impurities obtained in the course of deposition.

SM1 This fragment of ore or flux has a honeycomb structure like that encountered elsewhere in the course of the writer's analytical work on bloomery slags (Photos-Jones et al 1998). They appear as inclusions in smelting slag and some of them appear not to lose their characteristic structure even after being heated to temperatures prevalent in a bloomery furnace. The precise nature of this material is yet to be established. 


\section{Animal and Plant Remains}

\subsection{Animal bones from Smoo Cave by James H Barrett}

This section presents an analysis of fish, mammal, bird and amphibian bone recovered during small-scale sampling of cultural deposits inside the mouth of Smoo Cave in 1992. Most of the bone derived from the upper shell midden deposits (contexts 006a/b, Phase 5). Small quantities were also recovered from other contexts of other phases, including sand or cobble beach surfaces incorporating a lower density of anthropogenic material (Pollard 1992).

\subsubsection{Methodology}

Twelve sediment samples of unspecified volume were collected by hand during the excavation and subsequently sieved using $1 \mathrm{~mm}$ and $4 \mathrm{~mm}$ mesh. Bone considered here was sorted from the $>4 \mathrm{~mm}$ fraction. A small number of hand-collected specimens (six fish, 15 mammal) retrieved from the shell midden have been combined with the sieved material.

Some specimens will have been lost during sieving (see Jones 1982; Payne 1992). This issue is of greatest significance for fish, the only assemblage of sufficient size to justify analyses of taxonomic and butchery patterns. A comparison of results regarding $>4 \mathrm{~mm}$ and $<4 \mathrm{~mm}$ sample fractions from a broadly contemporary fish assemblage at Earl's Bu, Orkney suggests that the bias introduced by using $4 \mathrm{~mm}$ mesh may be modest (Barrett 1995). The cod family fishes which dominate northern Scottish assemblages reach $c$ $0.15 \mathrm{~m}$ within their first year of life and can grow to lengths in excess of $1.5 \mathrm{~m}$ (Wheeler 1969; Wheeler 1978; Whitehead et al 1986a). Their bones are correspondingly large. Potential impacts of recovery procedures on species and element distributions will be considered further below.

Slightly different analytical methods have been employed for each class of bone. The fish material was analysed following procedures discussed previously (Barrett 1995). All specimens were counted, weighed and examined for taphonomic alterations such as burning, butchery and carnivore-gnawing. Forty skeletal elements were routinely identified to family, genus or species. Qualitative data regarding degree of bone fragmentation, texture and size were recorded for nine diagnostic elements (Quantification Category 1 or 'Q1' elements as defined in Barrett 1995).

All mammal and amphibian specimens were identified to the finest possible taxonomic category (with the exception of mammal ribs which were only grouped by size). This strategy was appropriate given the tiny size of the assemblage. All specimens were counted, weighed and examined for taphonomic alterations. Bone texture and portion (the latter based on the Environmental Archaeology Unit's diagnostic zone system; K Dobney, pers comm) were recorded for specimens identified to a meaningful taxonomic category. Measurements (after von den Driesch 1976) were taken on the few bones that were sufficiently intact.

Bird specimens were analysed following a strategy similar to that used for mammals and amphibians. In this case, however, no attempt was made to identify ribs or vertebrae. In all three classes, the abundance of each taxon has been tabulated by fragment count. Minimum number of individuals (MNI) estimates were not tabulated as the dataset was too small to be treated as more than a species list. Details regarding the mammal elements recovered are noted in Appendix D (archive report) for the benefit of possible future comparative work.

\subsubsection{Results}

Fish In total, 2115 fish specimens weighing $323.6 \mathrm{~g}$ were recovered. The distribution among phases was very uneven, with 1694 of these specimens coming from Phase 5, the shell midden deposits (contexts 006a/b). A smaller concentration of 260 fish bones occurred in Phase 3 (context 010). All other periods yielded an insignificant number of specimens. Preservation was good, but not exceptional, in both periods.

No specimens from Phase 3 exhibited evidence of fire-alteration or butchery. Nevertheless, given the presence of anthropogenic deposits (Pollard 1992) and the virtual absence of evidence for carnivore damage, it seems likely that these bones derive from human activity rather than piscivore (eg otter, see Nicholson 1991) faeces.

Nine specimens from Phase 5 were fire-altered and the same number exhibited distinct V-shaped cut marks. Twenty-one specimens from this period exhibited crushing, which could be consistent with mastication (Wheeler \& Jones 1989). Given the virtual absence of partial digestion and the tiny number of gnawed specimens, however, it seems likely that most or all of this material also represents cultural rubbish.

Phases 3 and 5 were both dominated by the cod family, Gadidae. Phase 5 also yielded small concentrations of flatfish and gurnard bones. All other taxa were represented by fewer than 10 specimens each. 
Table 2 Fish specimens from Smoo Cave by fragment count

\begin{tabular}{|c|c|c|c|c|c|c|c|}
\hline & & \multicolumn{5}{|c|}{ Phase } & \multirow[b]{2}{*}{ Total } \\
\hline & & 1 & 3 & 4 & 5 & 6 & \\
\hline Shark, skate or ray & Selachii (Chondrichthyes) & & & & 2 & 1 & 3 \\
\hline Shark order & Pleurotremata & & & & 4 & & 4 \\
\hline Ray family & Rajidae & & & & $*$ & & $*$ \\
\hline Thornback ray & Raja clavata & & & & $*$ & & $*$ \\
\hline Salmon and trout family & Salmonidae & & & 2 & 2 & & 4 \\
\hline Eel & Anguilla anguilla & & 1 & & & & 1 \\
\hline Cod family & Gadidae & 1 & 237 & 24 & 1065 & 75 & 1402 \\
\hline Wrasse family & Labridae & & & & $* *$ & & $* *$ \\
\hline Atlantic mackerel & Scomber scombrus & & & 2 & & & 2 \\
\hline Gurnard family & Triglidae & & & & 9 & & 9 \\
\hline Grey gurnard? & Eutrigla gurnardus? & & & 3 & & & 3 \\
\hline Flatfish order & Heterosomata & & & & 3 & & 3 \\
\hline Halibut family & Pleuronectidae & & & & 13 & & 13 \\
\hline Dab? & Limanda limanda? & & & 1 & & & 1 \\
\hline Flounder? & Platichthys flesus? & & & 1 & & & 1 \\
\hline Plaice? & Pleuronectes platessa? & & & 11 & 1 & & 12 \\
\hline Unidentified & & & 23 & 10 & 578 & 46 & 657 \\
\hline Total & & 1 & 260 & 37 & 1694 & 123 & 2115 \\
\hline
\end{tabular}

*Dermal denticles

** Lower pharyngeal bone

In Phase 3, saithe dominate the small cod family assemblage (Table 2). Most of these specimens derived from relatively small fish between $0.15 \mathrm{~m}$ and $0.5 \mathrm{~m}$ in total length. Saithe can reach lengths of $c 1.2 \mathrm{~m}$ (Whitehead et al 1986a) and large specimens are common finds at Late Norse (medieval) sites in northern Scotland such as Freswick Links (Jones et al 1996) and Robert's Haven in Caithness (Barrett 1995). In this region, small saithe are typically a product of shore-based or shallow-water fishing using a line or net (Fenton 1978; Baldwin 1982). While the sample size is too small to justify definitive statements, it is therefore possible that this assemblage represents inshore fishing. In the absence of evidence for fire-alteration or butchering, it is difficult to suggest whether these fish were originally intended for consumption in the cave or for transport to another settlement. It may be relevant to note that charcoal (and a charred mammal specimen) derived from this period, and that caves were used for drying fish in northern Scotland during the 19th century (Walker 1982). Too few specimens were recovered from this period to facilitate seasonal inferences based on apparent year classes in the distribution of fish size estimates (see Mellars \& Wilkinson 1980; Enghoff 1986).

The gadid assemblage from Phase 5 is dominated by haddock. It is initially tempting to attribute this pattern to taphonomic factors, as haddock have extremely robust cleithra and post-temporals. It is evident, however, that other less anomalous elements from this species are similarly abundant. Haddock are bottom-dwelling fish found in depths from 30m to 300m (Whitehead et al 1986a, 687). Although unlikely to be abundant in shallow waters, they have been taken within $2 \mathrm{~km}$ of shore in northern Scotland (in deep water to the south and west of Orkney, for example) (Goodlad 1971; Colley 1983).

Haddock grow to $c 1 \mathrm{~m}$, but the majority found at Smoo were between $c 0.3 \mathrm{~m}$ and $c 0.8 \mathrm{~m}$ in total length. Most actually belong to the smaller end of this range, c $0.3-0.5 \mathrm{~m}$, and it is likely that additional small specimens were lost during sieving.

Only one other broadly contemporary assemblage from northern Scotland exhibits a substantial proportion of haddock: bone from the Late Norse deposits (perhaps 13th-14th centuries cal AD; C Batey, pers comm) of a high status domestic midden at Earl's Bu, Orkney (Barrett 1995). The size distribution is similar at both sites, perhaps suggesting that $0.3-0.8 \mathrm{~m}$ fish were purposely selected by fishermen - either after each catch or through choice of hook size (see Owen 1994). Hooks and hand-lines were probably the primary gear for deepwater fishing in medieval Scotland (Barrett 1995).

One initial interpretation of the shell midden at Smoo Cave was that it represented a specialized location for processing haddock for storage. Medieval dried (cod family) fish production typically involved removing the cranium and anterior vertebrae at the processing site, leaving appendicular elements (such as cleithrum and post-temporals) and caudal vertebrae in the finished product (Barrett 1995). In theory it is therefore possible to recognize a fish-curing station based on the relative 
Table 3 Comparison of nine (Q1) haddock cranial and 'appendicular' elements from Smoo Phase 5 and Earl's Bu

\begin{tabular}{|c|c|c|}
\hline & Phase 5 (NISP) & Earl's Bu (NISP) \\
\hline \multicolumn{3}{|c|}{ Cranial elements } \\
\hline Articular & 10 & 31 \\
\hline Dentary & 7 & 15 \\
\hline Maxilla & 12 & 22 \\
\hline Premaxilla & 9 & 17 \\
\hline Quadrate & 17 & 27 \\
\hline Parasphenoid & 5 & 10 \\
\hline Vomer & 6 & 21 \\
\hline Total & 66 & 143 \\
\hline \multicolumn{3}{|c|}{ 'Appendicular' elements } \\
\hline Post-temporal & 13 & 49 \\
\hline Cleithrum & 31 & 90 \\
\hline Total & 44 & 139 \\
\hline
\end{tabular}

Table 4 Chi-square comparison of haddock cranial and 'appendicular' specimens from Smoo Phase 5 and Earl's Bu

\begin{tabular}{llll}
\hline & Cranial & 'Appendicular' & Total \\
\hline Phase 5 & & 44 & 110 \\
Observed & 66 & 51.35 \\
Expected & 58.65 & 139 \\
Earl's $B u$ & & 131.65 \\
Observed & 143 & 183 \\
Expected & 150.35 & & 282 \\
Total & 209 & & 392 \\
Chi-square: 2.744 & & & \\
Degrees of freedom: 1 & & & \\
$P>0.05$ & & & \\
\hline
\end{tabular}

absence of appendicular elements and caudal vertebrae.

In practice, however, there is little use in considering the relative representation of vertebrae from Smoo. The proportion of tiny caudal vertebrae will have been seriously affected by recovery bias. Moreover, any interpretation of haddock butchery patterns is complicated by the anomalous preservation characteristics of the cleithrum and post-temporal. It is not surprising that they are among the most abundant haddock elements when tabulated by both fragment count and MNI.

An understanding of the anatomical breakdown of haddock elements from Phase 5 is best achieved by comparison with results from Earl's Bu (see Table 3). This assemblage has been interpreted, based on a combination of ecological, cut mark and anatomical evidence (Barrett 1995), as a consumption site to which a mixture of whole and cured fish was imported. A chi-square test of the ratio of appendicular to cranial elements suggests that there is no significant difference between the assemblages in this regard (see Table 4). Qualitative assessment of rank order lists of all identified gadid cranial and appendicular elements suggests a similar interpretation. Therefore, it is likely that haddock were not being cured in the cave for consumption elsewhere.

This interpretation is strengthened by the fact that, although both assemblages exhibit similar preservation characteristics, bones from Earl's Bu were slightly more degraded. If taphonomic biases have differentially exaggerated the proportion of robust post-temporals and cleithra at Earl's Bu, then the comparable abundance of appendicular elements at Smoo is even more notable.

Given these results, a second, alternative hypothesis requires consideration. Were some cured fish actually brought to the site for consumption? The scanty cut mark evidence could be considered to support this hypothesis. Two haddock elements were cut in a manner consistent with cured fish production. In contrast with this limited evidence, however, the abundance of haddock cranial elements indicates that many complete fish were consumed or discarded in the cave.

The interpretation of other gadid taxa from Phase 5 is more ambiguous. In no case is the sample size large enough to facilitate meaningful interpretation 
of relative representation of elements data. The few saithe specimens were all from relatively small fish ( $<0.5 \mathrm{~m}$ in total length). They may have been caught during a shore-based fishery and the smallest specimens could represent the gut contents of larger fish.

The few cod and ling bones were from large individuals that could have been incidental catches while haddock fishing in deep water (Whitehead et al 1986a). It is notable, however, that a few cod and ling specimens exhibited cut marks suggestive of cured fish production. These butchered bones are consistent with the residue one might expect at a processing site. It must be emphasized, however, that on the basis of present evidence any cod- or ling-processing in Smoo Cave was modest in scale.

Together, these two taxa represent only $c 11 \%$ of the gadid assemblage from Phase 5. Moreover, all of the Gadus and Molva specimens recovered could have come from as few as six individual fish.

As discussed above, only two other taxonomic groups are represented by significant quantities in Phase 5 - flatfish and gurnards. Virtually all of the flatfish specimens belonged to the halibut family and many closely resembled plaice. It must be emphasized, however, that the reference material available was not comprehensive and that the differentiation of fragmented Pleuronectidae bones can be difficult. The flatfish specimens were all from relatively small fish, at least one of which was less than $c 0.3 \mathrm{~m}$ in total length. They can be caught in shallow water using a spear or seine net (Low 1813; Colley 1983). They will also take a hook, however, and may represent incidental catches while fishing for gadid taxa (Muus \& Dahlstrom 1974).

A few of the 12 Triglidae bones were probably grey gurnard. Most, however, could only be identified to the family level. Gurnards are bottom-dwellers which occur from the shoreline to depths of over 300m (Whitehead et al 1986b). A Shetlandic fisherman informed me that they are often caught while line-fishing for cod family taxa (Leask 1993).

Birds The bird assemblage from Smoo Cave was very small. A total of 19 specimens weighing $2.5 \mathrm{~g}$ were recovered, only seven of which were identified to family or genus. All other specimens were tiny bone fragments, ribs and vertebrae.

A single tarsometatarsus from Phase 3 was closely matched by lapwing, Vanellus vanellus. In the absence of comprehensive reference material, however, here it is identified as plover family. This wader could be a natural or cultural addition to the archaeological deposits.

All other identified bird bones came from Phase 5 . Three crow family coracoids (from a minimum of two individuals) were probably jackdaw, Corvus monedula, given their small size and the absence of jays from northern Scotland (Heinzel et al 1973). Three dove or pigeon tarsometatarses (from a minimum of two individuals) matched rock dove, Columba livia, an identification with some support from the cave's setting on a rocky treeless coast in northern Scotland (Heinzel et al 1973). Both taxa frequent coasts and could represent natural deaths. Nevertheless, one unidentified bird specimen was charred, raising the possibility of human exploitation.

This minute sample is remarkable for the absence of all seabirds - taxa that dominate most avian assemblages from northern Scotland (Serjeantson 1988; Barrett 1995). It is tempting to suggest that no birds were purposely exploited at this unusual site. It is entirely possible, however, that other species would appear in a larger sample.

Mammals The mammal assemblage from Smoo Cave was also very small. A total of 421 specimens weighing $459.6 \mathrm{~g}$ were recovered, but 383 of these were tiny unidentified fragments retained by sieving with a $4 \mathrm{~mm}$ mesh. The sample size is too small to serve as anything other than a species list. Cattle and possibly red deer were found in the deposits from Phase 1. Phase 3 yielded sheep, sheep or goat and a fetal or neonatal ulna from a large ruminant, probably Bos taurus. Cattle, pig, sheep or goat and large ruminant specimens occurred in Phase 4.

The largest mammal assemblage derived from Phase 5. It included cattle, sheep or goat, dog or wolf, several broad ruminant categories and three wild taxa. The latter are Muridae, vole and stoat. The wild taxa exhibited no cut marks or fire-alteration and may represent natural death of midden colonizers. The rodents and birds found in Phase 5 may actually represent stoat kills. To the author's knowledge, the stoat has not yet been identified in other medieval assemblages from northern Scotland (see Barrett 1995).

There are insufficient data to facilitate a discussion of age at death profiles. As mentioned above, Phase 3 produced a fetal or neonatal ulna from a large ruminant (probably Bos). This phase also produced an unworn cattle deciduous third mandibular premolar. The limited epiphyseal fusion data are included in Appendix D (archive report).

Seventy-three of the mammal specimens were fire-altered and a few (from Phase 5) exhibited cut marks. It is probably safe to assume that meat was purposely brought to Smoo cave for consumption. It is more difficult to say whether living animals were kept in the cave for any length of time. No shed deciduous teeth were recovered.

Amphibians One toad humerus and two toad tibiofibulae were recovered from Phase 5. They are probably natural introductions to the midden deposits.

\subsubsection{Conclusion}

Only the shell midden (context 006, Phase 5) yielded sufficient material to justify any significant conclusions. This deposit is distinctive. It would appear that both fish and mammal flesh was consumed in 
Smoo Cave during Phase 5. The paucity of carnivore damage limits the likelihood that the assemblage was collected by non-human agents (see above for exceptions to this generalization). It is conceivable that some of the fish were discarded by fisher folk when landing catches in this natural harbour, and that some weak mammals stumbled into the cave for shelter and died there. However, burned bones and cut marks strongly imply that much of the material was food waste.

There is no anatomical or butchery evidence to suggest that the dominant taxon, haddock, was being processed and cured for consumption elsewhere. A tiny number of cod and ling bones could be consistent with cured fish production. They are much too rare, however, to imply that this practice was the site's prime function. Phase 5 at Smoo is not a fish-processing midden of the type tentatively identified at the relatively nearby sites of Robert's Haven and Freswick Links (Barrett 1995).

The zooarchaeological evidence would seem to imply that the cave was actually occupied up to the medieval period - at least as a sheltered location for the preparation of hot meals. The recovery of iron rivets may imply the presence of boats which coupled with Smoo's setting as a natural harbour - is consistent with use of the cave as a fisherman's shelter. Given this interpretation, the shell component of the assemblage may have resulted from collecting fish bait (Fenton 1992).

This discussion of Phase 5 requires an important caveat. This report has assumed hitherto that the samples are moderately representative of the shell midden as a whole. This assumption, however, could be incorrect. It is conceivable, for example, that the unusual abundance of haddock was created by sampling an area where a single catch from a rich haddock shoal had been discarded.

\subsection{The fish remains from Glassknapper's Cave, Antler Cave and Wetweather Cave by Ruby Cerón-Carrasco}

\subsubsection{Methodology}

The fish remains from the Geodha Smoo caves were recovered mainly by sieving through a $1 \mathrm{~mm}$ mesh, although a few elements were collected by hand during the excavations. Identification of the remains was done using modern fish bone reference collections and by reference to standard guides (RosellóIzquierdo 1988; Watt et al 1997).

All fish remains were examined and, where possible, identified to skeletal elements and species or assigned to a higher taxonomic level, that is, family group, or ultimately classed as unidentifiable when the bones consisted of mainly broken fragments (nomenclature follows Wheeler \& Jones 1989, 122-3).

Where appropriate, all major paired elements were assigned to the left or right side of the skeleton. All elements were examined for signs of butchery and burning. The colour of burnt bone was recorded to allow analysis of the nature of the burning.

Measurements were not taken on the identified elements; instead elements were classified into size categories for total body length. This was done by reference to modern specimens of known size. For the Gadidae group, some elements were categorized as 'very small' ( $<0.15 \mathrm{~m})$, 'small' $(0.15-0.3 \mathrm{~m})$, 'medium' (0.3-0.6m), 'large' (0.6-1.2m) or 'very large' $(1.2-1.5 \mathrm{~m})$. This approach will in most cases provide a sufficiently accurate picture of the size of the species present. For the non-gadoid species, a classification as 'juvenile', 'maturing' or 'mature' was made.

Recording of the preservation of bone was based on two characteristics: texture on a scale of 1 to 5 (fresh to extremely crumbly) and erosion also on a scale of 1 to 5 (none to extreme). The sum of both was used as an indication of bone condition; fresh bone would score 2 while poorly preserved bone would score 10 (after Nicholson 1991).

\subsubsection{Results}

The detailed results of the analysis of the fish remains from the Geodha Smoo caves are given in the catalogue, included in the archive report.

The level of preservation of the fish bone was consistent throughout the site, in terms of fragment size and condition. Most bones were 40-70\% complete. Their condition score was generally in the range of 7-9, indicating poor to extremely poorly preserved bone. A total of 24 taxa were identified: 19 to species and five to family level. The numerous unidentifiable fragments consisted of mainly cranial fragments and tiny fragments of ribs and fin rays. These were not considered in the results tables, as they would have given a distorted image of the assemblage; they are mainly the results of postdepositional and post-excavation damage.

Glassknapper's Cave This cave was more extensively excavated and therefore produced most of the fish remains from Geodha Smoo. Glassknapper's Cave also produced the greatest variety of species (see Table 12 below), which show that those using the cave practised mixed fishing.

Fishing from rocks for young saithe and pollack would have also caught young cod and rocklings. The use of boats and hand-lines would have been required for catching mature cod, haddock, ling and torsk as well as other species such as red sea bream, gurnard, rays, dogfish, ballan wrasse and mackerel. Hand-lines might have consisted of a wooden reel, small streamlined weight, and a line of several fathoms ending in a number of hooks attached by horse hair; such hand-lines, known as 'toams', were used in the Northern Isles during the 19th and early 
20th centuries (Goodlad 1971; Fenton 1978). Herring was also present. Nets were probably used for catching these, although they can occasionally be caught on line.

Element representation for the gadoid species appears to be quite even, with most elements well-represented. This rules out the possibility of Glassknapper's Cave having been used as a curing station for the production of stock fish (dried), as appendicular elements (for example, cleithra) are present in quite even numbers, as well as caudal vertebra in both large and small specimens. Appendicular elements and caudal veterbra are usually left on stock fish (Cerón-Carrasco 1994; Barrett 1997). This may be best appreciated by looking at the gadoid element representation for the three caves.

It therefore appears that the fish from Glassknapper's Cave were caught to be consumed on site and were not intended for preservation and transportation elsewhere.

This is further supported by the fact that only two elements with cut marks were recovered. One was a cleithra from a large gadidae from common sample Spit 13; such marks may have resulted from beheading the fish. A post-temporal from a large specimen also displayed several cut marks, which may have been produced during gutting or filleting.

Most of the samples from this assemblage also contained burnt fish bone; these were partially burnt black or grey, which would indicate the burning of domestic rubbish.

Antler Cave Due to the limited amount of material excavated at this cave (see Table 12 below), very few fish remains were recovered compared to the adjacent Glassknapper's Cave and Wetweather Cave.

Antler Cave produced a very limited number of species, mainly first- and second-year saithe and pollack, a few elements from medium-sized cod and a single element from a large individual (which was hand-collected). Also present were remains from mature herring $(0.35-0.4 \mathrm{~m})$, ballan wrasse and a single vertebra from sandeel.

Those using the cave may have fished for young saithe and pollack using a simple line and hook, and for medium-sized to large cod using boats. The presence of mature herring may also indicate the use of boats, although nets rather than lines would have been required for this catch. However, due to the poor preservation of the sediments in this cave as a result of heavy erosion (Pollard 1996b), the remains may present quite a biased picture when compared to the other two caves. There were no signs of gnawing or other activity related to animal intrusion.

Wetweather Cave The fish remains from Wetweather Cave were covered with a limy powder. The fish bone elements recovered were mainly vertebrae from very small and small specimens of saithe and pollack, and from small gadoid species such as shore rockling and bib, although rocker, grey gurnard and eel were also present (see Table 12 below).

None of the remains showed any signs of digestion or of gnawing such as may have been incurred by other mammals, like the coastal otter (Lutra lutra), implying they were fished for consumption by humans. Most of the remains from young saithe and pollack and bib derived mainly from two samples context 1/006, Slot 1, Spit 1 and context 1/006, Slot 1, Spit 3 - both midden deposits.

This assemblage represents inshore fishing probably carried out during autumn, when young saithe and pollack are most abundant and can be caught by line-fishing from rocks by the shore. Rocker and grey gurnard may also have been caught inshore, as well as eel, although this species may have been caught at burn entrances using a basket such as the cruive.

\subsubsection{Conclusion}

The assemblages from the Geodha Smoo caves represent different types of fishing strategies; these are best reflected by the differences in gadoid species size representation.

Glassknapper's Cave displayed more specialized fishing throughout the year than the other two caves, making full use of resources inshore and deep sea waters, although this consistently appears to have been for domestic consumption rather than for the production of stock fish.

Antler Cave may have been occupied at different times of the year. The small quantity of fish remains recovered is interpreted as the result of heavy erosion of the sediments in the cave.

Wetweather Cave reflects small-scale, domestic, inshore fishing, most probably carried out during the autumn when young pollack, and in particular saithe, are most abundant. While fishing for these may have been a priority, other species such as grey gurnard and rocker may have accidentally been caught.

In conclusion, the hypothesis that these caves were occupied at different times of the year or throughout the year is partly supported by the fishing strategies employed by their inhabitants. Nevertheless, the evidence seems to favour fishing for consumption in the caves rather than for the preservation and consumption of the fish elsewhere.

\subsection{The mammal and bird bone from Glassknapper's Cave, Antler Cave and Wetweather Cave by Catherine Smith}

\subsubsection{Methodology}

Extensive sampling, both on site and in the laboratory, of the archaeological deposits found in Glassknapper's Cave, Antler Cave and Wetweather Cave 
resulted in the recovery of plentiful faunal remains. These included the bones of mammals, birds and amphibians. All samples from Antler Cave and Wetweather Cave were examined and recorded, whether recovered on site or under laboratory conditions. Samples from Glassknapper's Cave collected on site, both by hand and by sieving, were examined and the faunal component recorded fully, while approximately two-thirds of the lab samples were also subject to detailed examination. All teeth, which had previously been extracted from the column samples, were examined because these were expected to provide useful confirmation of the species present.

The level to which a particular species could be identified was somewhat hindered by the exceptionally fragmented state of the bones. Thus, although cattle and red deer can normally be separated with some confidence, the surviving fragments from the caves were in many cases too small to retain the so-called diagnostic zones which aid identification. In particular, the assemblage was dominated by splinters of the shafts of long bones while very few articular ends, which are often diagnostic of particular species, were recovered.

Although cattle have been found to be the dominant species at the majority of Scottish archaeological sites dating from the later Iron Age to the medieval period, it was clear from the initial stages of the analyses that red deer bones were present in quantities more typical of cattle. It was therefore unsafe to assume that most of the large fragments from the caves came from cattle. The criterion was therefore adopted of recording all large fragments for which the particular bone could be recognized, but the species could not be ascertained with complete confidence, as cattle/red deer. This category included scapula blade fragments, but not shaft splinters which were obviously from major long bones but where the particular long bone itself could not be diagnosed with certainty. Such long bone shaft fragments were described as 'large ungulate'. The term was also used to describe all large vertebrae and rib fragments which could have come from cattle or red deer. This category would normally include vertebrae and ribs of horse, but as no horse long bones were found on the site it may be assumed that all bones described as 'large ungulate' came from cattle or red deer.

Bones of smaller domesticated animals were not so plentiful in the caves. Although the identification of sheep and goat bones present well-known difficulties in separating the two species, no bones were found which were thought definitely to represent goats. All sheep-sized vertebrae and ribs were recorded as 'small ungulate', a description which would usually include, sheep, goat and roe deer; however, no bones of roe deer (Capreolus capreolus) were noted.

Intermediate mammal fragments were present in almost all of the samples but because some of these fragments were only a few millimetres in size it was not thought profitable to count them.

It should be noted that the high degree of breakage also precluded collecting the relevant data which would have allowed the minimum numbers of animals to be estimated; likewise, anatomical measurements based on complete bone lengths and dimensions of the articular ends were possible for only a few bones and, because these were almost all red deer phalanges, their usefulness in indicating the size of the animals was limited.

\subsubsection{Species present}

The greater part of the faunal assemblage was recovered from Glassknapper's Cave, and the bones from this cave were in a better state of preservation than in the two other caves. In Antler Cave and Wetweather Cave, the bones were covered with limy deposits, in some cases obscuring any diagnostic features which would aid identification. However, bones from Glassknapper's Cave were free from limestone encrustation and in some cases were well enough preserved to show knife cuts or other man-made marks.

The range of mammalian species present included both domesticated and wild animals (see Table 5). The domesticated livestock were represented by bones of cattle, sheep (or goat) and pig. Wild mammals of economic importance were red deer (Cervus elaphus) and seal species. It was unfortunately not possible to say whether the seal bones came from the grey (Halichoerus grypus) or the common seal (Phoca vitulina), as the small number of bones were all from juvenile or pup seals.

The single canid bone was a large metatarsal which, given the nature of and date of the site, may represent a wolf or merely a large dog. There was ample evidence that some of the bones recovered from the site had been gnawed by sharp-toothed carnivores, and it is not unlikely that the caves had contained an animal den at some point in their history.

Bones of small mammals were also recovered. These came from bank vole (Clethrionomys glareolus) from Glassknapper's Cave, and vole species, probably the field vole (Microtus agrestis). Unfortunately, no complete dentitions were found which would have confirmed the species. However, it is unlikely that the vole bones were the Orkney vole (Microtus arvalis), as this species is not found in mainland Britain. The remaining small mammal long bones from the caves probably also came from voles. In addition to the mammalian remains, four amphibian bones (probably frog, Rana temporaria) were also noted in the samples from Wetweather Cave. Given that there is a source of fresh water, the Allt Smoo, in close proximity to the site, as well as water dripping from the cave walls the presence of frog bones is not too surprising.

No avian remains were noted in the material from Antler Cave. Only two bones, one from Glassknapper's Cave and one from the Wetweather Cave, were from a domesticated species, the fowl 
Table 5 Total numbers of mammal bones found in Glassknapper's Cave (GKC), Antler Cave (AC) and Wetweather Cave (WWC)

\begin{tabular}{|c|c|c|c|c|}
\hline \multirow[b]{2}{*}{ Species } & \multicolumn{3}{|l|}{ Site } & \multirow[b]{2}{*}{ Total } \\
\hline & GKC & $\mathbf{A C}$ & WWC & \\
\hline Cattle & 59 & 4 & 3 & 66 \\
\hline Red deer* & 157 & 14 & 6 & 177 \\
\hline Cattle/red deer & 29 & 1 & 1 & 31 \\
\hline Large ungulate (vertebrae and ribs) & 140 & 3 & 3 & 146 \\
\hline Large ungulate (long bone shafts) & 185 & 1 & 37 & 223 \\
\hline Sheep/goat & 33 & 4 & 1 & 38 \\
\hline Pig & 25 & & 3 & 28 \\
\hline Small ungulate (vertebrae and ribs) & 69 & & 4 & 73 \\
\hline Seal sp & 7 & & 1 & 8 \\
\hline Canid & & & 1 & 1 \\
\hline Clethrionomys glareolus (bank vole) & 1 & & & 1 \\
\hline Microtus sp (eg field vole) & & 2 & & 2 \\
\hline Vole sp & & 2 & 5 & 7 \\
\hline Small mammal & 4 & 1 & 1 & 6 \\
\hline Amphibian & & & 4 & 4 \\
\hline Indeterminate mammal & +++ & ++ & +++ & +++ \\
\hline Total & 709 & 32 & 70 & 811 \\
\hline
\end{tabular}

*The red deer total includes all antler fragments

+Indeterminate mammal fragments were ubiquitous in all samples and have not been counted

Gallus gallus. The majority of the bones were from wild species, mainly seabirds. These included the shag (Phalacrocorax aristotelis), guillemot (Uria aalge), razorbill (Alca torda), puffin (Fratercula arctica), herring/lesser black-back gull (Larus agrentatus/fuscus) and black-headed gull or kittiwake (Larus ridibundus/Rissa tridactyla). In addition, two bones were thought to have come from the manx shearwater (Puffinus puffinus), although this identification is less certain than for the other species. One bone of rock dove, or possibly its descendent the feral pigeon (Columba livia) and one from shelduck (Tadorna tadorna) were also recovered (see Table 6).

This wide range of seabirds contrasts with Smoo Cave, but it should be remembered that on that site a much smaller area was investigated and sampled.

\subsubsection{Age of animals at death}

Due to the high degree of fragmentation, little evidence of the age at which the animals were killed was available. However, two mandibles of sheep provided an estimate of age at death. One of the sheep, from Glassknapper's Cave (context 019), came from an animal of between two and three years old (based on Payne's 1973 criteria). A sheep mandible from the Antler Cave (context 040) was too fragmentary to ascertain the age with any certainty; however, the animal appears to have died between the age of three to eight years. Evidence for an older rather than a younger age is provided by a degree of dental pathology: there is recession of the alveolar bone in the area between the first molar and fourth premolar, a condition often found in older animals.

\subsubsection{Economy of the site-evidence of butchery and bone working}

Finds of clench nails and other materials in Glassknapper's Cave indicate that the caves may have served as a safe haven for the repair of boats during the Viking period. In addition, there is evidence that fish may have been processed in the caves (see Section 7.2 - The fish remains from Glassknappers Cave, Antler Cave and Wetweather Cave). Evidence from the mammal bones seems to indicate that meat from cattle, sheep, pigs, deer and seal was also prepared here. In addition, the bones, once removed from the carcasses, were utlized to make artefacts, as were the antlers of the red deer.

The evidence for meat preparation comes from the presence of parts of the carcasses associated with heavy musculature, which therefore yield relatively high quantities of meat and which in addition bear cut marks consistent with the removal of meat from the bones. For example, the presence of large numbers of rib shafts, which are unmodified apart from surface knife cuts, or from which the articular 
Table 6 Total numbers of bird bones found in Glassknapper's Cave (GKC) and Wetweather Cave (WWC)

\begin{tabular}{|c|c|c|c|}
\hline \multirow[b]{2}{*}{ Species } & \multicolumn{2}{|l|}{ Site } & \multirow[b]{2}{*}{ Total } \\
\hline & GKC & WWC & \\
\hline ?Manx shearwater:?Puffinus puffinus & 2 & & 2 \\
\hline Shag: Phalacrocorax aristotelis & 5 & & 5 \\
\hline Shag/cormorant: Phalacrocorax sp & & 1 & 1 \\
\hline Shelduck: Tadorna tadorna & 1 & & 1 \\
\hline Domestic fowl: Gallus gallus & 1 & 1 & 2 \\
\hline Herring/lesser black-back gull: Larus argentatus / fuscus & 1 & & 1 \\
\hline Black-headed gull/kittiwake: Larus ridibundus / Rissa tridactyla & 1 & & 1 \\
\hline Larus sp & 4 & & 4 \\
\hline Guillemot: Uria aalge & 5 & & 5 \\
\hline Razorbill: Alca torda & 1 & & 1 \\
\hline Guillemot/razorbill & 2 & & 2 \\
\hline Puffin: Fratercula arctica & 2 & & 2 \\
\hline i0cf Puffin & 2 & & 2 \\
\hline Rock dove: Columba livia & 1 & & 1 \\
\hline Indeterminate bird sp & 26 & 15 & 41 \\
\hline Total & 54 & 17 & 71 \\
\hline
\end{tabular}

'Indeterminate bird sp' includes all avian ribs, vertebrae, foot phalanges and shaft fragments

ends have been chopped, seem to point to meat production. Although ribs may be used to produce artefacts, those which survived in the caves had not been used in this way, but were discarded more or less intact, which is a good indication that they had been butchered for meat. Other bones indicating meat production are the vertebrae: evidence for carcass division at the site comes from the removal of the lateral processes of these bones. To produce vertebrae chopped in this way, the carcass would have been laid down on the floor of the cave and divided along the flanks to produce three main cuts of beef or venison, which could then be further subdivided into joints of meat. Because the vertebrae are too irregular in shape to be of use in artefact manufacture, their butchery must therefore be connected with the production of meat rather than the raw materials for bone working. Similarly, knife cuts on the premaxilla of a pig skull (layer 008, Slot 2, Spit 3 ), that is the snout region, also indicate meat removal, as the skull also is not suited for working by virtue of its shape.

However, there is definite evidence that long bones were deliberately chopped lengthwise (in the sagittal plane). The chopping of bones in this way was so severe that virtually no bone shafts were left intact. Articular ends (epiphyses) were also notably scarce. There are several explanations for this. It indicates that the bones had been chopped beyond recognition, or that once chopped open the spongy material of the more delicate epiphses (for example the proximal humerus) was easily destroyed under burial conditions, or that joints of meat containing the articulations were taken elsewhere to be consumed. Although this last is probably the most likely, the lack of knowledge of the whereabouts of contemporary Norse settlements in the vicinity presents the problem of just where the meat was taken.

The deliberate breakage of the long bones was almost certainly as much to do with artefact production as with marrow extraction, although there is definite archaeozoological evidence from Norse communities in Shetland and Iceland that the latter was a common occurrence (Bigelow 1993). Binford studied the butchering of caribou (known in Europe as reindeer) among the modern Nunamiut of Alaska and showed that marrow was customarily extracted, both at the settlement as well as the kill site, where the meat was initially butchered (Binford 1981, 1501). Evidence of split long bones is therefore difficult definitely to ascribe to either practice, and may have resulted from both processes being carried out on the same bones.

There is, however, further evidence from both Glassknapper's Cave and Antler Cave that red deer antlers were certainly processed into artefacts on the site. Such evidence supports the suggestion that long bones were also being worked in the caves. The evidence from the antlers consists not only of worked offcuts, which are immediately recognizable because of their relatively large size, but also of tiny fragments recovered from the samples sieved in the laboratory. These fragments, measuring only a few millimetres across, in some cases show evidence of knife cuts. Of the column samples studied from the Glassknapper's Cave, five out of 20 samples (25\%) contained antler flakes. In some cases, the slightly curved shape of the antler flakes indicates that a paring motion, perhaps with a draw knife, was used to produce them (for example, GKC column sample, Spits 23 \& 27). They are reminiscent in this way of 
the thin curls of wood produced when a plane is used, although the form of the antler flakes was a roughly rectangular shape, of $3-4 \mathrm{~mm}$ in thickness, with a 'pearled' outer surface consistent with comb manufacture. These offcuts possibly resulted from cutting away the outer, rough, 'pearled' surface of the antler, leaving behind a flat surface which could be polished smooth, suitable for comb side or tooth plates (for example GKC column sample, Spit 28).

None of the antler found within the caves was modified using saws. The implements were either axes, used to sever the tines from the main antler beam, or knives used to pare thin flakes from the antler surface. It is possible that adzes may also have been used: although there were no definite adze marks on any of the antlers, one burnt long bone shaft may have been butchered with an adze rather than an axe. Given that boat repair may have been going on in the immediate vicinity, it is not surprising that tools may have been used for several different jobs.

The presence of reindeer (Rangifer tarandus), or at least its antlers, has also to be considered. Work by Clutton-Brock \& MacGregor has shown that despite a long-cherished belief in the presence of reindeer in Scotland until the early medieval period, the species became extinct some 8000 years ago (Clutton-Brock \& MacGregor 1988). This is in spite of the assertion in the 13th-century Orkneyinga Saga that the Norse earls 'used to go over to Caithness every summer hunting red deer and reindeer in the woods there' (Palsson \& Edwards 1981, 209). However, antlers are of course portable, and there is some evidence that antler combs found at a broch site of the Late Iron Age/Pictish period in Orkney may have been made from reindeer antler rather than the red deer, which were indigenous to the islands at that date (Weber 1993; Ballin Smith 1995). That said, neither Glassknapper's Cave nor Antler Cave produced reindeer antler or long bone; the large fragments of antler were definitely from the red deer. However, it should be noted that current research has yet to resolve the difficulties in distinguishing between the antlers of the two species in artefactual material.

\subsubsection{Conclusion}

The faunal material from the caves in the Geodha Smoo is of great interest because it provides evidence both of the strategies employed to provision Norse settlers and of the raw materials used to make everyday artefacts. Although bones of domestic animals such as cattle, sheep and pigs were present in the deposits, it is not known in what way the livestock were obtained, whether by legitimate farming or by marauding, or by some combination of the two. However, it is obvious from the assemblage that the hunting of red deer was of great importance to the people who used the caves, to provide both food and the raw antlers and bones which were processed there. Because none of the antlers appear to have been cast and deer skull fragments were also present, it would seem that they originated from animals that were killed, rather than having been collected after the animals had cast them.

Less important, but still significant to the economy of the site, was the exploitation of marine mammals such as young seals and of a number of different seabird species. Seals could be killed when they hauled up on the shore, and were the source of fats both for consumption as food and as lubrication in industrial processes. Seabirds, such as guillemot, razorbill, puffin and kittiwake, nest on coastal cliffs and it is possible that the birds found in the excavation were taken close to the caves themselves. That the bird bones were not numerous, although representing a varied range of species, perhaps indicates the difficulty in scaling the cliffs at breeding time in order to capture them. A further possibility is that the birds were indeed utilized, but that the carcasses were taken away from the site and consumed elsewhere.

\subsection{Marine shells by Ruby Cerón-Carrasco}

\subsubsection{Methodology}

The marine shell remains from the caves in the Geodha Smoo were recovered by sieving. Apical fragments were identified to species using reference collections and standard guides (Campbell 1989). Frequency was estimated by counting shell apices for gastropods and valve umbos for bibalve species (Moreno-Nuño 1994b), but this method was only used for those Glassknapper's Cave samples which were $100 \%$ sorted.

Some of the Glassknapper's Cave's marine shell samples were not sorted, while none of the samples from Wetweather Cave and Antler Cave were sorted. This decision was taken because of the large amount of material and limited time available to analyse it. These samples were scanned and an approximate quantification has been given to give a general idea of the occurrence and importance of the different species represented.

\subsubsection{Results}

Smoo Cave (Table 7) The marine shell assemblage from Smoo Cave consisted of limpet (Patella vulgata), edible periwinkle (Littorina littorea) and common mussel (Mytilus edulis).

Patella vulgata is the most common limpet and is widely found on all rocky shores along the Scottish coast. Although its flesh is quite rubbery, when boiled it gives a milky broth which during times of hardship was commonly eaten for nourishment in some places in early modern Scotland, for example Lewis (Martin 1695). They are gathered by sharply knocking them from their toeholds on rocks, a technique that requires swiftness, accuracy and 
Table 7 The marine shell representation from Smoo Cave

\begin{tabular}{|c|c|c|c|c|c|}
\hline \multirow[b]{2}{*}{ Samples } & \multicolumn{4}{|l|}{ Species } & \multirow[b]{2}{*}{$\begin{array}{l}\text { Crushed } \\
\text { shell }\end{array}$} \\
\hline & $\begin{array}{l}\text { Patella } \\
\text { vulgata }\end{array}$ & $\begin{array}{l}\text { Littorina } \\
\text { littorea }\end{array}$ & $\begin{array}{l}\text { Littorina } \\
\text { littoralis }\end{array}$ & $\begin{array}{l}\text { Mytilus } \\
\text { edulis }\end{array}$ & \\
\hline 006/1 & $94 \mathrm{~m}+150 \mathrm{j}+* * *$ & $494 \mathrm{~m}+28 \mathrm{j}+* * *$ & & $29 \mathrm{~m}+12 \mathrm{j}+* * *$ & $* * * *$ \\
\hline $006 / 2$ & $10 \mathrm{~m}+6 \mathrm{j}+* * *$ & $58 \mathrm{~m}+13 \mathrm{j}+* *$ & $1 \mathrm{~m}$ & $* *$ & $* * * *$ \\
\hline $006 / 3$ & $89 \mathrm{~m}+180 \mathrm{j}+* * *$ & $150 \mathrm{~m}+20 \mathrm{j}+* *$ & $2 \mathrm{~m}$ & $7 m+* *$ & $* * * *$ \\
\hline 006A/1 & $14 \mathrm{~m}+40 \mathrm{j}+* *$ & $43 m+2 j+* *$ & & $2 \mathrm{~m}+* *$ & $* * * *$ \\
\hline $006 \mathrm{~A} / 2$ & $101 \mathrm{~m}+303 \mathrm{j}+* * * *$ & $322 m+44 j+* * *$ & & $11 \mathrm{~m}+* * *$ & $* * * *$ \\
\hline 008/1 & $13 m+5 j+* *$ & $54 m+7 j+* *$ & & $1 \mathrm{~m}+* * *$ & $* * * *$ \\
\hline $009 / 1$ & $4 m+2 j+* *$ & $5 m+1 j+* *$ & & $* *$ & $* * *$ \\
\hline 010/1 & $20 m+8 j+* * *$ & $20 \mathrm{~m}+6 \mathrm{j}+* *$ & & $15 \mathrm{~m}+10 \mathrm{j}+* * *$ & $* * *$ \\
\hline $010 / 3$ & $7 \mathrm{~m}+* * *$ & $14 \mathrm{~m}+8 \mathrm{j}+* *$ & & $* *$ & $* * *$ \\
\hline 013/1 & $40 m+16 j+* *$ & $28 \mathrm{~m}+4 \mathrm{j}+* *$ & & $22 \mathrm{~m}+* * *$ & $* * * *$ \\
\hline 020 & $32 \mathrm{~m}+58 \mathrm{j}+* * *$ & $53 \mathrm{~m}+4 \mathrm{j}+* *+* * b$ & & $* *+* * b$ & $* * *$ \\
\hline 021 & $2 \mathrm{~m}+* *$ & $9 m+*$ & & & $* *$ \\
\hline $024 / 2$ & $2 \mathrm{~m}+*$ & & & $*$ & $* *$ \\
\hline $\begin{array}{l}\text { Shell midden/lower } \\
\text { position, Sample } 1\end{array}$ & $66 \mathrm{~m}+120 \mathrm{j}+* * *$ & $133 \mathrm{~m}+20 \mathrm{j}+* *$ & & $2 \mathrm{~m}+* *$ & $* * * *$ \\
\hline $\begin{array}{l}\text { Shell midden/upper } \\
\text { position, Sample } 1\end{array}$ & $36 \mathrm{~m}+88 \mathrm{j}+* * *$ & $92 \mathrm{~m}+27 \mathrm{j}+* *$ & & $7 \mathrm{~m}+2 \mathrm{j}+* * *$ & $* * * *$ \\
\hline
\end{tabular}

Key: $\mathrm{m}=$ mature, $\mathrm{j}=$ juvenile, $\mathrm{b}=$ burnt

Crushed shell quantification key: $* *=$ occasional, $* * *=$ common, $* * * *=$ abundant

practice (Ellis 1995). They can also be used as bait for fishing.

Littorina littorea is found on rocks, stones and seaweed on the middle and lower shore, but especially on the shore during the breeding season (September-April). It is usually gathered by hand from designated areas (Ellis 1995). Edible limpet is usually eaten boiled or steamed.

Common mussel (Mytilus edulis) is usually found throughout Scotland on stones and rocks in estuaries and on rocks on more exposed shores.

Only one sample (from layer 020) contained burnt shell fragments. It is likely, however, that most of the specimens recovered had been used as food, although some may have been used as fishing bait.

Very few specimens of non-edible mollusc were recovered. Flat periwinkle (Littonina littoralis) was present in contexts 006/2 and 006/3. These are usually found on seaweed, on bladded wrack (Focus vesiculosus) and on knotted wrack (Ascophyllum nodosum), and may have been accidentally brought onto the site along with edible periwinkle (Littorina littorea).

The species of marine mollusc recovered in Smoo Cave appear to have formed part of the diet of its human occupants, although they may have also been used as fish bait.

Glassknapper's Cave (Table 8) The most abundant species in this cave were the common limpet (Patella vulgata) and the common mussel (Mytilus edulis); both produced large amounts of crushed shell, much of which was burnt. Edible periwinkle (Littorina littorea) appears to have been equally important in this area. Also present were the whelk (Baccium undatum) and the common oyster (Ostrea edulis).

The common oyster (Ostrea edulis) is found from shallow water down to about $80 \mathrm{~m}$. Whelks (Baccium undatum) are found on sand and mud from shallow water down to about $100 \mathrm{~m}$, and are usually caught from the sea in baited pots or baskets (Ellis 1995).

Remains of edible crab (Cancer pagurus) and common sea urchin (Echinus esculentus) were also recovered from the cave. Edible crab remains from column sample Spit 18 were burnt, which indicate this was used as foodstuff. The sea urchin remains were found in Sample 8 (Slot 2, Spit 3). Echinus esculentus is common around the Scottish coast and has been recorded at Cnip, Lewis (Cerón-Carrasco 1997). The manner of cooking these sea creatures is by boiling or roasting on hot stones (Renfrew 1993), although they can also be eaten raw.

The species present in Glassknapper's Cave are likely to be food remains, especially those which had been burnt. Some of the species could also have been used as fishing bait, in particular the limpet, periwinkle and mussel.

Rough periwinkle (Littorina saxatilis) was the only non-edible species recovered at Glassknapper's Cave. This was only present in one sample and may have been accidentally collected along with Littorina littorea by those using the cave. Rough periwinkle is found on rocks and stones and in cracks and crevices on the upper and middle shore, where it feeds on seaweed.

Antler Cave Only one context from Antler Cave contained sufficient marine shell for detailed analyses of marine shell exploitation. A midden 


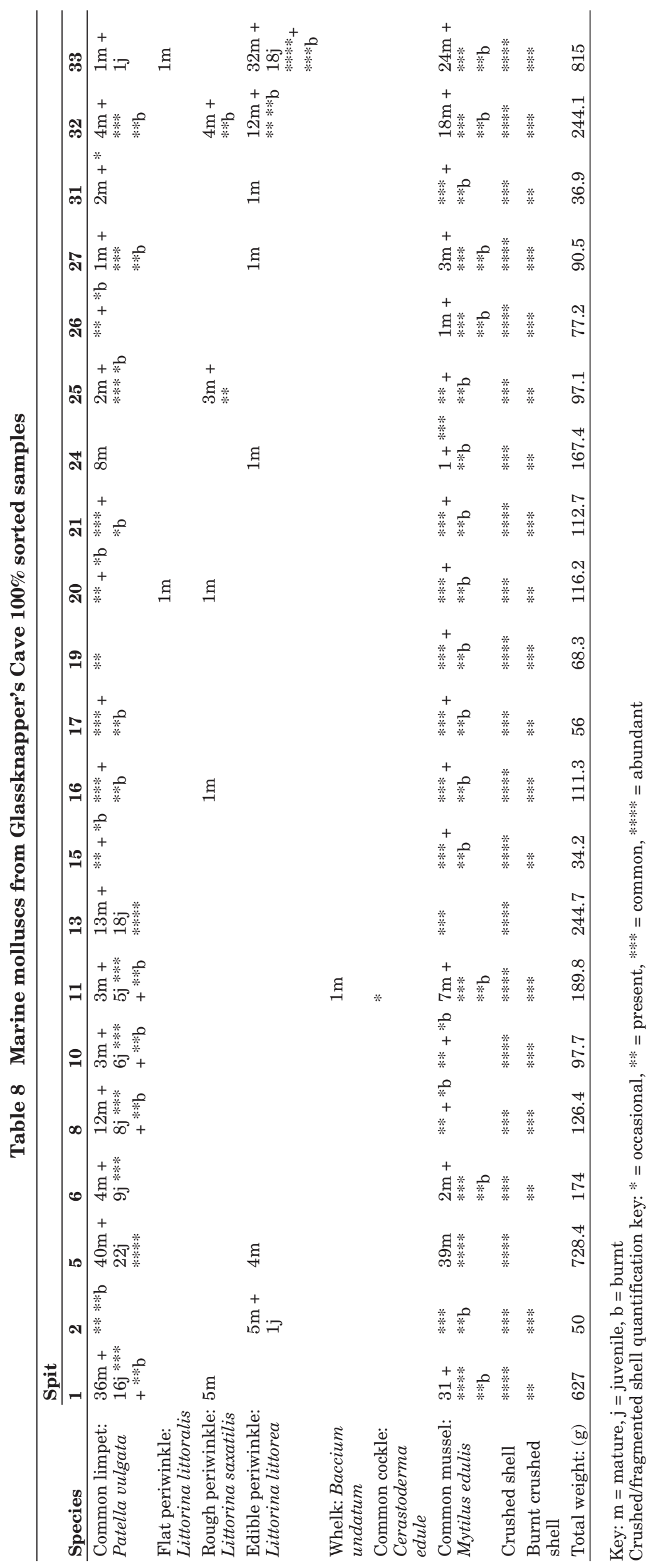


layer (035) produced large amounts of mainly common limpet (Patella vulgata), with some edible perwinkle (Littorena littorea). Crushed shells from edible mussel (Mytulis edulis) were also present in some of the contexts. There was no burnt shell in this cave. This and the fact that the assemblage was almost entirely represented by Patella vulgata from one context may suggest that these species were mainly used as fishing bait.

Wetweather Cave Common limpet (Patella vulgata) was the most commonly represented species in this cave, with common mussel (Mytilus edulis) and edible periwinkle (Littorina littorea) also present. There was a large quantity of broken shells, some of which were burnt. Therefore, while some specimens may have served as fishing bait, much would also have been consumed as foodstuff. Another edible species recovered at the Wetweather Cave was the common cockle (Cerastoderma edule), which is found buried in mud, sand or gravel on the lower shore and in estuaries.

The cave also produced the largest amount of edible crab (Cancer pagurus) in the Geodha, along with possible Norway lobster (cf Nephrops norvegicus). Both these species are widespread in the North Sea. Cancer pagurus inhabits substrates from the lower shore down to $100 \mathrm{~m}$, while Nephrops norvegicus is found on substrates from about $50 \mathrm{~m}$ downwards.

Non-edible species included the periwinkle (Littorina littoralis) and the whelk (Nucella lapillus); the latter is found on rocky shores in the middle shore region, in crevices and among barnacles (on which it preys).

The large numbers of the whelk Nucella lapillus, most of which had been deliberately broken, are the most important aspect of the assemblage from this cave. Nucella lapillus, also known as Purpura lapillus, were used in ancient times for the production of purple dye.

Large amounts of Nucella lapillus were also found in association with 'kitchen middens' of Patella vulgata and Littorina littorea in Dogsbay, Connemara, West Ireland (Jackson 1919). Jackson describes how the shell of the Nucella had been broken; the apical whorls had been smashed, leaving the lower whorl with the mouth intact. Most of the specimens recovered at Wetweather Cave had been split from the second and third whorl and also split from the shoulder to the base, leaving the cumella intact. This would have facilitated the removal of the animal from its shell to extract the ink.

A more recent analyses involving the study of Nucella lapillus for possible dye extraction has been carried out on material from Ballyconnelly, Co Galway in Northern Ireland (McCormick et al 1996). Here the shell of the Nucella had been broken in a way that clearly distinguished them from other species consumed as food.

Nucella lapillus are not an edible species, and those from Wetweather Cave have not been used as fishing bait. It is clear that purple dye was being extracted from the shells recovered from the cave. According to Jackson, purple dye extracted from the Nucella lapillus was largely employed as Tyrean purple for dyeing parchments and vellum for biblical manuscripts, which were also adorned with gold and silver (Jackson 1919). This may certainly be the case for many of the early Christian manuscripts in Scotland, such as those produced at Iona and other ecclesiastical sites.

Wetweather Cave seems to have produced the first known archaeological evidence of purple dye extraction in Scotland for, although Nucella lapillus is widespread along Scottish coasts, it may not have been carefully recorded in archaeological assemblages before.

\subsubsection{Conclusion}

The marine shells from the Geodha Smoo indicate the use of molluscs for quite specific purposes, with each cave demonstrating a different use.

The molluscs from Glassknapper's Cave seem to have been used mainly as a source of food, as much burnt shell was recovered, probably as the result of burning domestic rubbish. Some of the species may also have been used as fishing bait.

In Antler Cave there was no evidence of burnt shells and Patella vulgata was the only species present in any significant numbers. It is likely that these were mainly used as fishing bait.

Wetweather Cave, on the other hand, offers the most interesting example of specialized uses of marine molluscs. Some species served as a food source, as well as possible fishing bait (limpet, periwinkle, mussel). It is also evident that the whelk Nucella lapillus was being used for the extraction of purple dye. The presence of this mollusc has not previously been carefully considered in assemblages from Scottish sites, and Wetweather Cave is therefore possibly the first recorded evidence of this industry in Scotland. This serves to highlight the importance of analysing all marine molluscs to consider all their possible uses at sites where they are present.

\subsection{Plant remains by Diane Alldritt}

Analysis of the environmental samples was undertaken by the author during 1996 and formed part of a larger body of research into Late Iron Age/Early Norse economies in Northern Scotland (Alldritt 2003). The archaeobotanical evidence from Geodha Smoo is presented here, together with a wider consideration of the regional importance of the site during the Norse period. 
Table 9 Identified plant remains by dated phase

\begin{tabular}{|c|c|c|c|c|c|}
\hline $\begin{array}{l}\text { Geodha Smoo, } \\
\text { Sutherland, phasing }\end{array}$ & $\begin{array}{l}\text { Post } \\
\text { AD 890-1160 }\end{array}$ & $\begin{array}{l}\text { Post } \\
\text { AD 770-980 }\end{array}$ & $\begin{array}{l}\text { Post } \\
\text { AD 820-1000 }\end{array}$ & Undated bulk & \\
\hline Sample group & $\begin{array}{l}\text { Column } \\
\text { Spit 1-2 }\end{array}$ & $\begin{array}{l}\text { Column } \\
\text { Spit 3-15 }\end{array}$ & $\begin{array}{l}\text { Column } \\
\text { Spit 16-33 }\end{array}$ & GKC 008 & GKC Other \\
\hline Total sample (litres) & 8 & 42 & 47 & 106 & 76 \\
\hline \multicolumn{6}{|l|}{ Culitvated plants } \\
\hline Barley: hulled & 2 & 4 & 1 & 4 & 1 \\
\hline Barley: naked & 1 & 2 & 0 & 1 & 0 \\
\hline Barley: indeterminate & 7 & 16 & 2 & 21 & 6 \\
\hline Barley: total grain & 10 & 22 & 3 & 26 & 7 \\
\hline Barley: chaff & 0 & 1 & 0 & 0 & 0 \\
\hline Oat & 11 & 17 & 3 & 15 & 3 \\
\hline Oat: cultivated chaff & 1 & 0 & 0 & 0 & 3 \\
\hline Oat: indeterminate chaff & 1 & 10 & 0 & 0 & 1 \\
\hline Wheat & 0 & 1 & 0 & 2 & 0 \\
\hline $\begin{array}{l}\text { Wheat: indeterminate } \\
\text { cereal }\end{array}$ & 2 & 13 & 0 & 7 & 3 \\
\hline Weeds of cultivation & $29(5 \mathrm{sp})$ & $79(5 \mathrm{sp})$ & $10(2 \mathrm{sp})$ & $16(4 \mathrm{sp})$ & $1(1 \mathrm{sp})$ \\
\hline \multicolumn{6}{|l|}{ Wild resources } \\
\hline Peat & $2.8 \mathrm{~g}(79)$ & $2.4 \mathrm{~g}(220)$ & $14.2 \mathrm{~g}(388)$ & $3.2 \mathrm{~g}(5)$ & $0.35 \mathrm{~g}(3)$ \\
\hline Heather stems & $0.95 \mathrm{~g}(65)$ & $8.3 \mathrm{~g}(475)$ & 13.95g (733) & $0.61 \mathrm{~g}(31)$ & $2.8 \mathrm{~g}(118)$ \\
\hline Seaweed & $<0.05 \mathrm{~g}(2)$ & $0.1 \mathrm{~g}(2)$ & $<0.05 \mathrm{~g}(1)$ & $0.2 \mathrm{~g}(10)$ & $0.2 \mathrm{~g}(9)$ \\
\hline $\begin{array}{l}\text { Charcoal (not including } \\
\text { 'sorted indetermined') }\end{array}$ & $4.8 \mathrm{~g}(34)$ & $4.3 \mathrm{~g}(110)$ & $20.4 \mathrm{~g}(137)$ & $11.85 \mathrm{~g}(122)$ & $25.95 \mathrm{~g}(82)$ \\
\hline \multicolumn{6}{|l|}{ Other remains } \\
\hline Marine mollusc shell & $55.7 \mathrm{~g}(63)$ & $0.2 \mathrm{~g}(12)$ & $0.1 \mathrm{~g}(5)$ & $379.4 \mathrm{~g}(413)$ & $12.35 \mathrm{~g}(40)$ \\
\hline Fish bone & $22.65 \mathrm{~g}(500)$ & $15.45 \mathrm{~g}(399)$ & $0.55 \mathrm{~g}(27)$ & $80.6 \mathrm{~g}(785)$ & $5 g(115)$ \\
\hline Other bone & $5.5 \mathrm{~g}(4)$ & $1.25 \mathrm{~g}(8)$ & $9.95 \mathrm{~g}(239)$ & $93.7 \mathrm{~g}(36)$ & $1.95 \mathrm{~g}(52)$ \\
\hline Industrial waste (slag) & 0 & 0 & $2.4 \mathrm{~g}(66)$ & 0 & $26.05 \mathrm{~g}(2)$ \\
\hline
\end{tabular}

\subsubsection{Methodology}

Extensive midden deposits, often up to $2 \mathrm{~m}$ deep, were encountered in the Geodha Smoo, and consisted of large quantities of domestic waste, including fish bone, mammal bone, marine mollusc shell and carbonized plant remains. Glassknapper's Cave, in particular, revealed an extremely complex series of deposits, often impossible to excavate as a single context. Consequently, material from Glassknapper's Cave was both excavated and sampled as a continuous column sample. Deposits in Antler Cave formed looser, less compacted lenses of material, and hence were sampled in bulk.

A total of 48 samples from Glassknapper's Cave and a further five from Antler Cave were processed using an Ankara-style water flotation tank (French 1971 ), with sieve sizes of $>1 \mathrm{~mm}$ and $>250$ microns. Samples sizes varied from two to 14 litres, with almost 319 litres of sediment processed in total. The resultant flots were sorted and plant material identified utilizing a low-powered binocular microscope typically at magnifications of $10 x$ to $20 x$. Fragments of wood charcoal were examined under a high-power Zenith metallurgical microscope using magnifications from 50x to 200x. Residues from the samples were sorted and any plant material recovered for examination.

Zadenatlas der Nederlandsche Flora (Beijerinck 1947) and Botanical Macro-Remains: An Atlas for the Determination of Frequently Encountered and Ecologically Important Plant Seeds (Schoch et al 1988), together with modern reference material were consulted for identification of seeds, whilst Anatomy of European Woods (Schweingruber 1990) was used for charcoal. Dr J Miller identified the various macrofossils of Carex sp (sedges) which were recovered from the samples. Plant nomenclature used in the text follows New Flora of the British Isles (Stace 1997) for all vascular plants other than cereals, which follow Domestication of Plants in the Old World (Zohary \& Hopf 2000).

\subsubsection{Results}

The raw results from $\mathrm{Smoo}$ are provided in archive tables A1, A2 and A3. The samples from Antler Cave produced no environmental remains and will not be discussed further. Samples from Glassknapper's Cave proved more enlightening and produced abundant quantities of environmental material, 
Table 10 Identified cereals by context

\begin{tabular}{lccccc}
\hline & Column Spit 1-2 & Column Spit 3-15 & Column Spit 16-33 & GKC 008 & GKC Other \\
\hline Barley: hulled & 2 & 4 & 1 & 4 & 1 \\
Barley: naked & 1 & 2 & 0 & 2 & 21 \\
Barley: indet & 7 & 16 & 3 & 15 & 0 \\
Oat & 11 & 17 & 0 & 2 & 3 \\
cf Wheat & 0 & 1 & 10 & 16 & 0 \\
Weeds of cultivation & 29 & 79 & & 1 \\
\hline
\end{tabular}

including charcoal, a selection of which was submitted for radiocarbon dating. These results placed the midden accumulation firmly in the Norse period, with use of the site possibly extending into the very Early Norse period. The radiocarbon dating evidence was subsequently used to divide the midden remains into chronological groupings for ease of interpretation. Table 9 summarizes the identified remains with the aid of this chronology. Undated bulk samples have been split into two further groups and these are listed as 'GKC 008' and 'GKC Other' in Table 9 for comparative purposes.

\subsubsection{Discussion}

The carbonized plant remains summarized in Table 9 will firstly be discussed by general category, ie weeds, cereals, charcoal and so forth, before any wider conclusions are drawn.

Cultivated plants Carbonized cereal grain and occasional fragments of chaff were recovered from Glassknapper's Cave. Barley (mainly Hordeum vulgare sl) was the most commonly recovered cereal grain from the column samples, with a little six-row hulled barley (Hordeum vulgare var vulgare) also recognized. Six-row hulled barley appears to be the most typically found multi-period cereal grain on Scottish sites (Boyd 1988; Dickson \& Dickson 2000, 232). Naked barley (Hordeum vulgare var nudum) was present in small amounts in the more recent midden deposits only and may have been re-introduced as a cereal crop by the Norse. This has parallels with the work on Papa Stour (Dickson 1999), where it was suggested that Norse settlers carried seed corn with them to the island, and may even have been responsible for re-introducing naked barley throughout the Northern Isles.

Table 10 clearly shows that the presence of oat as a cultivated cereal at Smoo, perhaps for animal fodder as much as for human consumption, should not be underestimated. The peaks in oat grain reflected the peaks in barley, with most cereal grain recovered from the central portion of the midden deposits (dated to AD 770-980). Cultivation of oat cereal, for grain and straw, was probably equally as important as barley, particularly with an increasing need for the production of fodder for the over-wintering of animals during the later Norse period (Alldritt
2003). Weeds of cultivation also reached a peak during the central part of the midden, although their presence throughout the deposits largely outweighs that of cereals. This strongly suggested that a large constituent of the midden consisted of dumped cereal-processing waste.

A small amount of wheat was also recovered from the central part of the midden and context 008. This may well have formed a traded product during the Norse period, certainly ethnographic records have shown importation of cereal to North-West Sutherland from Caithness during the 18th century (Bangor-Jones 2000, 66).

Weed ecology: habitat categories The weed seeds recovered from Glassknapper's Cave were divided into nine ecological groupings based upon New Flora of the British Isles (Stace 1997) and these are listed below. The actual numbers of weeds recovered from each phase and divided into appropriate ecological groupings are summarized in Table 11.

Sandy arable land, damp sand, ditches and dunes: Myosotis arvensis (field forget-me-not), Spergula arvensis (corn spurrey), Ranunculus repens (creeping buttercup).

Non-sandy arable/waste and disturbed ground: Chenopodium album (fat hen), Stellaria media (chickweed), Polygonum aviculare sl (knotgrass), Galeopsis tetrahit (common hemp-nettle).

Grassland, grassy meadows/pasture: Prunella vulgaris (self heal), Plantago lanceolata (ribwort plantain), Carex flacca (glaucous sedge), Bromus sp (bromes), Silene cf vulgaris (cf bladder campion).

Mountain pastures/rock crevices: Alchemilla alpina (alpine lady's-mantle).

Wetland: Aquatic, waterside and mire (base-rich): Ranunculus flammula (lesser spearwort), Ranunculus scleratus (celery-leaved buttercup), Scirpus (Isolepis) setaceus (bristle club-rush), Carex viridula ssp oedocarpa (yellow sedge), Carex cf hostiana (cf tawny sedge).

Moors, bogs and heath/dry heath: Empetrum nigrum (crowberry), Danthonia decumbens (heathgrass), Erica tetralix (cross-leaved heath), Erica cinerea (bell heather).

Sea cliffs, banks and woodland scrub: Silene dioica (red campion), Sorbus aucuparia (rowen), Rosa canina sl (dog rose).

Shingle beaches and shores: Galium aparine (cleavers). 
Table 11 Number of weeds recovered from each phase, divided into ecological groupings

\begin{tabular}{|c|c|c|c|c|c|}
\hline Geodha Smoo, Sutherland, phasing & $\begin{array}{l}\text { Post } \\
\text { AD 890-1160 }\end{array}$ & $\begin{array}{l}\text { Post } \\
\text { AD 770-980 }\end{array}$ & $\begin{array}{l}\text { Post } \\
\text { AD 820-1000 }\end{array}$ & $\begin{array}{l}\text { Undated } \\
\text { bulk }\end{array}$ & $\begin{array}{l}\text { Undated } \\
\text { bulk }\end{array}$ \\
\hline Sample group & $\begin{array}{l}\text { Column } \\
\text { Spit 1-2 }\end{array}$ & $\begin{array}{l}\text { Column } \\
\text { Spit 3-15 }\end{array}$ & $\begin{array}{l}\text { Column } \\
\text { Spit 16-33 }\end{array}$ & GKC 008 & GKC Other \\
\hline \multicolumn{6}{|l|}{ Weed species ecology } \\
\hline Sandy arable, damp sand, ditches and dunes & $14(2 \mathrm{sp})$ & $34(3 \mathrm{sp})$ & 0 & $2(1 \mathrm{sp})$ & 0 \\
\hline Non-sandy arable/waste and disturbed ground & $15(3 \mathrm{sp})$ & $45(2 \mathrm{sp})$ & $10(2 \mathrm{sp})$ & $14(3 \mathrm{sp})$ & $1(1 \mathrm{sp})$ \\
\hline Grassland, grassy meadows/pasture & $3(2 \mathrm{sp})$ & $7(4 \mathrm{sp})$ & $1(1 \mathrm{sp})$ & $3(3 \mathrm{sp})$ & 0 \\
\hline Mountain pastures/rock crevices & 0 & 0 & 0 & $1(1 \mathrm{sp})$ & 0 \\
\hline $\begin{array}{l}\text { Wetland: Aquatic, waterside, marsh and mire } \\
\text { (base-rich) }\end{array}$ & $6(3 \mathrm{sp})$ & $7(3 \mathrm{sp})$ & 0 & 0 & $1(1 \mathrm{sp})$ \\
\hline Moors, bogs and heath/dry heath & $2(1 \mathrm{sp})$ & $8(1 \mathrm{sp})$ & $2(1 \mathrm{sp})$ & $2(1 \mathrm{sp})$ & $5(2 \mathrm{sp})$ \\
\hline Sea cliffs, banks and woodland & $8(3 \mathrm{sp})$ & $9(3 \mathrm{sp})$ & $1(1 \mathrm{sp})$ & $3(1 \mathrm{sp})$ & $2(2 \mathrm{sp})$ \\
\hline Shingle beaches and shores & 0 & $4(1 \mathrm{sp})$ & $2(1 \mathrm{sp})$ & 0 & 0 \\
\hline
\end{tabular}

Miscellaneous: Poaceae (grass family), Fabaceae (pea family), Carex sp (sedges), Luzulasp (wood rush), Scirpus sp (wood club-rushes), Ranunculus sp (buttercups), Rumex sp (docks), Potentilla sp (cinquefoils), Poa sp (meadow grasses).

\section{Discussion of weed ecology and wild resources} The majority of weeds recorded from Geodha Smoo were agricultural or waste/disturbed ground species. As shown in Table 11, a large number of the weeds present in the Glassknapper's Cave midden consisted of non-sandy arable species, and these were present throughout the dated column deposits. Sandy arable weeds only appeared in the middle portion (AD 770-980) and later. This is concurrent with the rise in cereal grain already discussed. It is possible that early local agriculture was occurring on less productive arable land - perhaps the only land available in the immediate area. However, by $\mathrm{AD}$ 770-980, this was supplemented by grain grown on good quality sandy agricultural soils, which may suggest this grain was imported from elsewhere.

Wetland plants and species preferring moors and drier heaths were recovered in small numbers, mostly in the mid-later parts of the midden accumulation. These probably originated from peat-cutting operations, with drier weed indicators present in the early deposits, peaking in the middle and declining toward the end. Wetter fen and bog species, however, appear mostly in the middle and later midden, perhaps suggesting increasing use of fen-like and wetter turves for fuel in the later period deposits. Abundant recovery of peat fragments and heather stems during the earliest part of the midden reinforces the idea that drier environments (and hence perhaps the best quality peatlands for fuel use) were exploited earliest. The abundance of fuel for domestic fires and the presence of charcoal and slag from metalworking in the early deposits lends weight to the argument that the caves were initially used as brief resting places for seafarers, to repair boats and gather supplies as part of longer journeys, and that this use was probably seasonal (Pollard 1996).
Woodland resource Geodha Smoo produced a large amount of wood charcoal, with types identified from a range of habitats including scrub and open woodland, mountainous areas and sheltered valleys and straths. Coniferous charcoal was found in small amounts, including Picea sp (spruce) which was probably driftwood gathered from the local shore (eg Dickson 1992), and Pinus sylvestris (Scots pine) which may have been driftwood or imported from further south on the Scottish mainland.

Other imports may have included the deciduous woods, Ulmus (elm) and Quercus (oak), present in small quantities, with oak only found in the early dated part of the midden sequence. It is possible, of course, that both these types may have been growing in the region of the caves. Oak can survive on very shallow acid soils, sometimes at over $300 \mathrm{~m}$, whilst Ulmus glabra (wych elm) inhabits limestone areas in the north and west of Britain (Stace 1997, 112, 123). However, if local, these trees were almost certainly extremely rare and found amongst scrub in sheltered areas, rather than as actual woodland. Other deciduous woods included types tolerant of bog and other wet conditions, such as Alnus (alder) and Betula (birch), and open woodland edge and scrub types such as Corylus (hazel) and Salix (willow). Overall, birch charcoal dominated the assemblage.

\subsubsection{Summary and overall conclusions}

The environmental material recovered from the Smoo deposits were in essence dumped midden material, containing a mixture of waste products such as cereal-processing waste, animal bone and so forth, which one might expect to have come from a nearby farm environment. Changes in the quantity of peat, charcoal and cereal grain recovered from the early dated midden layers compared to the later Norse deposits were detected during the course of the analysis. The presence of peat, charcoal and slag in the early period at Smoo may reflect temporary fires, with brief stopovers by sailors using fuel for heat and 
to assist with boat repairs. Subsequent (although still fairly early) Norse deposits showed increases in cereal grain and in the use of wet fen material for fuel (suggested by macrofossil remains). This may suggest a more regular Norse presence, probably involving occupation of this area by later periods. Comparison with the plant material from the excavation at nearby Sangobeg (Miller \& Ramsay, forthcoming) will provide further important data for the agricultural and settlement history of this area.

Analysis of the fish bone from Smoo by Cerón-
Carrasco suggested fish caught for local consumption, rather than preserving (Cerón-Carrasco 1996). Given the radiocarbon dating evidence from Smoo, which is mostly Early Norse, and combined with the archaeobotanical evidence, these data are in keeping with an economy seeking to support itself on a local scale, perhaps supplemented later by grain and other goods transported over short distances. Certainly between approximately AD 820 and 1000 at Smoo it could be suggested that transportation of cereal grain was taking place. 


\section{Conclusions and Discussion}

The excavation of the Geodha Smoo cave complex resulted in the recovery of numerous archaeological deposits containing well-preserved artefactual and environmental evidence (Table 12). These deposits clearly indicate the importance of this coastal location in the past. The deposits in the Wetweather Cave indicate prehistoric activity, but most of the evidence, from all of the other caves, indicates their use during the Viking, Late Norse and post-Norse periods.

\subsection{Prehistoric activity}

The discovery of evidence for prehistoric activity in the Wetweather Cave is of considerable importance. Our present understanding of the extent and character of prehistoric and indeed later settlement in this extreme north-west corner of mainland Scotland is limited, with very little fieldwork so far carried out in the area. Because the excavations reported here, survey of the Sutherland coast (Brady \& Morris 1998) and of the area around Durness (Lelong \& MacGregor 2003) has built on the work of rare predecessors (Reid et al 1967; Mercer 1985), and will make a valuable contribution to understanding the history of human activity in the region. However, a general absence of excavation work still makes it very difficult to place the sites reported here within their local and regional cultural context.

Despite the problems highlighted above, these cave sites should not be viewed in isolation. In the past a focus on coastal sites, which include caves, to the exclusion of other locations has resulted in a somewhat distorted picture of past human activity in these areas. The Oban cave sites are the most obvious example of this distortion, with discoveries of a limited artefact assemblage, including antler barbed points, recovered from Mesolithic shell middens, giving birth to the erroneous idea of the Obanian Culture (Pollard 1987; Pollard 1991; Bonsall 1996; Pollard 1996c).

In Oban it is now apparent that the caves and the shell middens which they contained did not represent settlements but specialized extraction camps given over to the procurement and processing of marine resources (Pollard 1987; Bonsall 1996). The settlements themselves were located further inland, and marine foodstuffs processed in the caves may have been consumed at these sites. Wetweather Cave may have functioned in the same way, with the site used as an extraction camp by people living elsewhere, but probably quite close to the cave.

Field survey has so far failed to identify any trace of Neolithic settlement in this corner of the Scottish mainland. However, the presence of a number of chambered cairns in the vicinity of Tongue and Bettyhill, around $15 \mathrm{~km}$ and $25 \mathrm{~km}$ respectively to the east, provides clear evidence that Neolithic communities were active in the region (Henshall \& Ritchie 1995). The apparent absence of settlement sites from this period should come as no surprise, as it is becoming increasingly apparent that Neolithic houses on the Scottish mainland, as opposed to the Northern Isles, may have been insubstantial timber structures unlikely to leave any upstanding remains detectable through field survey (Pollard 1997).

Although it has been suggested that people were not using the cave as a place of residence, the presence of structural features does point to something more than a temporary shelter. However, these structural elements may not relate to the Neolithic use of the cave but to much later activity. The recovery of a copper-alloy pin of Norse or later date demonstrates that people were at least visiting the cave, perhaps while most of the deposits in the other caves were accumulating.

The variety of marine shells from the caves suggests a wide-ranging use of the shoreline. The presence of Nucella lapillus is especially intriguing; its probable use in the production of purple dye has been noted in the shell report (see Section $7.4-$ Marine shells). However, the recovery of this species from a cave which also included late Neolithic pottery does not mean that purple dye was being produced during the Neolithic. The midden deposit $(1 / 006)$ from which the majority of these shells were recovered does not appear to be Neolithic, as it contained the copper-alloy pin of a type similar to those recovered from the Norse/early medieval site at Freswick, Caithness (see Section 5.3.2 - Copperalloy pin). Tyrean Purple was certainly in use during this later period, in places such as the monastery on Iona, but the use to which any dye produced from these shells was put is uncertain. It may have been transported elsewhere to be used in the production of illuminated manuscripts or the dyeing of fabrics.

Direct evidence for later prehistoric activity takes the form of Iron Age pottery sherds from Glassknapper's Cave. However, the analysis of this small assemblage has also highlighted a problem when dealing with cave deposits. The recovery of Iron Age sherds from upper and lower deposits that also included Norse and medieval sherds suggests that some mixing of strata has occurred in the past (see Section 5.1 - Pottery). This observation serves to highlight the complex nature of the deposits and the problems inherent in drawing firm conclusions from purely stratigraphic observations, as has also been recognized at the cave site of An Corran on Skye (A 


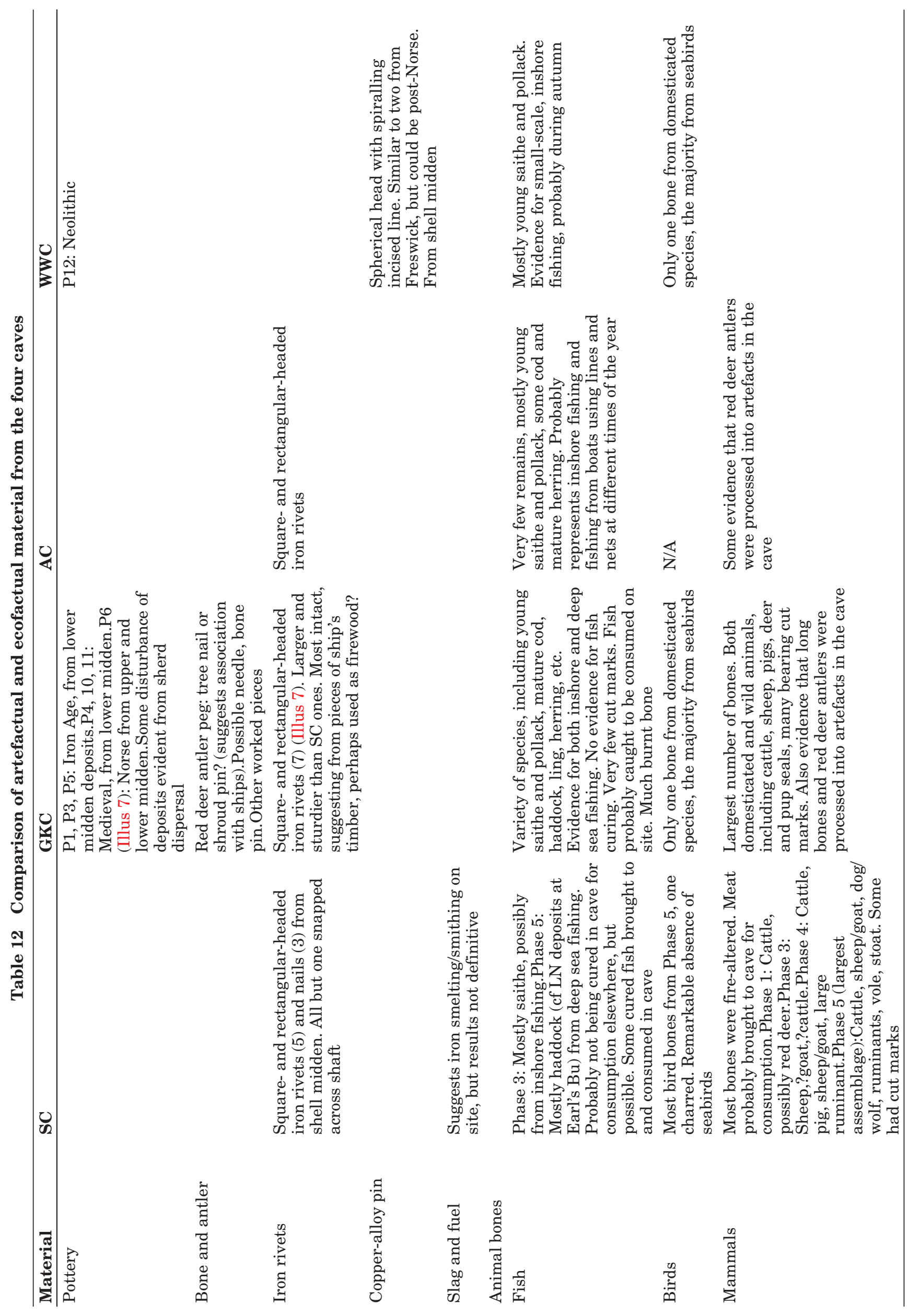




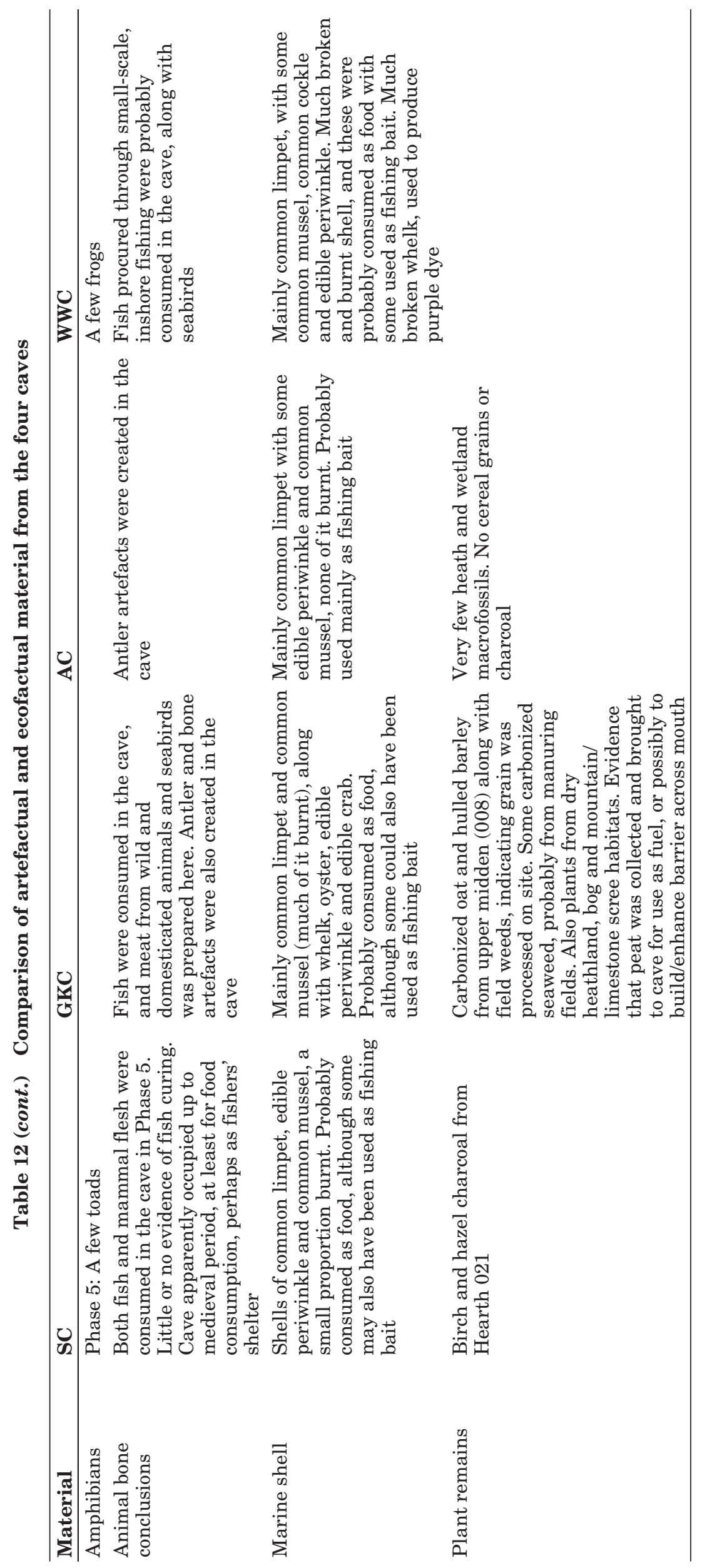


Saville, pers comm). Iron Age deposits may also have been present in Smoo Cave, within those deposits sealed by the Viking Age horizons, but in the absence of more direct evidence this suggestion must be treated with caution. A clearer understanding of deposition patterns and formation processes would be possible only with detailed geomorphological analysis, which was not possible within the constraints of the rescue excavation.

\subsection{Viking/Late Norse and later activity}

Whatever the true nature of the activity attested by the Neolithic deposits in Wetweather Cave and Iron Age evidence from Glassknapper's Cave, the evidence from the other caves clearly indicates that the Geodha was an important focus for activities related to marine exploitation in the Viking/Late Norse and later periods.

Evidence for fishing took the form of fish bones, which were recovered from all of the excavated caves. Analysis of samples recovered from the various cave deposits does suggest some difference in the type of fishing which took place at different periods in the history of the caves' use. The fish bone assemblage from the earlier, probably pre-Norse and possibly Iron Age phases of activity in Smoo Cave, notably Phase 3 , was dominated by saithe, which may indicate inshore fishing. In the Viking period (Phase 5), activity in Smoo Cave shifted to focus on haddock, which is indicative of deep sea fishing, a practice similar to that found in the Late Norse deposits at Earl's Bu. It is doubtful whether these fish were being cured in the cave, but some cured fish may have been brought to the cave and consumed there (see Section 7.1 - Animal bones from Smoo Cave).

The evidence for fishing from Glassknapper's Cave suggests both inshore and deep sea fishing, with a variety of species including young saithe and pollack, mature cod, haddock, ling, herring, etc. The fish bones displayed very few cut marks and were probably caught to be consumed on site. Antler Cave produced very few fish remains, and these were limited to young saithe and pollack, along with some cod and mature herring. This mix may suggest inshore fishing using lines and nets at different times of the year. A more seasonal pattern may be suggested from the sample recovered from Wetweather Cave, where young saithe and pollack may have been caught close to shore during the autumn months (see Section 7.2 - The fish remains from Glassknapper's Cave, Antler Cave and Wetweather Cave).

The dominant feature, at least visually, of many of the deposits excavated were of course the marine shells which were to be found in varied concentrations throughout all of the caves. The dominant species in all of the caves were limpet and mussel, both of which are still found in abundance in the tidal zone of the inlet. Other species included periwinkle, which was found in all of the caves, while oyster and crab were found in greatest quantity in Glassknapper's Cave. Whelk shells were recovered from Glassknapper's Cave and Wetweather Cave, and in the latter it has been suggested that their fragmented state may be indicative of dye extraction (see Section 7.4 - Marine shells). Evidence of the burning of shells from Smoo Cave and Wetweather Cave may be indicative of human consumption, but this seems likely of at least some of the species from all of the caves. Studies elsewhere suggest that species such as the mussel, periwnkle and oyster were commonly consumed, while the limpet may have been used more commonly for bait in line-fishing (Pollard 1994), but human consumption cannot be ruled out.

Fish bones and marine shells represented only one part of a mixed economy practiced by people utilizing the caves. The earliest phase of activity from Smoo Cave (Phase 1) included the use of cattle and possibly red deer. The later phases in Smoo Cave are dominated by domestic species, which may indicate less reliance on hunting. However, it would be rash to draw too many conclusions from samples recovered from a small portion of the site. Phase 3 included sheep and possibly goat and cattle; Phase 4 cattle, pig and sheep/goat; and Phase 5 cattle, sheep/ goat and $\operatorname{dog} /$ wolf. Although red deer antler and some long bones were recovered from both Glassknapper's Cave and Antler Cave, the general picture is of an economy which utilized domesticated species, but continued to place some importance on hunting red deer (see Section 7.3 - The mammal and bird bone from Glassknapper's Cave, Antler Cave and Wetweather Cave) while the antler was used in artefact production in these caves. The presence of a few young seal bones may indicate some low-scale, opportunistic exploitation of seal colonies perhaps inhabiting the shore line not far from the inlet.

By far the largest number of domestic animal bones was recovered from Glassknapper's Cave, but this again is likely to reflect the greater intensity of the investigation rather than a difference in economy or activity. Samples from throughout the deposits included cattle, sheep and pig. Many of these bones exhibited cut marks, which may suggest that meat was processed in the cave, although it is also possible that butchered animal bones were brought to the cave to be modified into artefacts (see Section 7.3.4 - Economy of the site - evidence of butchery and bone working).

Evidence for cereal cultivation was restricted to small quantities of oat and hulled barley from the upper parts of a shell midden deposit (context 008) in Glassknapper's Cave. Only natural plant residues were recovered from the other caves, notably birch and hazel from the hearth (021) in the Smoo Cave section. However, caution must again be exercised in drawing conclusions as the other caves were not subject to such intensive investigation. Interestingly, though, the presence of field weeds may 
indicate that grain was processed in the cave (see Section 7.5 - Plant remains).

As with the prehistoric deposits in Wetweather Cave, the remnants of Norse-period use of the other caves must represent only one component of a complex archaeological landscape, with settlements located not far away from the caves. Indeed, since the excavations reported here a possibly contemporary settlement has been identified and investigated at Sangobeg, $1 \mathrm{~km}$ to the south-east of the Geodha Smoo (Brady \& Lelong 2001).

Some of the evidence reported here may suggest that the caves themselves were inhabited. In the case of Glassknapper's Cave and Antler Cave, especially, this seems somewhat unlikely, as today these are relatively shallow and exposed, but at the time of Viking/Norse activity may have been somewhat deeper. If these caves were to have been in any way habitable, it is probable that they would have required some form of modification. No convincing evidence was found for structures inside them, although a concentration of stones near the entrance of Glassknapper's Cave may have resulted from a crude attempt to create a barrier at the mouth.

The most likely candidate for any longer-term occupation is Smoo Cave, where limited investigation has suggested that structures did exist. However, at certain times of the year the cave would have been inundated by storm-driven waves and exceptionally high tides, and any occupation may therefore have been on a seasonal rather than year-round basis. This is obviously not a problem that would befall the much higher Wetweather Cave, which has provided evidence for structures in the form of probable post-holes.

It should also be noted that the artefact assemblage from the caves is at odds with what one would expect to recover from a full-time settlement site, with only very small amounts of pottery present. Other artefacts such as combs, which are fairly ubiquitous on Norse settlement sites, were also absent. Numerous examples have been recovered from the various excavations at Freswick Links, Caithness (Batey 1987; Morris et al 1995), and even the very limited trial trench evaluation of the site in sand dunes at Dunnet, Caithness, recovered a fine antler comb (Pollard 1996a). This absence does not, however, negate the possibility that antler combs may have been manufactured in the caves, as evidenced by waste shavings, and exported elsewhere (see Section 7.3 - The mammal and bird bone from Glassknapper's Cave, Antler Cave and Wetweather Cave).

Given the marine context of the sites and the nature of much of the material (fish bones, shells, ship's fittings, etc.), the caves may have been devoted to a limited range of specialized craft and procurement activities focused on the sea. The working of bone and antler is a notable feature, with an interesting collection of bone and antler artefacts recovered from Glassknapper's Cave. Analysis of the mammal bone assemblage has established that these pieces were probably made in the caves, with small bone splinters and removal scars from larger bones suggesting waste from the production process (see Section 7.3 - The mammal and bird bone from Glassknapper's Cave, Antler Cave and Wetweather Cave). Although it is not possible to assign many of these worked pieces a definite function, it has been suggested (see Section 5.2 - Bone and antler artefacts) that at least some may relate to the repair of boats.

A more definite indicator of craft activity related to boats and their maintenance is the presence, in Smoo Cave and Glassknapper's Cave, of iron rivets of a type known to have been used on Viking and Late Norse vessels. The recovery of lumps of iron ore and slag from the same caves could suggest that nails were manufactured on site. It is important to note, however, that most of the nails recovered had already been used, having both heads in place, rather than just one as would be the case with a newly manufactured nail. The presence of both heads would suggest that the rivet had at one time been attached to a boat timber which had totally decayed as opposed to nails which had been extracted from timbers, a process that would have dislodged or damaged at least one head. It is perhaps more likely that damaged timbers cut from a boat, with nails in place, were used as fuel on a fire, a process that would obviously have left the nails undamaged.

The presence of large quantities of marine shells and fish bones, along with the bones of some sea birds and seals, also suggests that these were specialist sites related to marine exploitation, linked to practices such as deep sea fishing. The apparent importance of coastal and marine exploitation need not be negated by the presence of terrestrial mammal bone and deer antler, which as suggested above may have been brought to the caves as raw materials for the manufacture of artefacts used to procure marine resources.

This picture of specialized use breaks down somewhat when the charred plant remains are considered. The presence of quantities of cereal grains from the Norse-period deposits appear somewhat out of place on sites related to marine exploitation. The recovery of oats and barley, including the waste products from processing, strongly suggests that the caves saw the wider range of activities which one might expect to occur on settlement sites.

This point is further emphasized by the recovery of a quern stone eroding from the Glassknapper's Cave/ Antler Cave section prior to the excavation ( $R$ Hingley, pers comm). It may be that harvested oats and barley were brought to the caves to be processed before being taken to a settlement site for consumption. Although the caves may have provided suitable shelters for crop processing, it seems unlikely that people would have gone to the effort of carrying stalks from fields down into the inlet only to have to carry the processed grains back up to the settlement. It is more likely that harvested grain was brought 
into the inlet by boat, in which case the caves would be the obvious place in which to carry out processing, thus reducing the weight of material which had to be carried up the steep slope. Whatever the case, the processing of grain clearly negates any suggestion that the cave sites were exclusively related to marine exploitation, while also making it harder to reject the possibility that people were living in the caves, even if this were on a temporary basis.

Although no Viking (Norse), as opposed to Late Norse, settlements have thus far been identified on the Scottish mainland, there is little reason to believe that they did not exist, given their presence on the nearby Northern Isles. It has been suggested that the failure to locate these sites may be due to their location beneath modern settlements or destruction during early broch excavations (Batey 1987). Until recently, evidence for Late Norse activity has been lacking in Sutherland, although it has been suggested that rectangular buildings at Tongue, Klibreck and Ault Loch Sian may represent Viking or Late Norse settlements (Batey 1987). More recently, however, a number of probable Late Norse sites have been identified, including a grave found eroding from sand dunes at Balnakeil (Low et al 2000 ), some $4 \mathrm{~km}$ to the west of Smoo, and the occupation site mentioned above at Sangobeg (Brady \& Lelong 2001).

As with the case of prehistoric settlement, our understanding of Early to Late Norse activity along this part of the northern Scottish coast requires a more intensive programme of research. The excavations at Freswick Links and Robert's Haven have provided physical evidence for the Norse presence in Caithness, already suggested by a proliferation of Norse place-names, while small-scale excavation at Dunnet Bay, some $75 \mathrm{~km}$ to the east of Smoo, has revealed the presence of a Norse settlement on the northern coast of Caithness (Pollard 1996a). It remains to be established whether the Norse-period activity at Smoo fits into this larger settlement pattern or whether the deposits in the caves resulted from temporary stopovers by Norse mariners on their voyages from Scandinavia and the Northern Isles to the Western Isles, Ireland and the Isle of Man.

In the absence of further evidence, the latter hypothesis is an attractive one, with the sheltered Geodha and the caves the ideal place in which to carry out repairs on boats that suffered damage in heavy seas, the beach allowing boats to be hauled ashore if necessary. They would also provide the opportunity to process and consume (see Section 7.1 - Animal bones from Smoo Cave and Section 7.2 The fish remains from Glassknapper's Cave, Antler Cave and Wetweather Cave) fish caught on the voyage and to procure other foodstuffs, both wild and domestic, from the immediate environs of the caves. Although the deposits in both Glassknapper's Cave and Antler Cave were of considerable depth, radiocarbon dates suggest they accumulated quite rapidly, the majority perhaps over 200-300 years, and possibly resulted from regular visits, perhaps several times a year. Although most of the remains appear to relate to Viking/Norse-period activity, the potential for earlier activity, suggested by what is probably Iron Age pottery in the lower levels (see Section 5.1 - Pottery) and later (medieval and post-medieval) phases of use, should not be overlooked.

The deposits in Glassknapper's Cave strongly suggest that the Norse, in an area with an exposed coastline regularly battered by heavy seas, regarded the Geodha Smoo as an important natural harbour. The place had probably long been known to Norse mariners, certainly by the time the Earldom of Orkney was established by the late ninth century. At this time Viking raiders regularly set out from Orkney and may have visited Smoo during voyages to places further south and west. Such visits would certainly be in keeping with the earlier end of the range provided by radiocarbon dates, with the two earliest date ranges from Glassknapper's Cave being cal AD 820-1000 (OxA-8212) and cal AD 770-980 (OxA-8211), expressed at the 2-sigma (95.4\%) level of confidence. The broad range from Smoo Cave, cal AD 780-1020 (at $95.4 \%$ confidence) (GU-4545) is perhaps not so helpful, but the relatively high stratigraphic position of a similar range from Glassknapper's Cave, cal AD 890-1160 (OxA-8210), does point to continuation of activity into the period when the Norse were probably settlers rather than raiders, with the site ceasing to be treated merely as a port in a storm and instead perhaps adopted as a beach-head for settlement in this area.

A consideration of the environmental evidence, both plant and animal, does not really allow for grand statements to be made about a change in the type of economy practiced over this period, as raiders became settlers. However, this is not necessarily something we should expect to detect from the archaeological record as it is the mode of resource procurement that is more likely to have changed than the resources used. 


\section{Acknowledgements}

Work in Smoo Cave was funded by Caithness and Sutherland Enterprise. Work in the other caves was funded by Historic Scotland, who also funded the post-excavation analysis and report writing. Both projects were monitored by The Highland Archaeology Service. This report was edited for GUARD by Olivia Lelong.

Tony Pollard would like to thank the 1995 excavation team, whose unstinting efforts allowed so much to be done in so little time and in such appalling conditions. They were: Michael Donnelly, Lorna Innes and Biddy Simpson. Dorothy Low assisted during the 1992 work in Smoo Cave. Thanks also to Richard Hingley, formerly of Historic Scotland, for facilitating the grant which enabled the 1995 work to take place. Keith Speller, Gerry McArdle and Dave Swan produced the plans and section drawings. The finds from Smoo Cave were drawn by Jill Sievewright and those from the other caves by Henny Piezonka.

James H Barrett would like to thank Dr Keith Dobney who kindly provided access to reference material at the Environmental Archaeology Unit, University of York; also Mark Beech, Deborah Jaques and Sarah King for practical assistance and helpful comments.

Robert Squair would like to thank Ewan Campbell, Steve Driscoll, Rae Harry, Mary MacLeod and Bob Will for their invaluable information regarding the Norse, medieval and post-medieval pottery. 


\section{References}

Albarella, U \& Davis, S J M 1996 'Mammals and birds from Launceston Castle, Cornwall: decline in status and the rise of agriculture', Circaea 12, 1-156.

Alldritt, D M 2003 Economy and Environment in the First Millennium AD in Northern Scotland and the Northern Isles. Unpublished $\mathrm{PhD}$ Thesis, University of Glasgow, Glasgow.

Baldwin, J R 1982 'Fishing the sellag: hand-netting traditions from Caithness, the Northern and Western Isles', in Baldwin, J R (ed) Caithness: A Cultural Crossroads, 161212. Edina Press, Edinburgh.

Ballin Smith, B 1995 'Reindeer antler combs at Howe. Contact between late Iron Age Orkney and Norway', Universitetets Oldsaksamling Arbok 1993 / 1994, 207-11. Oslo.

Bangor-Jones, M 2000 'From clanship to crofting: landownership, economy and the church in the province of Strathnaver', in Baldwin, J R (ed) The Province of Strathnaver, 35-99. Scottish Society for Northern Studies, Edinburgh.

Barclay, G J 1985 'Excavations at Upper Suisgill, Sutherland', Proc Soc Antiq Scot 115, 159-98.

Barrett, J H 1995 Few Know an Earl in Fishing-clothes: Fish Middens and the Economy of the Viking Age and Late Norse Earldoms of Orkney and Caithness, Northern Scotland. PhD Thesis, University of Glasgow, Glasgow.

Barrett, J H 1997 'Fish trade in Norse Orkney and Caithness: a zooarchaeological approach', Antiquity 71(273), 616-38.

Batey, C E 1987 Freswick Links, Caithness: A Re-appraisal of the Late Norse Site. Oxford ( = Brit Archaeol Res, Brit Ser, 179).

Batey, C E 1996 'Bone', in Morris, C D The Birsay Bay Project. Vol 2, Sites in Birsay Village and on the Brough of Birsay, Orkney, 93-6. Alan Sutton, Durham.

Batey, C E \& Freeman, C 1986 'Lavacroon, Orphir, Orkney', Proc Soc Antiq Scot 116, 285-300.

Batey, C E \& Graham-Campbell, J 1998 Vikings in Scotland: An Archaeological Survey. Edinburgh University Press, Edinburgh.

Batey, C E, Morris, C D \& Rackham, D J 1984 'Freswick Castle, Caithness: report on rescue excavations carried out in 1979', Glasgow Archaeol J 11, 83-118.

Beedham, G E 1972 Identification of British Mollusca. Pitman Press, Bath.

Beijerinck, W 1947 Zadenatlas der Nederlandsche Flora. Veenman \& Zonen, Wageningen.

Bigelow, G F 1993 ‘Archaeological and ethnohistoric evidence of a Norse island food custom', in Batey, C E, Jesch, J \& Morris, C D (eds) The Viking Age in Caithness, Orkney and the North Atlantic, 441-53. Edinburgh.

Binford, L R 1981 Bones: Ancient Men and Modern Myths. London.

Bond, J M forthcoming 'Beyond the fringe? Recognizing change and adaptation in Pictish and Norse Orkney', in Coles, G \& Mills, CM (eds) Human Settlement In Hospitable Areas. Proceedings AEA Annual Conference 1992, Edinburgh.

Bonsall, C 1996 'The 'Obanian problem': coastal adaptation in the Mesolithic of Western Scotland', in Pollard, T \& Morrison A (eds) The Early Prehistory of Scotland. Edinburgh University Press, Edinburgh.

Boyd, W E 1988 'Cereals in Scottish antiquity', Circaea 5, 101-10.

Brady, K \& Lelong, O 2001 Sangobeg, Durness Data Structure Report. GUARD Report, Glasgow.

Brady, K \& Morris, C 1998 Sutherland Coastal Survey. GUARD Report 516, Glasgow.

Bronk-Ramsay, C, Pettitt, P B, Hedges, R E M, Hodgins, G W L \& Owen, D C 1999

'Radiocarbon dates from the Oxford AMS system, Archaeometry Datelist 28', Archaeometry 41(2), 421-31.

Butzer, K W 1977 Archaeology as Human Ecology. Cambridge University Press, Cambridge.

Campbell, A C 1989 Seashores and Shallow Seas of Britain and Europe. Hamlyn, London.

Cerón-Carrasco, R 1994 'The investigation of the fish remains from an Orkney farm mound', in Van Neer, W (ed) Fish Exploitation in the Past. Musee Royal de l'Afrique Centrale, Annales Sciences Zoologiques, Vol 274. Tervuren, Belgique.

Cerón-Carrasco, R 1997 Cnip: the Marine Molluscs, with Notes on the Echinoidea Remains and Terrestrial Snails. Unpublished CFA report, Edinburgh.

Cerón-Carrasco, $\mathrm{R}$ forthcoming 'The fish remains', in Lowe, C Excavations at St Boniface, Papa Westray, Orkney.

Cerón-Carrasco, $\mathrm{R}$ forthcoming 'Ethnographic observations on domestic fishing in Lewis, Hebrides'.

Clutton-Brock, J \& MacGregor, A 1988 'An end to medieval reindeer in Scotland', Proc Soc Antiq Scot 118, 23-35.

Colley, S M 1983 The Role of Fish Bone Studies in Economic Archaeology: With Special Reference to the Orkney Isles. PhD Thesis, University of Southampton, Southampton. 
Cowie, T G forthcoming 'Torrs Warren, Luce Sands, Galloway: a report on archaeological and palaeoecological investigations undertaken in 1977 and 1979'.

Courty, A C, Goldberg, P \& Macphail, R 1989 Soils and Micromorphology in Archaeology. Cambridge University Press, Cambridge.

Crumlin-Pedersen, O 1997 Viking-Age Ships and Zhipbuilding in Hedeby/Haithabu and Schleswig. Viking Museum, Roskilde.

Dawson, S \& Smith, D E 1997 'Relative sea level changes around the margin of a glacio-isostatically uplifted area: an example from northern Caithness, Scotland', The Holocene 7, 59-71.

Dickson, C 1983 'The macroscopic plant remains', in Hedges, $\mathrm{J} \mathrm{W}$ 'The excavations on Pictish and Viking settlements at Saevar Howe, Birsay, Orkney', Glasgow Archaeol J 10(114), M93.

Dickson, C 1994 'The plant remains', in Ballin-Smith B (ed) Howe: Four Millennia Of Orkney Prehistory Excavations 1978-1982. Edinburgh ( = Soc Antiq Scot monogr 9).

Dickson, C 1999 'The plant remains', in Crawford, B E \& Ballin Smith, B (eds) The Biggings Papa Stour Shetland: The History and Archaeology of a Royal Norwegian Farm. Edinburgh ( = Soc Antiq Scot monogr 15), 104-17.

Dickson, C \& Dickson, J H 2000 Plants and People in Ancient Scotland. Tempus, Gloucesterhire.

Dickson, J H 1992 'North American driftwood, especially Picea (spruce), from archaeological sites in the Hebrides and Northern Isles of Scotland', Rev Palaeobot Palynol 73, 49-56.

von den Driesch, A 1976 A Guide to the Measurement of Animal Bones from Archaeological Sites. Peabody Museum Bulletin 1, Cambridge.

Ellis, L 1995 Best of British Fish and Seafood. Dial House, Surrey.

Enghoff, I B 1986 'Freshwater fishing from a sea-coast settlement - the Ertebolle locus classicus revisited', J Danish Archaeol 5, 6276.

Fenton, A 1978 The Northern Isles: Orkney and Shetland. John Donald, Edinburgh.

Fenton, A 1992 'Shellfish as bait: the interface between domestic and commercial fishing', in Smout, T C Scotland and the Sea, 137-53. John Donald, Edinburgh.

Fraser, I 1995 'Norse settlement on the north-west seaboard', in Crawford, B (ed) Scandinavian Settlement in Northern Britain, 92-107.

Leicester University Press, Leicester.

French, D H 1971 'An experiment in water sieving', Anatolian Studies 21, 59-64.

Gibson, A M 1995 'The Neolithic pottery from Allt Chrisal', in Branigan, K \& Foster, P Barra: Archaeological Research on Ben Tangaval, Sheffield Environmental and Archaeological Research Campaign in the Hebrides, Vol 1. Sheffield Academic Press, Sheffield.
Gleed-Owen, C P 1992 The Flandrian Palaeoenvironmental History of Smoo Cave, Sutherland: Faunal and Sedimentological Evidence. Unpublished dissertation, Department of Geography, Coventry Polytechnic, Coventry.

Goodlad, C A 1971 Shetland Fishing Saga. Shetland Times, Lerwick.

Graham-Campbell, J \& Batey, C E 1998 Vikings in Scotland: An Archaeological Survey. Edinburgh University Press, Edinburgh.

Gray, M 1978 The Fishing Industry of Scotland 1790-1914: A Study of Regional Variation. Studies Series 15. University of Aberdeen, Aberdeen.

Greig, J R A 1991 'The British Isles', in Van Zeist, Wasylikowa \& Behre (eds) Progress in Old World Palaeoethnobotany, 299-334. Balkema, Rotterdam.

Hamilton, J R C 1956 Excavations at Jarlshof, Shetland. HMSO, Edinburgh.

Heinzel, H, Fitter, R \& Parslow, J 1973 The Birds of Britain and Europe with North Africa and the Middle East. Collins, London.

Henshall, A \& Ritchie, J N G 1995 The Chambered Cairns of Sutherland. Edinburgh University Press, Edinburgh.

Hunter, J R 1996 Fair Isle. The Archaeology of An Island Community. The National Trust for Scotland, HMSO, Edinburgh.

Huntly, J P 1992a 'Carbonized plant remains', in Morris, CD, Batey, C, Jones, A K G et al (eds) Freswick Links, Caithness: Excavation and Survey of a Norse Settlement, 76-84. Inverness ( = Highland Regional Council monogr no 1).

Huntly, J P 1992b 'Environmental column samples from the cliff-side', in Morris C D \& Rackham D J (eds) Norse and Later Settlement and Subsistence in the North Atlantic, 43-102. Occasional Paper Series No 1, Department of Archaeology, University of Glasgow, Glasgow.

Huntly, J P 1994 'Some botanical aspects of a Norse economy in northern Scotland', in Dickson, J H \& Mill, R R (eds) 'Plants and people: economic botany in Northern Europe AD 800-1800', Bot J Scot 46(4), 538-41.

Jackson, J W 1919 Shells as Evidence of the Migrations of Early Culture. Manchester University Press, Manchester.

Jane F W 1970 The Structure of Wood, 2nd Edn. Black, London.

Johnston, J A 1981 'In the great cave of Smoo', Scot Magazine (Aug 1981), 467-8.

Johnston, J B 1892 The Place Names of Scotland. David Douglas, Edinburgh.

Jones, A K G 1982 'Bulk-sieving and the recovery of fish remains from urban archaeological sites', in Hall, A R \& Kenward, H Environmental Archaeology in the Urban Context, 79-85. Council for British Archaeology Research Report 43, London.

Jones, A K G 1991 The Fish Remains from 
Excavations at Freswick Links, Caithness.

DPhil Thesis, University of York, York.

Jones, A K G, Morris, C D \& Rackham, D J 1996

'The fish remains', in Morris, C D, Batey, C,

Jones, A K G et al Freswick Links Caithness:

Excavation and Survey of a Norse Settlement.

Inverness ( = Highland Regional Council monogr 1).

Keiller, I 1972 'Smoo Cave', Discovery Excav Scot $1972,41$.

Kerney, M P \& Cameron, R A D 1996 Land Snails of Britain and North-West Europe. Harper Collins, London.

Lawson, T J (ed) 1988 Caves of Assynt: The Limestone Caves of Scotland, part 2. Grampian Speleological Group, Edinburgh.

Leask, W 1993 Interview. Shetland, Lerwick.

Leitch, R \& Smith, C 1993 'Archaeology and ethnohistory of cave dwelling in Scotland', Scott Studies 31, 101-9.

Lelong, O \& MacGregor, G 2003 Loch Borralie, Kyle of Durness: An Archaeological Survey. GUARD Report 950, Glasgow.

Longworth, I H 1967 'Further discoveries at Brackmont Mill, Brackmont Farm and Tentsmuir, Fife', Proc Soc Antiq Scot 99 (19667), 60-92.

Low, D, Batey, C E \& Gourlay, R 2000 'A Viking burial at Balnakeil, Sutherland', in Baldwin, J $\mathrm{R}$ (ed) The Province of Strathnaver. Scottish Society for Northern Studies, Edinburgh.

Low, G 1813 Fauna Orcadensis or The Natural History of the Quadrupeds, Birds, Reptiles, and Fishes of Orkney and Shetland. George Ramsay \& Co, Edinburgh.

MacAskill, N 1982 'The pottery', in McGavin, N A 'Excavations in Kirkwall, 1978', Proc Soc Antiq Scot 112, 405-13.

McCarthy, M R \& Brooks, C M 1988 Medieval Pottery in Britain AD 900-1600. Leicester University Press, Leicester.

McCormick, F, Gibbons, M, McCormac, F G \& Moore, J 1996 'Bronze Age to medieval coastal shell middens near Ballyconneely, Co Galway', J Irish Archaeol, VII.

McGavin, N A 1982 'Excavations in Kirkwall, 1978', Proc Soc Antiq Scot 112, 405-13.

McInnes, I J 1964 'The Neolithic and Bronze Age pottery from Luce Sands, Wigtownshire', Proc Soc Antiq Scot 87 (1964), 40-81.

Martin, M C 1695 A Description of the Western Isles of Scotland. Birlinn, Edinburgh.

Mercer, R J 1985 Archaeological Field Survey in Northern Scotland. Department of Archaeology occasional paper no 2, University of Edinburgh, Edinburgh.

Mellars, P A \& Wilkinson, M R 1980 'Fish otoliths as indicators of seasonality in prehistoric shell middens: the evidence from Oronsay (Inner Hebrides)', Proc Prehist Soc 46, 19-44.

Miller, J \& Ramsay, S forthcoming 'The plant remains', in Brady, K, Lelong, O \& Batey, C E
Sangobeg, Durness: A Pictish Burial and a

Norse Settlement in Sutherland.

Milles, A 1986 'Comparative analysis of charred plant remains from Ness of Gruting', in Whittle A Scord of Brouster: An Early Agricultural Settlement on Shetland, Excavations 1977-9. Oxford ( = Oxford Univ Comm Archaeol monogr 9).

Milles, A, Noddle, B, Rees, S \& Romans, J C C 1986 Scord of Brouster: An Early Agricultural Settlement on Shetland, 123-4. Oxford ( = Oxford Univ Comm Archaeol monogr 9).

Mitchell, A (ed) 1906 MacFarlane's Geographical Collections, Vol 1. Publication of the Scottish History Society Vol LI. Edinburgh University Press, Edinburgh.

Moreno-Nuño, M R 1994a Arqueomalacolgía: Identificación de moluscos. Informe no 1994/19. Laboratorio de Arqueozoología. Informe técnico. Universidad Autónoma, Madrid.

Moreno-Nuño, M R 1994b Arqueomalacología: Cuantificación de moluscos. Informe no 1994/ 19. Laboratorio de Arqueozoología. Informe técnico. Universidad Autónoma, Madrid.

Morris, C D 1989 The Birsay Bay Project. Durham ( = Univ Durham, Dept Archaeol monogr 1).

Morris, C D 1996 The Birsay Bay Project, Vol 2, Sites in Birsay Village and on the Brough of Birsay, Orkney. Alan Sutton, Durham.

Morris, C D, Batey C \& Rackham, O 1995 Freswick Links, Caithness. Excavation and Survey of a Norse Settlement. North Atlantic Biocultural Organization monograph 1. Alan Sutton, Durham.

Muus, B J \& Dahlstrom, P 1974 Collins Guide to the Sea Fishes of Britain and North-Western Europe. Collins, London.

Nicholson, R A 1991 An Investigation into Variability within Archaeologically Recovered Assemblages of Faunal Remains: the Influence of Pre-Depositional Taphonomic Processes. DPhil Thesis, University of York, York.

Owen, J F 1994 'Analysis of coastal middens in south-eastern Australia: selectivity of angling and other fishing techniques related to Holocene deposits', J Archaeol Sci 21, 11-16.

Palsson, H \& Edwards, P (eds) 1981 Orkneyinga Saga. Harmondsworth.

Payne, S 1973 'Kill-off patterns in sheep and goats - the mandibles from Asvan Kale', $J$ Anatolian Studies 23, 281-303.

Payne, S 1992 Some Notes on Sampling and Sieving for Animal Bones. Ancient Monuments Laboratory Report 55/92.

Photos-Jones, E, Atkinson, J A, Hall, A J \& Banks, I 1998 'The bloomery mounds of the Scottish Highlands. Part 1: The archaeological background', J Hist Metallurgy Soc 32(1), 16-32.

Pollard, T 1987 A Reconsideration of the 'Obanian Culture' with Special Reference to the Oban Cave Sites. Unpublished undergraduate dissertation, University of Glasgow, Glasgow. 
Pollard, T 1991 'Down through the ages: a review of the Oban cave deposits', Scott Archaeol Rev 7, 57-84.

Pollard, T 1992 Smoo Cave. GUARD Report 60, Glasgow.

Pollard, T 1994 A Study of Marine Exploitation in Prehistoric Scotland: with Special Reference to Marine Shells and their Archaeological Contexts. Unpublished PhD Thesis, University of Glasgow, Glasgow.

Pollard, T 1996a Assessment Excavation of a Norse Coastal Settlement at Marymas Green, Dunnet Bay, Caithness. GUARD Report 306, Glasgow.

Pollard, T 1996b Caves in the Geodha Smoo: the Excavation of Three Caves Near Durness, Sutherland. GUARD Report 214, Glasgow.

Pollard, T 1996c 'Time and tide: coastal environments, cosmology and ritual practice in early prehistoric Scotland', in Pollard, T \& Morrison A (eds) The Early Prehistory of Scotland, 198-213. Edinburgh University Press, Edinburgh.

Pollard, T 1997 'Excavation of a Neolithic settlement and ritual complex at Beckton Farm, Lockerbie, Dumfries and Galloway', Proc Soc Antiq Scot 127, 69-121.

Reid, R W K, David, G \& Aitken, A 1967 'Prehistoric settlement in Durness', Proc Soc Antiq Scot 99 (1966-67), 21-53.

Renfrew, J 1993 'Prehistoric Britain', in Black, M (ed) A Taste of History: 10,000 Years of Food in Britain. English Heritage and British Museum Press, London.

Ringrose, T J 1993 'Bone counts and statistics: a critique', J Archaeol Sci 20, 121-57.

Roselló-Izquierdo, E 1988 Contribución al Atlas Osteológico de los Teleósteos Ibericos: I Dentario y Articular. Colección de Estudios. Ediciones de la Universidad Autónoma de Madrid.

Schoch, W H, Pawlik, B \& Schweingruber, F H 1988 Botanical Macro-Remains: An Atlas for the Determination of Frequently Encountered and Ecologically Important Plant Seeds. Paul Haupt, Berne.

Schweingruber, F H 1990 Anatomy of European Woods. Paul Haupt, Berne.

Serjeantson, D 1988 'Archaeological and ethnographic evidence for seabird exploitation in Scotland', Archaeozoologia 2, 209-24.

Stace, C 1997 New Flora of the British Isles, 2nd Edn. Cambridge University Press, Cambridge.

Walker, B 1982 'Scottish methods of preserving white fish', in Gailey, A \& Ohóg \& Gold, D Under the Furze: Studies in Folk Tradition, 138-49. Glendale Press, Dublin.

Watt, J, Pierce, G J \& Boyle, P R 1997 Guide to the Identification of North Sea Fish Using Premaxilla and Vertebra. ICES Cooperative Research Report 220, Denmark.

Weber, B 1993 'Norwegian reindeer antler export to Orkney. An analysis of combs from Pictish/ early Norse sites', Universitetets Oldsaksamling Arbok 1991 / 1992, 161-74, Oslo.

Wheeler, A 1969 The Fishes of the British Isles and North-west Europe. Macmillan, London.

Wheeler, A 1978 Key to the Fishes of Northern Europe. Frederick Warne, London.

Wheeler, A \& Jones, A K G 1989 Fishes. Cambridge Manuals in Archaeology. Cambridge University Press, Cambridge.

Whitehead, P J P, Bauchot, M L, Hureau, J C, Nielsen, J \& Tortonese, E 1986a Fishes of the North-eastern Atlantic and the Mediterranean, Vol 2. United Nations Educational, Scientific and Cultural Organization, Paris.

Whitehead, P J P, Bauchot, M L, Hureau, J C, Nielsen, J \& Tortonese, E 1986b Fishes of the North-eastern Atlantic and the Mediterranean, Vol 3. United Nations Educational, Scientific and Cultural Organization, Paris.

Zohary, D \& Hopf, M 1993 Domestication of Plants in the Old World, 2nd Edn. Clarendon, Oxford. 